\title{
A New Synthetic Approach to Phenol Derivatives: Use of Ring-Closing Olefin Metathesis
}

\author{
Kazuhiro Yoshida* and Tsuneo Imamoto* \\ Department of Chemistry, Faculty of Science, Chiba University, Yayoi-cho, Inage-ku, Chiba 263-8522, \\ Japan
}

\section{Supporting Data}

General. All anaerobic and moisture-sensitive manipulations were carried out with standard Schlenk techniques under predried nitrogen or glovebox techniques under prepurified argon. NMR spectra were recorded on a JEOL JNM LA-500 spectrometer $\left(500 \mathrm{MHz}\right.$ for ${ }^{1} \mathrm{H}, 76.5 \mathrm{MHz}$ for ${ }^{2} \mathrm{H}$, and $125 \mathrm{MHz}$ for ${ }^{13} \mathrm{C}$ ) and LA-400 spectrometer (400 MHz for ${ }^{1} \mathrm{H}$ and $100 \mathrm{MHz}$ for ${ }^{13} \mathrm{C}$ ). Chemical shifts are reported in $\delta \mathrm{ppm}$ referenced to an internal $\mathrm{SiMe}_{4}$ standard for ${ }^{1} \mathrm{H} \mathrm{NMR}$, chloroform- $d(\delta 7.26)$ for ${ }^{2} \mathrm{H}$ NMR, and chloroform- $d(\delta 77.05)$ for ${ }^{13} \mathrm{C}$ NMR.

Materials. Anhydrous THF was purchased and used as received. Dicholoromethane was distilled from $\mathrm{CaH}_{2}$ under nitrogen and stored in a glass flask with a Teflon stopcock under nitrogen. Toluene was distilled from sodium benzophenone-ketyl under nitrogen and stored in a glass flask with a Teflon stopcock under nitrogen. Ruthenium complexes, $\left(\mathrm{PCy}_{3}\right)_{2} \mathrm{Cl}_{2} \mathrm{Ru}=\mathrm{C}(\mathrm{H}) \mathrm{Ph} \quad(\mathbf{1 0})^{1}$ and $\left(\mathrm{PCy}_{3}\right)(\operatorname{Imes}) \mathrm{Cl}_{2} \mathrm{Ru}=\mathrm{C}(\mathrm{H}) \mathrm{Ph}(\mathbf{1 1})^{2}$, were prepared according to the reported procedures. Bromodienes 5 were prepared by bromoallylation of alkynes according to the reported procedures. ${ }^{3}$ (E)-Hex-4-en-1-yn3-ol ${ }^{4}, \mathrm{MnO}_{2}{ }^{5}, 2$-ethyl-propenal ${ }^{6}$, and $(Z)$-4-chloro-2,7-dimethyl-5-phenyl-octa-1,5,7-trien-3-one $(\mathbf{1 5} \mathbf{j})^{7}$ were prepared according to the reported procedures. Acrolein, methacrolein, 2-ethylacrolein, $N, N$ diisopropylethylamine, acetyl chloride, imidazole, TBDMSCl, crotonaldehyde, and Lindlar catalyst (5 wt\%) were used as received.

\section{Scheme S-1}<smiles>C=CCC(CCC)=C(Br)CCC</smiles>

1) $t$-BuLi (2 eq)

2)<smiles>C=CC=CC=CC=[18O]</smiles>

3) $\mathrm{H}_{2} \mathrm{O}$<smiles>C=CC/C=C(\Br)c1ccccc1</smiles>

1) $t$-BuLi (2 eq)

2)<smiles>C=CC=O</smiles>

3) $\mathrm{H}_{2} \mathrm{O}$<smiles>[2H]/C(CC=C)=C(\Br)c1ccccc1</smiles>

1) $t$-BuLi (2 eq)

2)

$\pi^{\mathrm{CHO}}(3 \mathrm{eq})$

3) $\mathrm{H}_{2} \mathrm{O}$



4a (70\%)

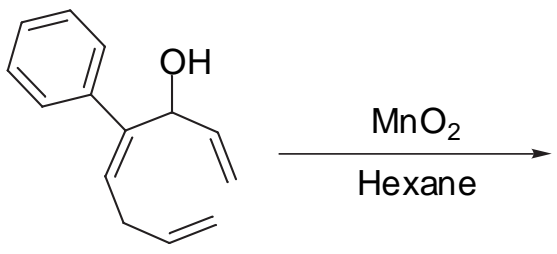

4b $(69 \%)$

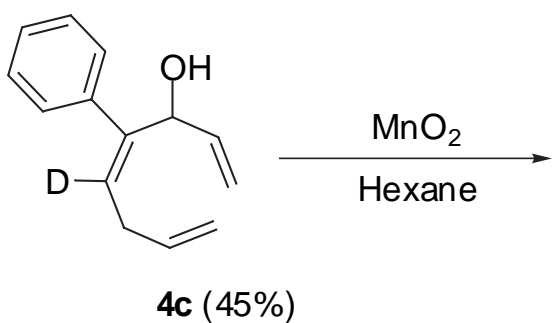

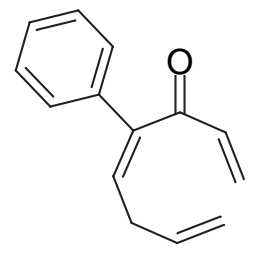

3b (54\%)

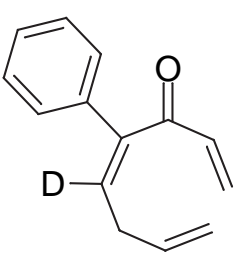

3c $(52 \%)$ 
$\overbrace{}^{B r}$

1) $\prod_{(3 \mathrm{eq})}^{\mathrm{CHO}}$

3) $\mathrm{H}_{2} \mathrm{O}$

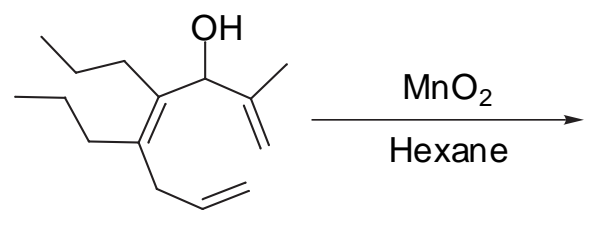

4d (54\%)

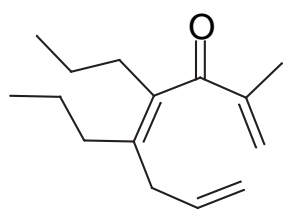

$3 d(82 \%)$

$\underbrace{\mathrm{Br}}_{\triangle}$<smiles>C=C(C[18OH])C(=O)OC(=O)O</smiles><smiles>C=CC/C=C(\C(O)C(=C)CC)S(C)(=O)=O</smiles><smiles>COCCOC</smiles>

4e $(50 \%)$<smiles>C=CC/C=C(\C(=O)C(=C)CC)S(C)(C)C</smiles>

3 e $(59 \%)$<smiles>C=CCC=C(Br)c1ccccc1</smiles>

\section{1) $t$-BuLi (2 eq)}<smiles>C=C(C=O)CCO</smiles>

3) $\mathrm{H}_{2} \mathrm{O}$<smiles>C=CC/C=C(/c1ccccc1)C(O)C(=C)CCO</smiles>

$4 f(39 \%)$<smiles>C=CCC=C(C(=C)CCO)c1ccccc1</smiles>

$3 f(83 \%)$<smiles>C=CC/C=C(\C(=O)C(=C)CCO)C(=O)C(=C)CCOC(C)=O</smiles>

$3 f$

$3 g(96 \%)$<smiles>C=C(C)CC=C(Br)c1ccccc1</smiles>

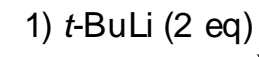<smiles>C=C(C)C=O</smiles>
3) $\mathrm{H}_{2} \mathrm{O}$

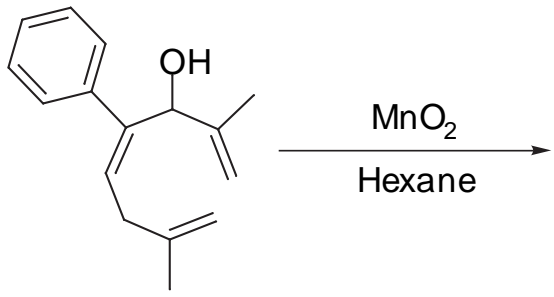

4h $(36 \%)$

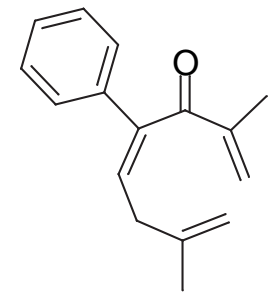

3h $(73 \%)$<smiles>C#CC(O)/C=C/C</smiles>
$9 \mathrm{i}(99 \%) \quad$ 3) $\mathrm{H}_{2} \mathrm{O}$<smiles>CC=CC(=O)C#CC(C=CC)O[Mg]C(=O)OCC</smiles>

$7 \mathbf{i}(78 \%)$<smiles>C/C=C\C(=O)/C=C\C(/C=C/C)O[Ga]</smiles>

$3 \mathbf{i}(77 \%)$ 
Preparation of trienol 4. $t$-BuLi $(1.47 \mathrm{M}$ solution in pentane, $10.0 \mathrm{mmol})$ was added to a solution of bromodiene $5(5.00 \mathrm{mmol})$ in THF $(12.5 \mathrm{~mL})$ at $-78{ }^{\circ} \mathrm{C}$. After $5 \mathrm{~min}$, aldehyde $(15.0 \mathrm{mmol})$ was added and the mixture was stirred for $30 \mathrm{~min}$ at the same temperature. The reaction mixture was then quenched by addition of water and extracted with EtOAc twice. The organic phases were dried with $\mathrm{MgSO}_{4}$ and concentrated under vacuum. The residue was purified by silica gel column chromatography to give trienol 4.

(Z)-4,5-Dipropyl-octa-1, 4,7-trien-3-ol (4a): purified by silica gel column chromatography (hexane/EtOAc $=4 / 1)(70 \%$ yield $) ;{ }^{1} \mathrm{H}$ NMR $\left(\mathrm{CDCl}_{3}\right) \delta 0.91(\mathrm{t}, J=7.3 \mathrm{~Hz}, 3 \mathrm{H}), 0.92(\mathrm{t}, J=7.4 \mathrm{~Hz}$, $3 \mathrm{H}), 1.35-1.60(\mathrm{~m}, 5 \mathrm{H}), 1.95-2.07(\mathrm{~m}, 4 \mathrm{H}), 2.84(\mathrm{dd}, J=15.6,6.1 \mathrm{~Hz}, 1 \mathrm{H}), 2.91(\mathrm{dd}, J=15.6,6.1$ $\mathrm{Hz}, 1 \mathrm{H}), 4.99(\mathrm{dd}, J=11.0,1.8 \mathrm{~Hz}, 1 \mathrm{H}), 5.02(\mathrm{dd}, J=17.1,1.9 \mathrm{~Hz}, 1 \mathrm{H}), 5.07(\mathrm{br} \mathrm{d}, J=6.4 \mathrm{~Hz}, 1 \mathrm{H})$, $5.11(\mathrm{dd}, J=10.7,1.5 \mathrm{~Hz}, 1 \mathrm{H}), 5.27$ (dd, $J=17.1,1.5 \mathrm{~Hz}, 1 \mathrm{H}), 5.80$ (ddt, $J=16.8,10.1,6.1 \mathrm{~Hz}$, $1 \mathrm{H}), 5.89$ (ddd, $J=16.8,10.4,4.6 \mathrm{~Hz}, 1 \mathrm{H}) .{ }^{13} \mathrm{C} \mathrm{NMR}\left(\mathrm{CDCl}_{3}\right) \delta 14.45,14.75,21.79,24.35,30.16$, 34.90, 35.57, 72.44, 113.95, 114.97, 135.24, 135.81, 137.19, 139.52. HRMS (EI) calcd for $\mathrm{C}_{14} \mathrm{H}_{22}$ $\left(\mathrm{M}^{+}-\mathrm{H}_{2} \mathrm{O}\right)$ 190.1722, found 190.1735 .

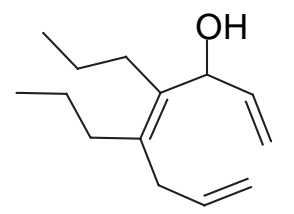

$4 a$

(Z)-4-Phenyl-octa-1, 4,7-trien-3-ol (4b): purified by silica gel column chromatography (hexane/EtOAc $=5 / 1)(69 \%$ yield $) ;{ }^{1} \mathrm{H}$ NMR $\left(\mathrm{CDCl}_{3}\right) \delta 1.74(\mathrm{~d}, J=5.2 \mathrm{~Hz}, 1 \mathrm{H}), 3.00-3.11(\mathrm{~m}, 2 \mathrm{H})$, $5.06(\mathrm{dq}, J=10.1,1.5 \mathrm{~Hz}, 1 \mathrm{H}), 5.13(\mathrm{dq}, J=17.1,1.9 \mathrm{~Hz}, 1 \mathrm{H}), 5.17-5.20(\mathrm{~m}, 1 \mathrm{H}), 5.30-5.35(\mathrm{~m}$, 2H), $5.72(\mathrm{t}, J=7.7 \mathrm{~Hz}, 1 \mathrm{H}), 5.90(\mathrm{ddt}, J=16.5,10.4,6.1 \mathrm{~Hz}, 1 \mathrm{H}), 6.02(\mathrm{ddd}, J=17.7,10.7,4.3$ $\mathrm{Hz}, 1 \mathrm{H}), 7.24-7.32(\mathrm{~m}, 3 \mathrm{H}), 7.36-7.39(\mathrm{~m}, 2 \mathrm{H}) .{ }^{13} \mathrm{C} \mathrm{NMR}\left(\mathrm{CDCl}_{3}\right) \delta 32.25,71.41,115.04,115.54$, 127.20, 128.11, 129.33, 136.32, 139.33, 140.39, 141.98. HRMS (EI) calcd for $\mathrm{C}_{14} \mathrm{H}_{14}\left(\mathrm{M}^{+}-\mathrm{H}_{2} \mathrm{O}\right)$ 182.1096, found 182.1107.

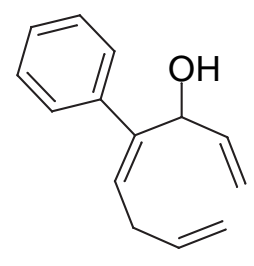

$4 \mathrm{~b}$

(Z)-5-Deuterio-4-phenyl-octa-1,4,7-trien-3-ol (4c): purified by silica gel column chromatography (hexane/EtOAc $=5 / 1)(45 \%$ yield $) ;{ }^{2} \mathrm{H} \mathrm{NMR}\left(\mathrm{CHCl}_{3}\right) \delta 5.74$.

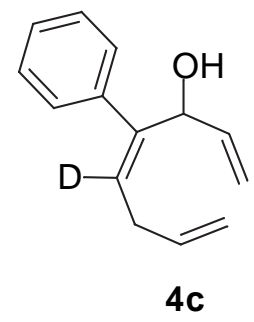

(Z)-2-Methyl-4,5-dipropyl-octa-1,4,7-trien-3ol (4d): purified by silica gel column chromatography $($ hexane/EtOAc $=20 / 1)(54 \%$ yield $) ;{ }^{1} \mathrm{H} \mathrm{NMR}\left(\mathrm{CDCl}_{3}\right) \delta 0.89(\mathrm{t}, J=7.3 \mathrm{~Hz}, 3 \mathrm{H}), 0.92$ $(\mathrm{t}, J=7.3 \mathrm{~Hz}, 3 \mathrm{H}), 1.28-1.49(\mathrm{~m}, 4 \mathrm{H}), 1.61(\mathrm{br} \mathrm{s}, 1 \mathrm{H}), 1.62(\mathrm{~s}, 3 \mathrm{H}), 1.87-2.10(\mathrm{~m}, 4 \mathrm{H}), 2.88$ (ddt, $J$ $=15.6,6.1,1.9 \mathrm{~Hz}, 1 \mathrm{H}), 2.94(\mathrm{ddt}, J=15.6,6.1,1.9 \mathrm{~Hz}, 1 \mathrm{H}), 4.89-4.91(\mathrm{~m}, 1 \mathrm{H}), 4.93(\mathrm{~s}, 1 \mathrm{H}), 5.00$ $(\mathrm{dq}, J=10.1,1.5 \mathrm{~Hz}, 1 \mathrm{H}), 5.05(\mathrm{dq}, J=17.1,1.9 \mathrm{~Hz}, 1 \mathrm{H}), 5.12-5.14(\mathrm{~m}, 1 \mathrm{H}), 5.81(\mathrm{ddt}, J=16.5$, 10.1, 6.4 Hz, 1H). ${ }^{13} \mathrm{C} \mathrm{NMR}\left(\mathrm{CDCl}_{3}\right) \delta 14.37,14.82,20.14,21.69,24.32,29.98,34.78,35.54$, 
73.96, 109.43, 115.04, 135.13, 136.39, 137.28, 146.05. HRMS (EI) calcd for $\mathrm{C}_{15} \mathrm{H}_{26} \mathrm{O}\left(\mathrm{M}^{+}\right) 222.1985$, found 222.1994 .

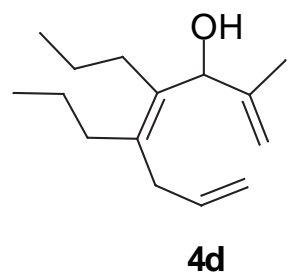

(E)-2-Ethyl-4-trimethylsilyl-octa-1,4,7-trien-3ol (4e): purified by silica gel column chromatography (hexane/EtOAc $=20 / 1)(50 \%$ yield $) ;{ }^{1} \mathrm{H}$ NMR $\left(\mathrm{CDCl}_{3}\right) \delta 0.11(\mathrm{~s}, 9 \mathrm{H}), 1.06(\mathrm{t}, J=7.3$ $\mathrm{Hz}, 3 \mathrm{H}), 1.59$ (br s, 1H), 1.92-2.07 (m, 2H), 2.84-2.99 (m, 2H), 4.91 (quint, $J=1.5 \mathrm{~Hz}, 1 \mathrm{H}), 5.01$ $(\mathrm{dq}, J=10.1,1.5 \mathrm{~Hz}, 1 \mathrm{H}), 5.04(\mathrm{dq}, J=17.1,1.6 \mathrm{~Hz}, 1 \mathrm{H}), 5.10(\mathrm{br} \mathrm{s}, 1 \mathrm{H}), 5.12$ (quint, $J=1.2 \mathrm{~Hz}$, $1 \mathrm{H}), 5.82$ (ddt, $J=16.5,10.1,6.2 \mathrm{~Hz}, 1 \mathrm{H}), 5.91(\mathrm{td}, J=7.0,1.2 \mathrm{~Hz}, 1 \mathrm{H}) .{ }^{13} \mathrm{C} \mathrm{NMR}\left(\mathrm{CDCl}_{3}\right) \delta 0.45$, $12.15,25.25,33.64,74.24,108.25,115.36,136.44,139.72,143.81,151.95$. HRMS (EI) calcd for $\mathrm{C}_{12} \mathrm{H}_{21} \mathrm{OSi}\left(\mathrm{M}^{+}-\mathrm{CH}_{3}\right)$ 209.1362, found 209.1360.

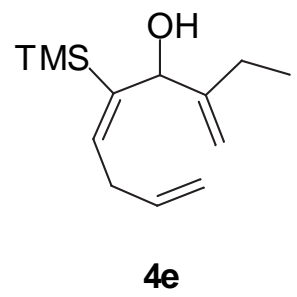

(Z)-3-Methylene-5-phenyl-nona-5,8-diene-1,4-diol (4f): purified by silica gel column chromatography (hexane/EtOAc $=2 / 3)(39 \%$ yield $) ; \mathrm{mp}=72-74{ }^{\circ} \mathrm{C} ;{ }^{1} \mathrm{H}$ NMR $\left(\mathrm{CDCl}_{3}\right) \delta 2.23(\mathrm{dt}, J=$ $14.7,5.8 \mathrm{~Hz}, 1 \mathrm{H}), 2.33$ (dt, $J=14.7,6.1 \mathrm{~Hz}, 1 \mathrm{H}), 2.35$ (br s, 1H), 2.78 (br s, 1H), 3.00-3.11 (m, 2H), $3.69(\mathrm{t}, J=6.4 \mathrm{~Hz}, 2 \mathrm{H}), 5.00-5.01(\mathrm{~m}, 1 \mathrm{H}), 5.05(\mathrm{dq}, J=10.1,1.6 \mathrm{~Hz}, 1 \mathrm{H}), 5.12(\mathrm{dq}, J=17.1,1.6$ $\mathrm{Hz}, 1 \mathrm{H}), 5.22-5.23(\mathrm{~m}, 1 \mathrm{H}), 5.26(\mathrm{~s}, 1 \mathrm{H}), 5.81(\mathrm{t}, J=7.7 \mathrm{~Hz}, 1 \mathrm{H}), 5.89$ (ddt, $J=16.5,10.4,6.4 \mathrm{~Hz}$, $1 \mathrm{H}), 7.21-7.28(\mathrm{~m}, 3 \mathrm{H}), 7.36(\mathrm{dd}, J=8.2,1.5 \mathrm{~Hz}, 2 \mathrm{H}) .{ }^{13} \mathrm{C} \mathrm{NMR}\left(\mathrm{CDCl}_{3}\right) \delta 32.50,36.15,61.58$, $72.49,112.90,115.51,127.05,127.93,127.97,130.80,136.36,140.63,141.10,146.38$. HRMS (FAB) calcd for $\mathrm{C}_{16} \mathrm{H}_{19} \mathrm{O}\left(\mathrm{M}^{+}-\mathrm{OH}\right) 227.1436$, found 227.1435.

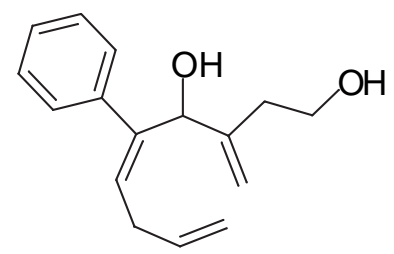

4f

(Z)-2,7-Dimethyl-4-phenyl-octa-1,4,7-trien-3-ol (4h): purified by silica gel column chromatography (hexane/EtOAc/ $\left.\mathrm{CHCl}_{3}=5 / 2 / 5\right)\left(36 \%\right.$ yield); ${ }^{1} \mathrm{H} \mathrm{NMR}\left(\mathrm{CDCl}_{3}\right) \delta 1.69(\mathrm{t}, J=0.6 \mathrm{~Hz}$, $3 \mathrm{H}), 1.81(\mathrm{~s}, 3 \mathrm{H}), 1.87(\mathrm{~d}, J=5.2 \mathrm{~Hz}, 1 \mathrm{H}), 2.97-3.06(\mathrm{~m}, 2 \mathrm{H}), 4.80-4.81(\mathrm{~m}, 2 \mathrm{H}), 4.92-4.94(\mathrm{~m}, 1 \mathrm{H})$, $5.10-5.12(\mathrm{~m}, 1 \mathrm{H}), 5.21(\mathrm{brd}, J=5.2 \mathrm{~Hz}, 1 \mathrm{H}), 5.85(\mathrm{t}, J=7.6 \mathrm{~Hz}, 1 \mathrm{H}), 7.23-7.30(\mathrm{~m}, 3 \mathrm{H}), 7.37-$ $7.39(\mathrm{~m}, 2 \mathrm{H}) .{ }^{13} \mathrm{C} \mathrm{NMR}\left(\mathrm{CDCl}_{3}\right) \delta 19.85,22.91,36.33,72.98,110.68,111.01,127.11,127.95$, 128.01, 130.88, 140.56, 141.49, 144.52, 145.44. HRMS (EI) calcd for $\mathrm{C}_{16} \mathrm{H}_{20} \mathrm{O}\left(\mathrm{M}^{+}\right) 228.1515$, found 228.1513. 


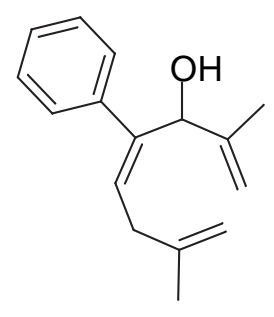

4h

Preparation of trienone 3. To a solution of trienol $4(0.500 \mathrm{mmol})$ in hexane $(3.2 \mathrm{~mL})$ or $\mathrm{CH}_{2} \mathrm{Cl}_{2}(3.2 \mathrm{~mL})$ was added $\mathrm{MnO}_{2}(869 \mathrm{mg}, 10.0 \mathrm{mmol})$ in one portion under air and stirred for $30 \mathrm{~min}$ at room temperature. The mixture was passed through celite and concentrated under reduced pressure. Purification by column chromatography gave trienone 3 .

(Z)-4,5-Dipropyl-octa-1,4,7-trien-3-one (3a): purified by silica gel column chromatography (hexane/EtOAc $=8 / 1)\left(84 \%\right.$ yield); ${ }^{1} \mathrm{H} \mathrm{NMR}\left(\mathrm{CDCl}_{3}\right) \delta 0.89(\mathrm{t}, J=7.3 \mathrm{~Hz}, 3 \mathrm{H}), 0.95(\mathrm{t}$, $J=7.3 \mathrm{~Hz}, 3 \mathrm{H}), 1.31-1.39(\mathrm{~m}, 2 \mathrm{H}), 1.42-1.49(\mathrm{~m}, 2 \mathrm{H}), 2.08-2.11(\mathrm{~m}, 2 \mathrm{H}), 2.22-2.25(\mathrm{~m}, 2 \mathrm{H}), 2.73$ $(\mathrm{dt}, J=6.8,1.5 \mathrm{~Hz}, 2 \mathrm{H}), 4.98-5.03(\mathrm{~m}, 2 \mathrm{H}), 5.69(\mathrm{ddt}, J=17.4,9.5,6.4 \mathrm{~Hz}, 1 \mathrm{H}), 5.93(\mathrm{dd}, J=10.4$, $1.3 \mathrm{~Hz}, 1 \mathrm{H}), 6.17(\mathrm{dd}, J=17.4,1.5 \mathrm{~Hz}, 1 \mathrm{H}), 6.43(\mathrm{dd}, J=17.7,10.4 \mathrm{~Hz}, 1 \mathrm{H}) .{ }^{13} \mathrm{C} \mathrm{NMR}\left(\mathrm{CDCl}_{3}\right) \delta$ $14.09,14.31,21.56,22.10,32.26,32.75,37.93,116.34,130.21,136.04,136.66,137.44,138.59$, 201.38. HRMS (EI) calcd for $\mathrm{C}_{14} \mathrm{H}_{22} \mathrm{O}\left(\mathrm{M}^{+}\right)$206.1671, found 206.1671.

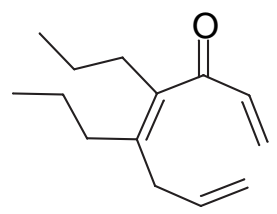

3a

(Z)-4-Phenyl-octa-1, 4,7-trien-3-one (3b): purified by florisil column chromatography (hexane/EtOAc $=10 / 1)(54 \%$ yield $) ;{ }^{1} \mathrm{H}$ NMR $\left(\mathrm{CDCl}_{3}\right) \delta 2.97(\mathrm{ddt}, J=7.9,6.4,1.5 \mathrm{~Hz}, 2 \mathrm{H}), 5.06(\mathrm{dq}$, $J=10.1,1.6 \mathrm{~Hz}, 1 \mathrm{H}), 5.11(\mathrm{dq}, J=17.1,1.5 \mathrm{~Hz}, 1 \mathrm{H}), 5.86(\mathrm{ddt}, J=16.5,10.1,6.1 \mathrm{~Hz}, 1 \mathrm{H}), 5.96$ $(\mathrm{dd}, J=10.4,1.3 \mathrm{~Hz}, 1 \mathrm{H}), 6.15(\mathrm{t}, J=7.6 \mathrm{~Hz}, 1 \mathrm{H}), 6.24(\mathrm{dd}, J=17.7 \mathrm{~Hz}, 1.3 \mathrm{~Hz}, 1 \mathrm{H}), 6.44(\mathrm{dd}, J=$ $17.4,10.4 \mathrm{~Hz}, 1 \mathrm{H}), 7.26-7.34(\mathrm{~m}, 5 \mathrm{H}) .{ }^{13} \mathrm{C} \mathrm{NMR}\left(\mathrm{CDCl}_{3}\right) \delta 33.92,116.20,126.54,127.92,128.73$, $131.35,131.84,135.46,136.99,137.30,141.48,197.87$. HRMS (EI) calcd for $\mathrm{C}_{14} \mathrm{H}_{14} \mathrm{O}\left(\mathrm{M}^{+}\right)$ 198.1045, found 198.1034. This material proved to be unstable. The half-life period is about 1 day in $\mathrm{CDCl}_{3}$ at room temperature.

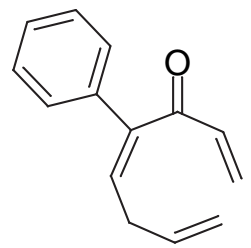

$3 b$

(Z)-5-Deuterio-4-phenyl-octa-1,4,7-trien-3-one (3c): purified by florisil column chromatography $($ hexane/EtOAc $=10 / 1)(52 \%$ yield $) ;{ }^{2} \mathrm{H} \mathrm{NMR}\left(\mathrm{CHCl}_{3}\right) \delta 6.15$.

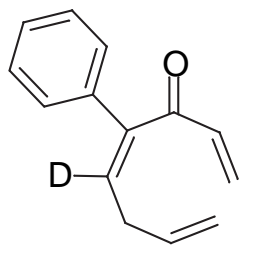

3c 
(Z)-2-Methyl-4,5-dipropyl-octa-1,4,7-trien-3-one (3d): purified by silica gel column chromatography (hexane/EtOAc $=8 / 1)\left(82 \%\right.$ yield); ${ }^{1} \mathrm{H} \mathrm{NMR}\left(\mathrm{CDCl}_{3}\right) \delta 0.89(\mathrm{t}, J=7.1 \mathrm{~Hz}, 3 \mathrm{H}), 0.94(\mathrm{t}$, $J=7.3 \mathrm{~Hz}, 3 \mathrm{H}), 1.30-1.37(\mathrm{~m}, 2 \mathrm{H}), 1.42-1.49(\mathrm{~m}, 2 \mathrm{H}), 1.90(\mathrm{~s}, 3 \mathrm{H}), 2.06-2.09(\mathrm{~m}, 2 \mathrm{H}), 2.18-2.21$ $(\mathrm{m}, 2 \mathrm{H}), 2.63(\mathrm{~d}, J=6.7 \mathrm{~Hz}, 2 \mathrm{H}), 4.96-5.00(\mathrm{~m}, 2 \mathrm{H}), 5.61-5.69(\mathrm{ddt}, J=16.2,11.0,6.7 \mathrm{~Hz}, 1 \mathrm{H})$, 5.86-5.90 (m, 2H). ${ }^{13} \mathrm{C}$ NMR $\left(\mathrm{CDCl}_{3}\right) \delta 14.16,14.31,16.71,21.46,22.04,32.35,32.89,38.16$, 116.26, 127.94, 136.13, 136.45, 136.78, 144.89, 203.45. HRMS (EI) calcd for $\mathrm{C}_{15} \mathrm{H}_{24} \mathrm{O}\left(\mathrm{M}^{+}\right)$ 220.1827 , found 220.1840 .

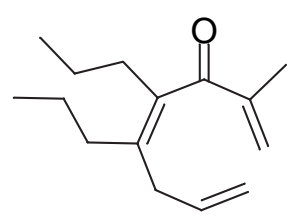

3d

(E)-2-Ethy l-4-trimethylsilyl-octa-1,4,7-trien-3one (3e): purified by silica gel column chromatography $($ hexane/EtOAc $=10 / 1)(59 \%$ yield $) ;{ }^{1} \mathrm{H}$ NMR $\left(\mathrm{CDCl}_{3}\right) \delta 0.11(\mathrm{~s}, 9 \mathrm{H}), 1.07(\mathrm{t}, J=7.3$ $\mathrm{Hz}, 3 \mathrm{H}), 2.35(\mathrm{qt}, J=7.3,1.2 \mathrm{~Hz}, 2 \mathrm{H}), 2.74(\mathrm{tt}, J=6.5,1.5 \mathrm{~Hz}, 2 \mathrm{H}), 4.98-5.03(\mathrm{~m}, 2 \mathrm{H}), 5.75(\mathrm{ddt}, J$ $=17.7,9.8,6.4 \mathrm{~Hz}, 1 \mathrm{H}), 5.86(\mathrm{q}, J=1.5 \mathrm{~Hz}, 1 \mathrm{H}), 5.91-5.94(\mathrm{~m}, 2 \mathrm{H}) .{ }^{13} \mathrm{C} \mathrm{NMR}\left(\mathrm{CDCl}_{3}\right) \delta-1.34$, $12.82,22.95,36.14,115.97,127.27,135.53,139.64,147.03,150.97,203.23$. HRMS (EI) calcd for $\mathrm{C}_{13} \mathrm{H}_{22} \mathrm{OSi}\left(\mathrm{M}^{+}\right) 222.1440$, found 222.1432.

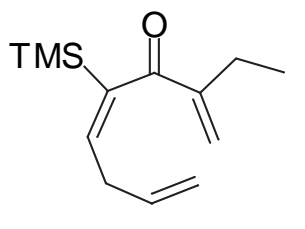

$3 e$

(Z)-2-(2-Hydroxy-ethyl) - 4-phenyl-octa-1,4,7-trien-3-one (3f): purified by silica gel column chromatography (hexane/EtOAc $=2 / 1)(83 \%$ yield $) ;{ }^{1} \mathrm{H} \mathrm{NMR}\left(\mathrm{CDCl}_{3}\right) \delta 1.93(\mathrm{br} \mathrm{s}, 1 \mathrm{H}), 2.65(\mathrm{t}$, $J=6.1 \mathrm{~Hz}, 2 \mathrm{H}), 2.85(\mathrm{ddt}, J=7.6,6.4,1.6 \mathrm{~Hz}, 2 \mathrm{H}), 3.78(\mathrm{brt}, J=5.8 \mathrm{~Hz}, 2 \mathrm{H}), 5.06(\mathrm{dq}, J=10.1$, $1.5 \mathrm{~Hz}, 1 \mathrm{H}), 5.09(\mathrm{dq}, J=17.1,1.5 \mathrm{~Hz}, 1 \mathrm{H}), 5.82(\mathrm{ddt}, J=16.5,10.1,6.4 \mathrm{~Hz}, 1 \mathrm{H}), 6.03(\mathrm{~d}, J=0.6$ $\mathrm{Hz}, 1 \mathrm{H}), 6.13(\mathrm{t}, J=7.8 \mathrm{~Hz}, 1 \mathrm{H}), 6.13(\mathrm{~d}, J=0.6 \mathrm{~Hz}, 1 \mathrm{H}), 7.24-7.33(\mathrm{~m}, 5 \mathrm{H}) .{ }^{13} \mathrm{C} \mathrm{NMR}\left(\mathrm{CDCl}_{3}\right) \delta$ $33.83,33.92,61.82,116.23,125.81,127.87,128.77,128.91,132.18,135.23,137.37,141.25$, 145.72, 200.87. HRMS (FAB) calcd for $\mathrm{C}_{16} \mathrm{H}_{19} \mathrm{O}_{2}\left(\mathrm{M}^{+}+\mathrm{H}\right)$ 243.1386, found 243.1370.

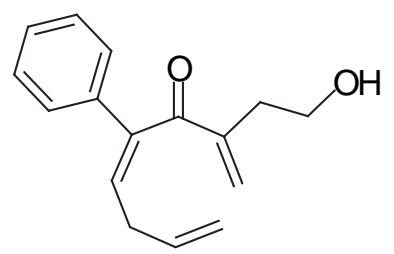

$3 \mathbf{f}$

(Z)-2,7-Dimethyl-4-phenyl-octa-1,4,7-trien-3-one (3h): purified by silica gel column chromatography (hexane/EtOAc $=4 / 1)(73 \%$ yield $) ;{ }^{1} \mathrm{H}$ NMR $\left(\mathrm{CDCl}_{3}\right) \delta 1.75(\mathrm{~s}, 3 \mathrm{H}), 1.97(\mathrm{dd}, J=1.5$, $0.9 \mathrm{~Hz}, 3 \mathrm{H}), 2.78(\mathrm{~d}, J=7.9 \mathrm{~Hz}, 2 \mathrm{H}), 4.76(\mathrm{~s}, 1 \mathrm{H}), 4.79(\mathrm{~s}, 1 \mathrm{H}), 5.92(\mathrm{dq}, J=2.8,1.3 \mathrm{~Hz}, 1 \mathrm{H}), 6.00$ $(\mathrm{dq}, J=2.8,0.9 \mathrm{~Hz}, 1 \mathrm{H}), 6.15(\mathrm{t}, J=7.7 \mathrm{~Hz}, 1 \mathrm{H}), 7.24-7.33(\mathrm{~m}, 5 \mathrm{H}) .{ }^{13} \mathrm{C} \mathrm{NMR}\left(\mathrm{CDCl}_{3}\right) \delta 16.58$, $22.77,37.94,111.43,125.84,127.74,128.70,128.77,130.14,137.60,141.88,143.62,144.52$, 200.49. HRMS (EI) calcd for $\mathrm{C}_{16} \mathrm{H}_{18} \mathrm{O}\left(\mathrm{M}^{+}\right) 226.1358$, found 226.1370 . 


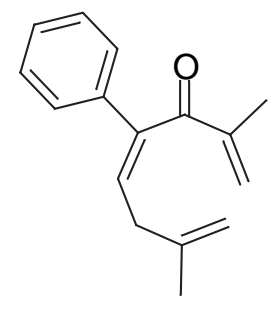

$3 h$

$(Z)$-Acetic acid 3-methylene-4-oxo-5-phenyl-nona-5,8-dienyl ester (3g): To a solution of $3 f(20.0 \mathrm{mg}, 0.0825 \mathrm{mmol})$ in $\mathrm{CH}_{2} \mathrm{Cl}_{2}(1.7 \mathrm{~mL})$ at $-78{ }^{\circ} \mathrm{C}$ under $\mathrm{N}_{2}$ were added $N, N$ diisopropylethylamine $(57 \mu \mathrm{L}, 0.330 \mathrm{mmol})$ and acetyl chloride $(12 \mu \mathrm{L}, 0.165 \mathrm{mmol})$. The reaction mixture was stirred for $5 \mathrm{~min}$, then warmed to room temperature and stirred for additional $15 \mathrm{~min}$. After quenching with sat. $\mathrm{NH}_{4} \mathrm{Cl}$ (aq) and extracting with $\mathrm{CH}_{2} \mathrm{Cl}_{2}$ (3 times), the combined extracts were dried over $\mathrm{MgSO}_{4}$, filtered, and concentrated in vacuo. Purification by silica gel column chromatography (hexane/EtOAc $=3 / 1)$ gave the desired product $3 \mathrm{~g}(96 \%$ yield $) ;{ }^{1} \mathrm{H} \mathrm{NMR}\left(\mathrm{CDCl}_{3}\right) \delta 2.01(\mathrm{~s}, 3 \mathrm{H}), 2.73(\mathrm{t}$, $J=6.7 \mathrm{~Hz}, 2 \mathrm{H}), 2.84(\mathrm{ddt}, J=8.0,6.4,1.6 \mathrm{~Hz}, 2 \mathrm{H}), 4.25(\mathrm{t}, J=6.8 \mathrm{~Hz}, 2 \mathrm{H}), 5.06(\mathrm{dq}, J=10.1,1.6$ $\mathrm{Hz}, 1 \mathrm{H}), 5.09(\mathrm{dq}, J=17.1,1.9 \mathrm{~Hz}, 1 \mathrm{H}), 5.81(\mathrm{ddt}, J=16.8,10.4,6.4 \mathrm{~Hz}, 1 \mathrm{H}), 6.00(\mathrm{~s}, 1 \mathrm{H}), 6.13(\mathrm{t}$, $J=7.7 \mathrm{~Hz}, 1 \mathrm{H}), 6.14(\mathrm{~s}, 1 \mathrm{H}), 7.24-7.33(\mathrm{~m}, 5 \mathrm{H}) .{ }^{13} \mathrm{C} \mathrm{NMR}\left(\mathrm{CDCl}_{3}\right) \delta 20.92,29.40,33.88,62.73$, $116.22,125.82,127.84,128.72,128.77,131.98,135.24,137.33,141.13,144.69,170.92,199.61$. HRMS (FAB) calcd for $\mathrm{C}_{16} \mathrm{H}_{17} \mathrm{O}\left(\mathrm{M}^{+}-\mathrm{OAc}\right) 225.1280$, found 225.1262.

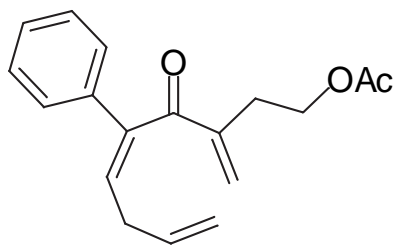

$3 g$

Preparation of $(E)$-3-tert-butyldimethylsilyloxy-hex-4-en-1-yne (9i). To a solution of $(E)$-hex-4-en-1-yn-3-ol (865 mg, $9.00 \mathrm{mmol})$ in $\mathrm{CH}_{2} \mathrm{Cl}_{2}(50 \mathrm{~mL})$ were added imidazole $(695 \mathrm{mg}, 14.4$ $\mathrm{mmol}$ ) and TBDMSCl (1.63g, $10.8 \mathrm{mmol})$ under air. The mixture was stirred for $5 \mathrm{~h}$ at room temperature and then passed through celite. Solvent concentration in vacuo followed by column chromatography of the crude oil (hexane) yielded compound 9i $\left(1.89 \mathrm{~g}, 99 \%\right.$ yield). $;{ }^{1} \mathrm{H}$ NMR $\left(\mathrm{CDCl}_{3}\right) \delta 0.13(\mathrm{~d}, J=5.2 \mathrm{~Hz}$, $6 \mathrm{H}), 0.92(\mathrm{~s}, 9 \mathrm{H}), 1.72(\mathrm{dt}, J=7.0,1.3 \mathrm{~Hz}, 3 \mathrm{H}), 2.48(\mathrm{~d}, J=2.1 \mathrm{~Hz}, 1 \mathrm{H}), 4.83-4.85(\mathrm{~m}, 1 \mathrm{H}), 5.55$ $(\mathrm{ddq}, J=15.3,5.8,1.5 \mathrm{~Hz}, 1 \mathrm{H}), 5.82(\mathrm{dqd}, J=15.3,6.4,1.5 \mathrm{~Hz}, 1 \mathrm{H}) .{ }^{13} \mathrm{C} \mathrm{NMR}\left(\mathrm{CDCl}_{3}\right) \delta-4.78$, $-4.57,17.43,18.34,25.83,63.31,72.99,84.17,127.07,130.70$. HRMS (EI) calcd for $\mathrm{C}_{12} \mathrm{H}_{22} \mathrm{OSi}$ $\left(\mathrm{M}^{+}\right)$210.1440, found 210.1435.

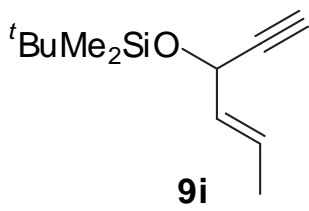

Preparation of ( $2 E, 8 E)$-7-tert-butyldimethylsilyloxy-deca-2,8-dien-5-yn-4-ol (8i). $n$-BuLi (1.60 M solution in hexane, $3.30 \mathrm{mmol})$ was added to a solution of $9 \mathbf{i}(631 \mathrm{mg}, 3.00 \mathrm{mmol})$ in THF $(5 \mathrm{~mL})$ at $-78{ }^{\circ} \mathrm{C}$. After $5 \mathrm{~min}$, crotonaldehyde $(3.60 \mathrm{mmol})$ was added and the mixture was stirred for $20 \mathrm{~min}$ at the same temperature. The reaction mixture was then quenched by addition of saturated aqueous $\mathrm{NH}_{4} \mathrm{Cl}$ and extracted with $\mathrm{Et}_{2} \mathrm{O}$ twice. The organic phases were dried with $\mathrm{MgSO}_{4}$ and concentrated under vacuum. The residue was purified by silica gel column chromatography (hexane/EtOAc $=10 / 1)$ to give 8i. $\left(773 \mathrm{mg}, 92 \%\right.$ yield). $;{ }^{1} \mathrm{H}$ NMR $\left(\mathrm{CDCl}_{3}\right) \delta 0.12(\mathrm{~s}, 3 \mathrm{H}), 0.13(\mathrm{~s}, 3 \mathrm{H})$, $0.91(\mathrm{~s}, 9 \mathrm{H}), 1.70-1.74(\mathrm{~m}, 6 \mathrm{H}), 1.85($ br s, $1 \mathrm{H}), 4.84-4.87(\mathrm{~m}, 1 \mathrm{H}), 4.88-4.91(\mathrm{~m}, 1 \mathrm{H}), 5.54(\mathrm{ddq}, J$ 
$=15.3,5.5,1.5 \mathrm{~Hz}, 1 \mathrm{H}), 5.61(\mathrm{ddq}, J=15.3,6.4,1.9 \mathrm{~Hz}, 1 \mathrm{H}), 5.79(\mathrm{dqd}, J=14.7,6.7,1.3 \mathrm{~Hz}, 1 \mathrm{H})$, 5.89 (dqt, $J=15.3,6.4,1.2 \mathrm{~Hz}, 1 \mathrm{H}) .{ }^{13} \mathrm{C} \mathrm{NMR}\left(\mathrm{CDCl}_{3}\right) \delta-4.70,-4.48,17.43,17.45,18.36,25.85$, 63.01, 63.52, 84.38, 86.25, 126.86, 128.85, 130.11, 130.80. HRMS (FAB) calcd for $\mathrm{C}_{16} \mathrm{H}_{27} \mathrm{O}_{2} \mathrm{Si}$ $\left(\mathrm{M}^{+}-\mathrm{H}\right)$ 279.1781, found 279.1782.

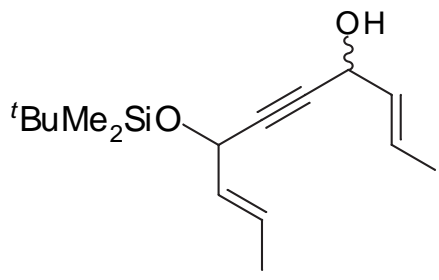

$8 \mathbf{i}$

Preparation of $(2 E, 8 E)$-7-tert-butyldimethylsilyloxy-deca-2,8-dien-5-yn-4-one (7i). To a solution of $8 \mathbf{i}(112 \mathrm{mg}, 0.399 \mathrm{mmol})$ in hexane $(2.6 \mathrm{~mL})$ was added $\mathrm{MnO}_{2}(695 \mathrm{mg}, 7.99$ mmol) in one portion under air and stirred for $30 \mathrm{~min}$ at room temperature. The mixture was passed through celite and concentrated under reduced pressure. The resulting residue was purified by column chromatography (hexane/EtOAc $=10 / 1)$ to give $7 \mathbf{i}(86.3 \mathrm{mg}, 78 \%$ yield $) . ;{ }^{1} \mathrm{H} \mathrm{NMR}\left(\mathrm{CDCl}_{3}\right) \delta 0.13(\mathrm{~s}$, $3 \mathrm{H}), 0.15(\mathrm{~s}, 3 \mathrm{H}), 0.92(\mathrm{~s}, 9 \mathrm{H}), 1.73(\mathrm{dt}, J=6.4,1.6 \mathrm{~Hz}, 3 \mathrm{H}), 1.98(\mathrm{dd}, J=7.1,1.5 \mathrm{~Hz}, 3 \mathrm{H}), 5.00-$ 5.02 (d quint, $J=5.8,1.2 \mathrm{~Hz}, 1 \mathrm{H}), 5.56(\mathrm{ddq}, J=15.3,5.8,1.5 \mathrm{~Hz}, 1 \mathrm{H}), 5.84(\mathrm{dqd}, J=15.3,6.4$, $1.6 \mathrm{~Hz}, 1 \mathrm{H}), 6.17(\mathrm{dq}, J=15.6,1.6 \mathrm{~Hz}, 1 \mathrm{H}), 7.19(\mathrm{dq}, J=15.6,7.0 \mathrm{~Hz}, 1 \mathrm{H}) .{ }^{13} \mathrm{C} \mathrm{NMR}\left(\mathrm{CDCl}_{3}\right) \delta$ $-4.79,-4.65,17.48,18.28,18.42,25.73,63.47,81.91,91.97,128.20,129.29,133.76,149.89$, 178.11. HRMS (FAB) calcd for $\mathrm{C}_{16} \mathrm{H}_{25} \mathrm{O}_{2} \mathrm{Si}\left(\mathrm{M}^{+}-\mathrm{H}\right)$ 277.1625, found 277.1626.

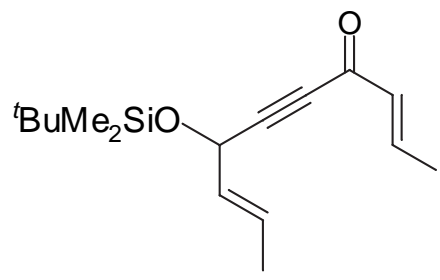

7

Preparation of $(2 E, 5 Z, 8 E)$-7-tert-butyldimethylsilyloxy-deca-2,5,8-trien-4-one (3i). To a solution of 7i $(36.9 \mathrm{mg}, 0.133 \mathrm{mmol})$ in 1 -hexene/EtOAc $(1: 1,4 \mathrm{~mL})$ was added Lindlar catalyst $(11.0 \mathrm{mg}, 5 \mathrm{wt} \%)$ and the mixture was stirred under hydrogen atmosphere for $10 \mathrm{~min}$ at room temperature. The mixture was passed through celite and concentrated under reduced pressure. The resulting residue was purified by column chromatography (hexane/EtOAc $=10 / 1$ ) to give trienone 3i (28.8 mg, 77\% yield).; ${ }^{1} \mathrm{H}$ NMR $\left(\mathrm{CDCl}_{3}\right) \delta 0.01(\mathrm{~s}, 3 \mathrm{H}), 0.02(\mathrm{~s}, 3 \mathrm{H}), 0.87(\mathrm{~s}, 9 \mathrm{H}), 1.67(\mathrm{dt}, J=6.4$, $1.6 \mathrm{~Hz}, 3 \mathrm{H}), 1.91(\mathrm{dd}, J=7.0,1.8 \mathrm{~Hz}, 3 \mathrm{H}), 5.49(\mathrm{ddq}, J=15.3,4.9,1.8 \mathrm{~Hz}, 1 \mathrm{H}), 5.66(\mathrm{ddq}, J=7.7$, $4.9,1.5 \mathrm{~Hz}, 1 \mathrm{H}), 5.79(\mathrm{dqd}, J=15.3,6.7,1.5 \mathrm{~Hz}, 1 \mathrm{H}), 6.01(\mathrm{dd}, J=11.6,7.7 \mathrm{~Hz}, 1 \mathrm{H}), 6.19(\mathrm{dq}, J=$ 15.6, $1.9 \mathrm{~Hz}, 1 \mathrm{H}), 6.23(\mathrm{dd}, J=11.6,1.2 \mathrm{~Hz}, 1 \mathrm{H}), 6.87(\mathrm{dq}, J=15.6,6.8 \mathrm{~Hz}, 1 \mathrm{H}) .{ }^{13} \mathrm{C}$ NMR $\left(\mathrm{CDCl}_{3}\right) \delta-4.74,-4.69,17.77,18.29,18.39,25.89,69.60,122.60,125.77,131.01,132.95,143.49$, 150.26, 190.37. HRMS (FAB) calcd for $\mathrm{C}_{16} \mathrm{H}_{27} \mathrm{O}_{2} \mathrm{Si}\left(\mathrm{M}^{+}-\mathrm{H}\right)$ 279.1781, found 279.1794.

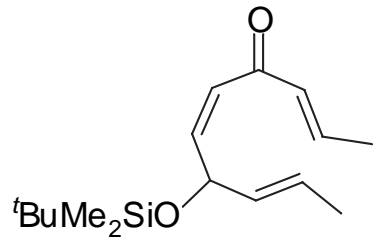

$3 \mathbf{i}$

General procedure of the ring-closing olefin metathesis for phenol derivatives. A solution of trienone $3(0.200 \mathrm{mmol})$ in $\mathrm{CH}_{2} \mathrm{Cl}_{2}(20 \mathrm{~mL}, 0.01 \mathrm{M})$ was treated with $7.5 \mathrm{~mol} \%$ catalyst 11 $(12.7 \mathrm{mg}, 0.015 \mathrm{mmol})$ in one portion under nitrogen and stirred for $2 \mathrm{~h}$ at room temperature. The 
mixture was concentrated under reduced pressure and purified by silica gel column chromatography or PTLC on silica gel to phenol 1.<smiles>[R]C=C([R])C(=O)C([R])=C([R])C([R7])C([R7])=C[R]</smiles>

3

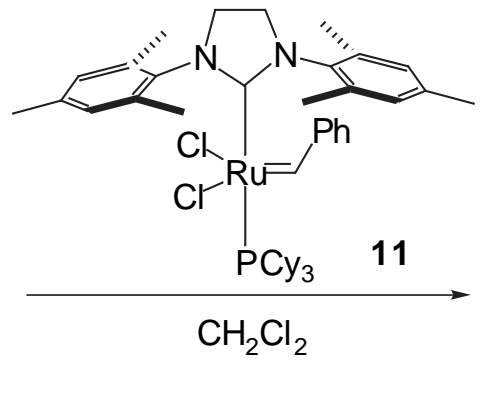

2,3-Dipropylphenol (1a): purified by silica gel column chromatography (hexane/EtOAc $=$ 20/1) (93\% yield); ${ }^{1} \mathrm{H}$ NMR $\left(\mathrm{CDCl}_{3}\right) \delta 0.98(\mathrm{t}, J=7.4 \mathrm{~Hz}, 3 \mathrm{H}), 1.01(\mathrm{t}, J=7.4 \mathrm{~Hz}, 3 \mathrm{H}), 1.52-1.63(\mathrm{~m}$, $4 \mathrm{H}), 2.55-2.62(\mathrm{~m}, 4 \mathrm{H}), 4.78(\mathrm{br} \mathrm{s}, 1 \mathrm{H}), 6.59(\mathrm{~d}, J=8.0 \mathrm{~Hz}, 1 \mathrm{H}), 6.75(\mathrm{~d}, J=7.7 \mathrm{~Hz}, 1 \mathrm{H}), 6.97(\mathrm{dd}$, $J=8.0,7.7 \mathrm{~Hz}, 1 \mathrm{H}) .{ }^{13} \mathrm{C} \mathrm{NMR}\left(\mathrm{CDCl}_{3}\right) \delta 14.26,14.50,23.16,24.55,28.11,35.03,112.81,121.90$, 126.25, 127.00, 142.42, 153.69. HRMS (EI) calcd for $\mathrm{C}_{12} \mathrm{H}_{18} \mathrm{O}\left(\mathrm{M}^{+}\right)$178.1358, found 178.1370.

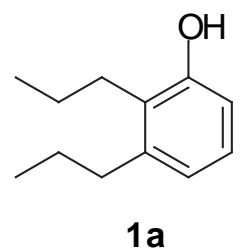

2-Phenylphenol (1b): purified by PTLC (hexane/EtOAc = 4/1) $\left(90 \%\right.$ yield); ${ }^{1} \mathrm{H}$ NMR $\left(\mathrm{CDCl}_{3}\right)$

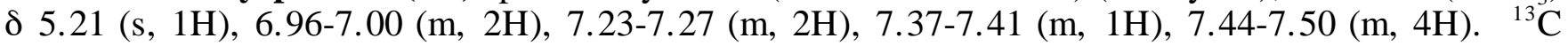
$\operatorname{NMR}\left(\mathrm{CDCl}_{3}\right) \delta 115.86,120.88,127.90,128.17,129.13,129.18,129.31,130.27,137.13,152.46$. This product was characterized by comparison of the spectroscopic data with those reported previously. ${ }^{8}$<smiles>Oc1ccccc1-c1ccccc1</smiles>

$1 b$

3-Deuterio-2-phenylphenol (1c): purified by PTLC (hexane/EtOAc $=4 / 1)(92 \%$ yield $) ;{ }^{2} \mathrm{H}$ $\operatorname{NMR}\left(\mathrm{CHCl}_{3}\right) \delta 7.28$.<smiles>[2H]c1cccc(O)c1-c1ccccc1</smiles>

1c

6-Methyl-2,3-dipropylphenol (1d): purified by silica gel column chromatography $($ hexane/EtOAc $=20 / 1)(92 \%$ yield $) ; \mathrm{mp}=30-31{ }^{\circ} \mathrm{C} ;{ }^{1} \mathrm{H} \mathrm{NMR}\left(\mathrm{CDCl}_{3}\right) \delta 0.97(\mathrm{t}, J=7.3 \mathrm{~Hz}, 3 \mathrm{H}), 1.02(\mathrm{t}$, 
$J=7.3 \mathrm{~Hz}, 3 \mathrm{H}), 1.52-1.62(\mathrm{~m}, 4 \mathrm{H}), 2.20(\mathrm{~s}, 3 \mathrm{H}), 2.52-2.61(\mathrm{~m}, 4 \mathrm{H}), 4.57(\mathrm{~s}, 1 \mathrm{H}), 6.67(\mathrm{~d}, J=7.6$ $\mathrm{Hz}, 1 \mathrm{H}), 6.89(\mathrm{~d}, J=7.7 \mathrm{~Hz}, 1 \mathrm{H}) .{ }^{13} \mathrm{C} \mathrm{NMR}\left(\mathrm{CDCl}_{3}\right) \delta 14.28,14.58,15.84,23.16,24.66,28.37$, $35.04,120.22,121.29,126.33,127.76,139.87,151.98$. HRMS (FAB) calcd for $\mathrm{C}_{13} \mathrm{H}_{19} \mathrm{O}\left(\mathrm{M}^{+}-\mathrm{H}\right)$ 191.1436, found 191.1446.

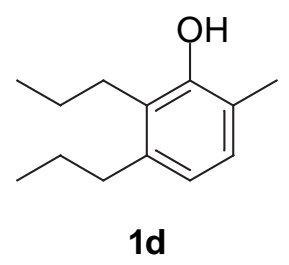

2-Ethyl-6-trimethylsilylphenol (1e): purified by PTLC (hexane/ $\left.\mathrm{CH}_{2} \mathrm{Cl}_{2}=1 / 1\right)$ (97\% yield); ${ }^{1} \mathrm{H} \mathrm{NMR}\left(\mathrm{CDCl}_{3}\right) \delta 0.31(\mathrm{~s}, 9 \mathrm{H}), 1.27(\mathrm{t}, J=7.7 \mathrm{~Hz}, 3 \mathrm{H}), 2.59(\mathrm{q}, J=7.7 \mathrm{~Hz}, 2 \mathrm{H}), 4.81(\mathrm{~s}, 1 \mathrm{H}), 6.90$ $(\mathrm{t}, J=7.4 \mathrm{~Hz}, 1 \mathrm{H}), 7.15(\mathrm{dd}, J=7.3,1.9 \mathrm{~Hz}, 1 \mathrm{H}), 7.23(\mathrm{dd}, J=7.3,1.9 \mathrm{~Hz}, 1 \mathrm{H}) .{ }^{13} \mathrm{C} \mathrm{NMR}\left(\mathrm{CDCl}_{3}\right)$ $\delta-0.73,13.72,22.75,120.69,125.06,127.64,130.19,133.01,158.24$. HRMS (EI) calcd for $\mathrm{C}_{11} \mathrm{H}_{18} \mathrm{OSi}\left(\mathrm{M}^{+}\right)$194.1127, found 194.1112.<smiles>CCc1cccc(S(C)(=O)=O)c1O</smiles>

6-(2-Hydroxy-ethyl) -2-phenylphenol (1f): purified by silica gel column chromatography (hexane/EtOAc $=2 / 1)\left(93 \%\right.$ yield); ${ }^{1} \mathrm{H}$ NMR $\left(\mathrm{CDCl}_{3}\right) \delta 2.34(\mathrm{br} \mathrm{s}, 1 \mathrm{H}), 2.94(\mathrm{t}, J=5.8 \mathrm{~Hz}, 2 \mathrm{H}), 3.92(\mathrm{t}$, $J=5.5 \mathrm{~Hz}, 2 \mathrm{H}), 6.92(\mathrm{t}, J=7.7 \mathrm{~Hz}, 1 \mathrm{H}), 7.09$ (dd, $J=7.3,1.9 \mathrm{~Hz}, 1 \mathrm{H}), 7.15$ (br s, $1 \mathrm{H}), 7.17$ (dd, $J$ $=7.7,1.9 \mathrm{~Hz}, 1 \mathrm{H}), 7.34(\mathrm{tt}, J=7.3,1.2 \mathrm{~Hz}, 1 \mathrm{H}), 7.44(\mathrm{t}, J=7.7 \mathrm{~Hz}, 2 \mathrm{H}), 7.50(\mathrm{dd}, J=8.3 \mathrm{~Hz}, 1.3$ $\mathrm{Hz}, 2 \mathrm{H}) .{ }^{13} \mathrm{C} \mathrm{NMR}\left(\mathrm{CDCl}_{3}\right) \delta 34.59,64.10,120.47,126.74,127.35,128.65,129.27,129.37,129.44$, 130.47, 138.14, 151.79. HRMS (FAB) calcd for $\mathrm{C}_{14} \mathrm{H}_{14} \mathrm{O}_{2}\left(\mathrm{M}^{+}\right) 214.0994$, found 214.0991.<smiles>OCCc1cccc(-c2ccccc2)c1O</smiles>

$1 f$

6-(2-Acetoxy-ethyl) -2-phenylphenol (1g): purified by silica gel column chromatography (hexane/EtOAc $=4 / 1)\left(98 \%\right.$ yield); ${ }^{1} \mathrm{H}$ NMR $\left(\mathrm{CDCl}_{3}\right) \delta 2.06(\mathrm{~s}, 3 \mathrm{H}), 3.03(\mathrm{t}, J=7.0 \mathrm{~Hz}, 2 \mathrm{H}), 4.33(\mathrm{t}, J$ $=7.0 \mathrm{~Hz}, 2 \mathrm{H}), 5.55(\mathrm{~s}, 1 \mathrm{H}), 6.93(\mathrm{t}, J=7.6 \mathrm{~Hz}, 1 \mathrm{H}), 7.12-7.15(\mathrm{~m}, 2 \mathrm{H}), 7.40(\mathrm{tt}, J=9.2,1.9 \mathrm{~Hz}$, $1 \mathrm{H}), 7.44-7.51(\mathrm{~m}, 4 \mathrm{H}) .{ }^{13} \mathrm{C} \mathrm{NMR}\left(\mathrm{CDCl}_{3}\right) \delta 21.08,30.15,64.00,120.39,124.28,127.94,128.28$, 128.89, 129.19, 129.33, 130.44, 137.17, 150.82, 171.27. HRMS (FAB) calcd for $\mathrm{C}_{16} \mathrm{H}_{16} \mathrm{O}_{3}\left(\mathrm{M}^{+}\right)$ 256.1100 , found 256.1088 .<smiles>CC(=O)OCCc1cccc(-c2ccccc2)c1O</smiles> 
2,3-Dimethyl-6-phenylphenol (1h): purified by PTLC (hexane/ $\left.\mathrm{CH}_{2} \mathrm{Cl}_{2}=1 / 1\right)(92 \%$ yield); ${ }^{1} \mathrm{H} \mathrm{NMR}\left(\mathrm{CDCl}_{3}\right) \delta 2.23(\mathrm{~s}, 3 \mathrm{H}), 2.31(\mathrm{~s}, 3 \mathrm{H}), 5.26(\mathrm{~s}, 1 \mathrm{H}), 6.81(\mathrm{~d}, J=7.6 \mathrm{~Hz}, 1 \mathrm{H}), 6.97(\mathrm{~d}, J=7.9$ $\mathrm{Hz}, 1 \mathrm{H}), 7.38(\mathrm{tt}, J=7.3,1.6 \mathrm{~Hz}, 1 \mathrm{H}), 7.42-7.44(\mathrm{~m}, 2 \mathrm{H}), 7.46-7.49(\mathrm{~m}, 2 \mathrm{H}) .{ }^{13} \mathrm{C} \mathrm{NMR}\left(\mathrm{CDCl}_{3}\right) \delta$ $11.94,20.16,121.86,123.11,125.47,126.68,127.75,129.21,129.41,137.69,137.91,150.31$. HRMS (FAB) calcd for $\mathrm{C}_{14} \mathrm{H}_{14} \mathrm{O}\left(\mathrm{M}^{+}\right)$198.1045, found 198.1062.<smiles>Cc1ccc(-c2ccccc2)c(O)c1C</smiles>

$1 \mathrm{~h}$

2-Chloro-5,6-dimethyl-3-phenylphenol (1j): purified by PTLC (hexane/ $\mathrm{CH}_{2} \mathrm{Cl}_{2}=1 / 1$ ) (84\% yield); mp = 40-41 ${ }^{\circ}$; ${ }^{1} \mathrm{H}$ NMR $\left(\mathrm{CDCl}_{3}\right) \delta 2.25(\mathrm{~s}, 3 \mathrm{H}), 2.27(\mathrm{~s}, 3 \mathrm{H}), 5.81(\mathrm{~s}, 1 \mathrm{H}), 6.75(\mathrm{~s}, 1 \mathrm{H})$, 7.34-7.38 (m, 1H), 7.40-7.42 (m, 4H). ${ }^{13} \mathrm{C}$ NMR $\left(\mathrm{CDCl}_{3}\right) \delta 12.50,19.79,115.85,123.09,123.85$, 127.51, 128.07, 129.34, 136.44, 137.45, 139.43, 149.44. HRMS (FAB) calcd for $\mathrm{C}_{14} \mathrm{H}_{13} \mathrm{ClO}\left(\mathrm{M}^{+}\right)$ 232.0656, found 232.0663.<smiles>Cc1cc(-c2ccccc2)c(Cl)c(O)c1C</smiles>

1) Dorta, R.; Kelly III, R. A.; Nolan, S. P. Adv. Synth. Catal. 2004, 346, 917.

2) Trnka, T. M.; Morgan, J. P.; Sanford, M. S.; Wilhelm, T. E.; Scholl, M.; Choi, T.-L.; Ding, S.; Day, M. W.; Grubbs, R. H. J. Am. Chem. Soc. 2003, 125, 2546.

3) (a) Kaneda, K.; Uchiyama, T.; Fujiwara, Y.; Imanaka, T.; Teranishi, S. J. Org. Chem. 1979, 44, 55. (b) Llebaria, A.; Camps, F.; Moretó, J. M. Tetrahedron 1993, 49, 1283. (c) Thadani, A. N.; Rawal, V. H. Org. Lett. $2002,4,4317$.

4) Spino, C.; Thibault, C.; Gingras, S. J. Org. Chem. 1998, 63, 5283.

5) Attenburrow, J.; Cameron, A. F. B.; Chapman, J. H.; Evans, R. M.; Hems, B. A.; Jansen, A. B. A.; Walker, T. J. Chem. Soc. 1952, 1094.

6) Kajiyashiki, T.; Kido, Y.; Ohnishi, T. Jpn. Kokai Tokkyo Koho JP, 1999. CAN: 131:336745.

7) Hamura, T.; Kawano, N.; Tsuji, S.; Matsumoto, T.; Suzuki, K. Chem. Lett. $2002,1042$.

8) Zhou, Q. J.; Worm, K.; Dolle, R. E. J. Org. Chem. 2004, 69, 5147. 


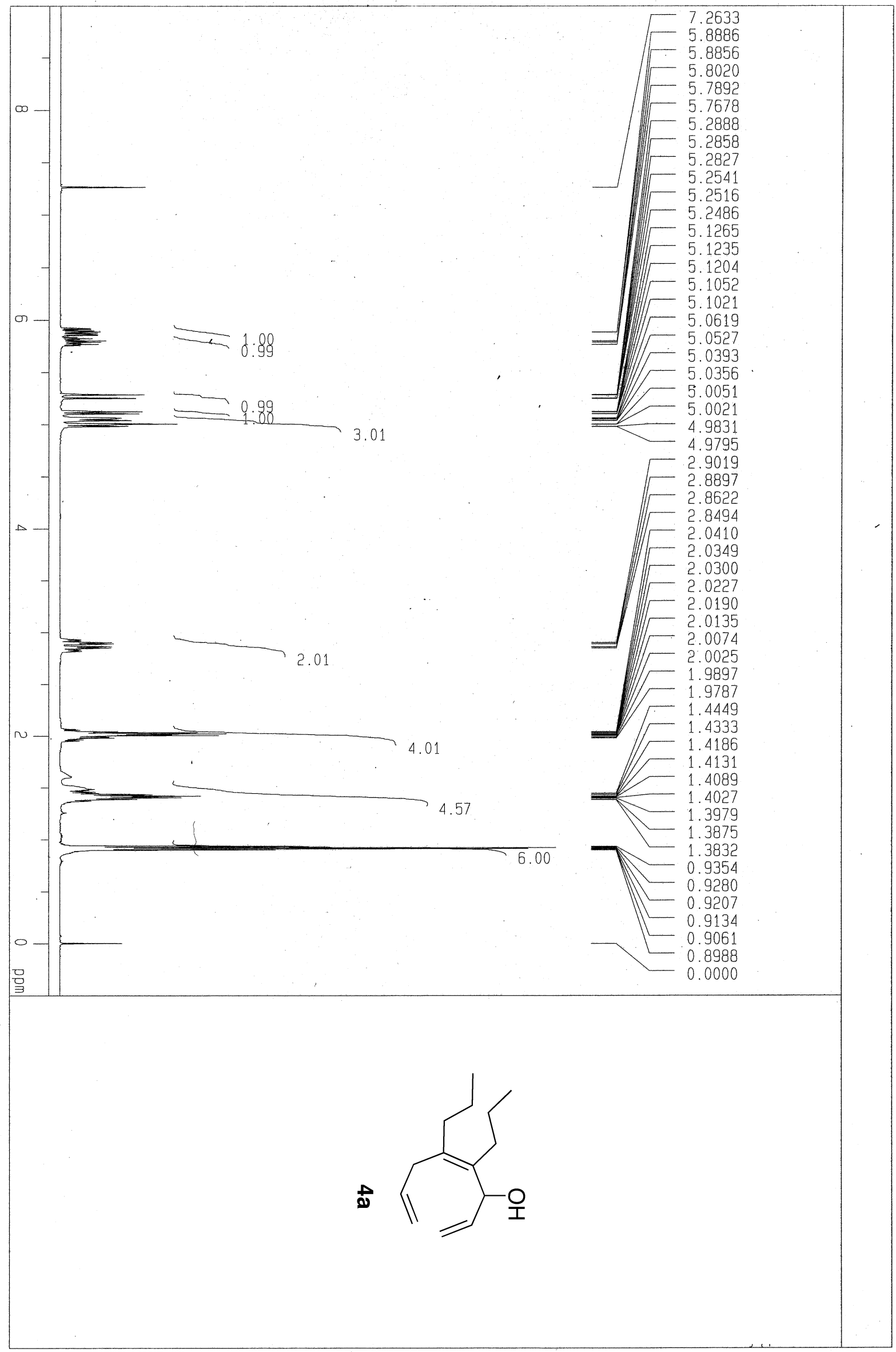




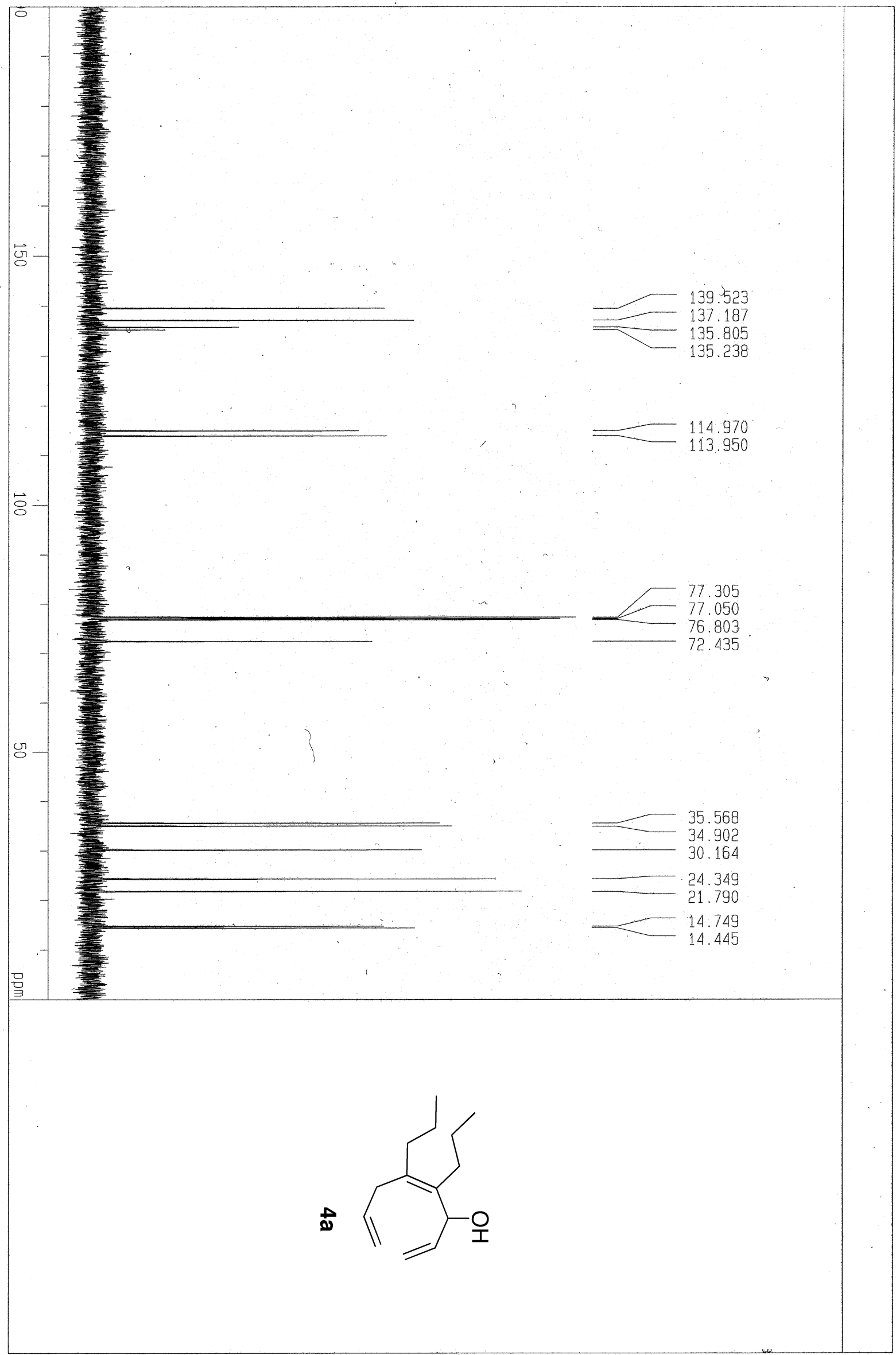

S13 


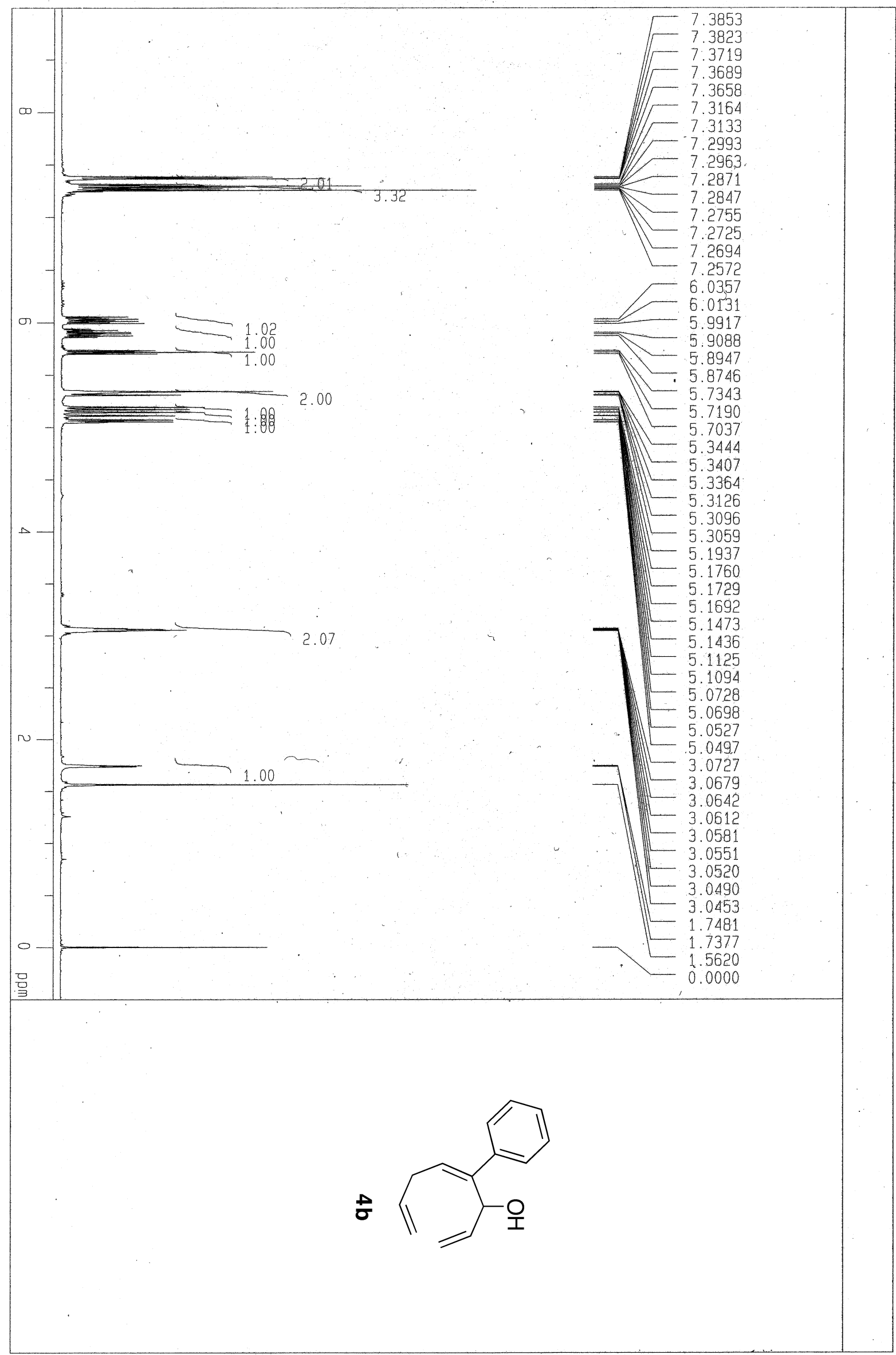




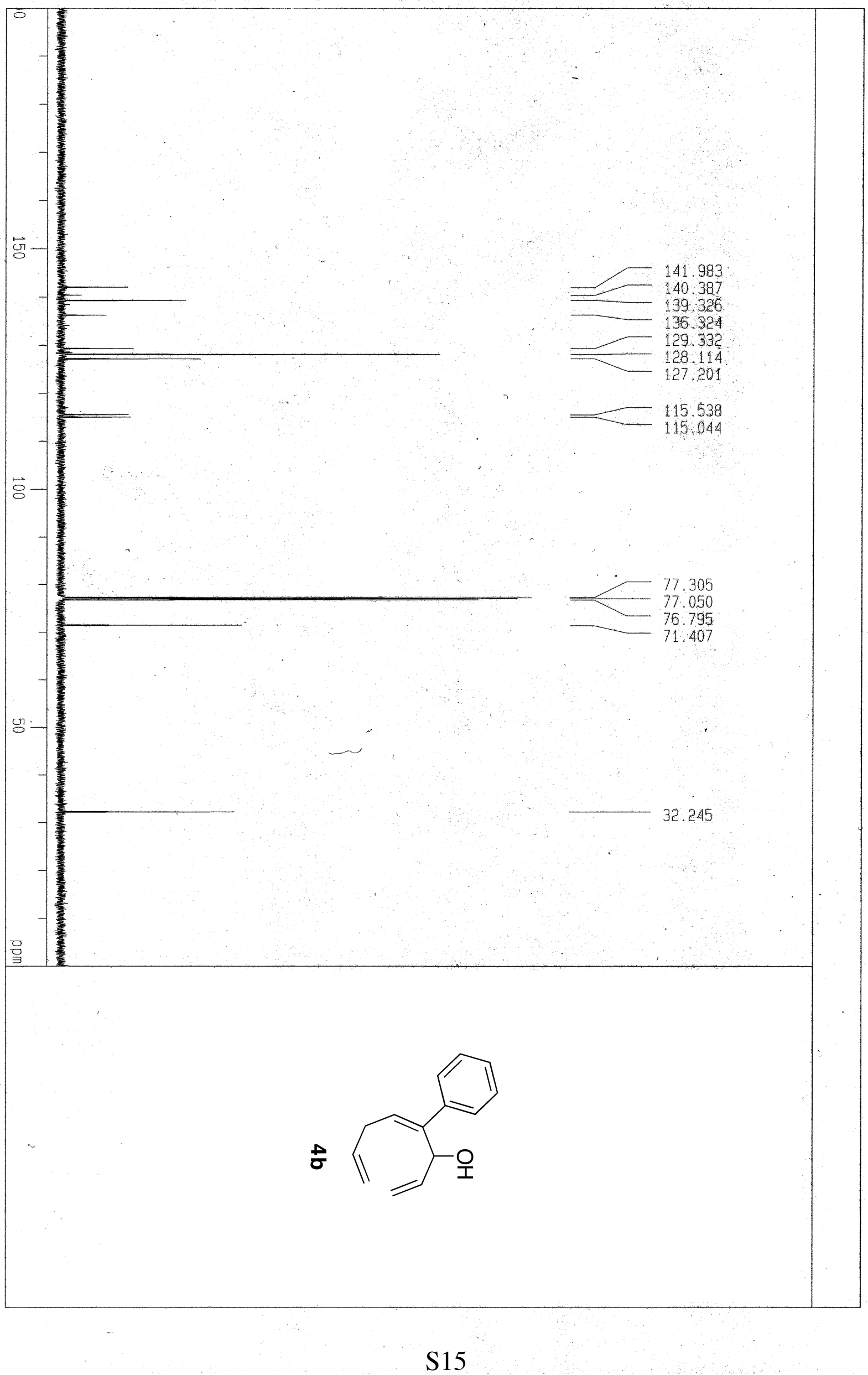




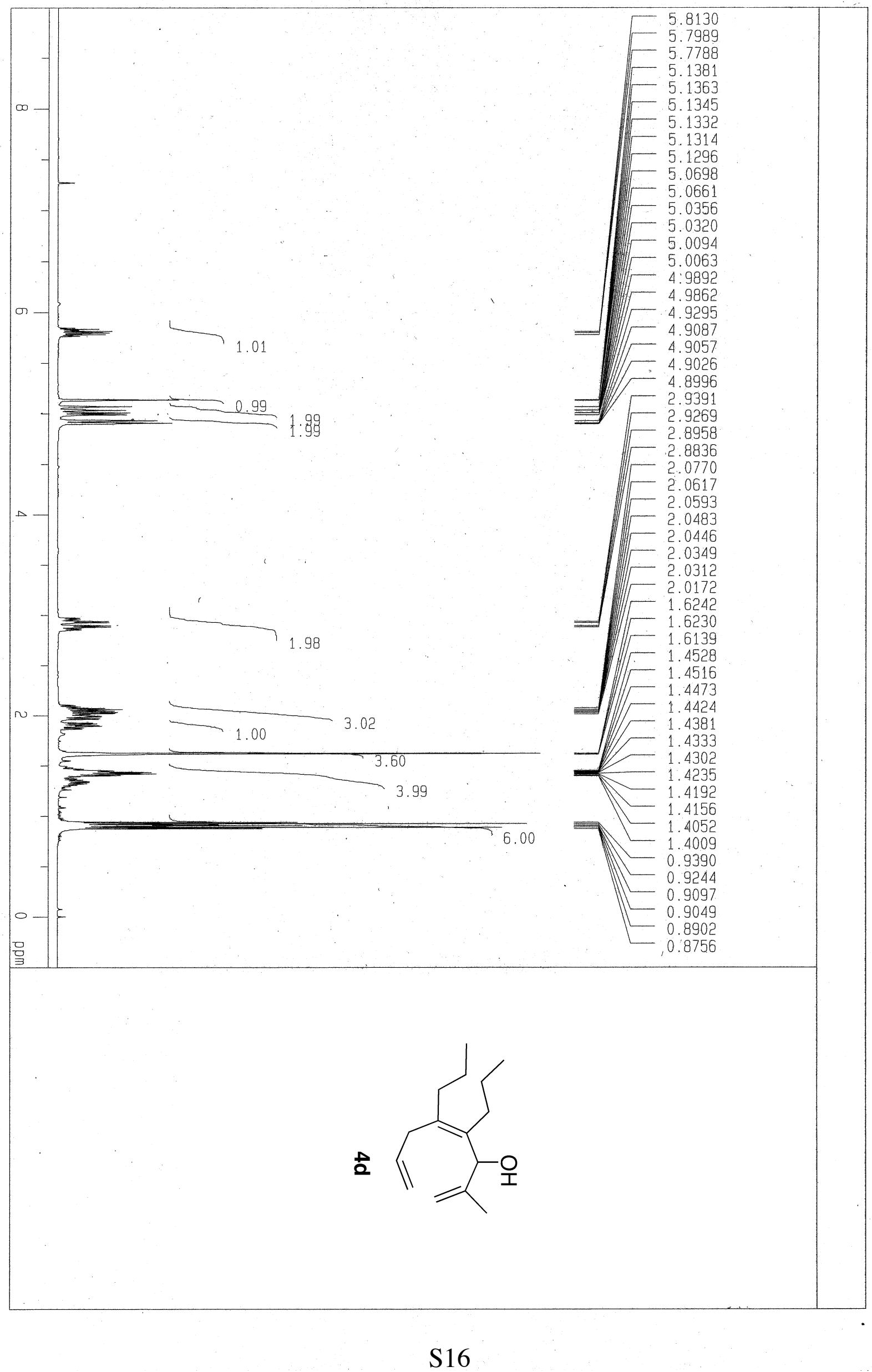




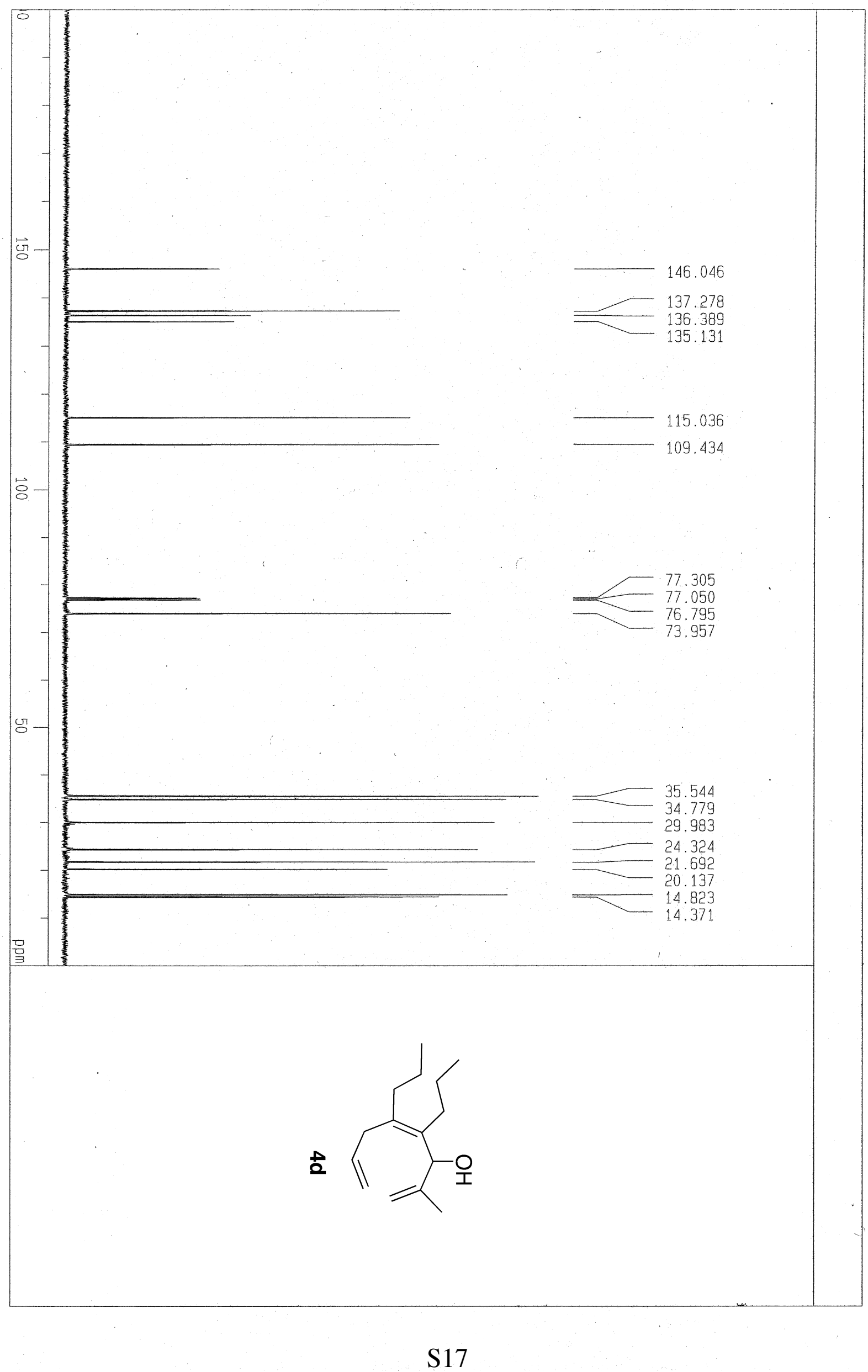




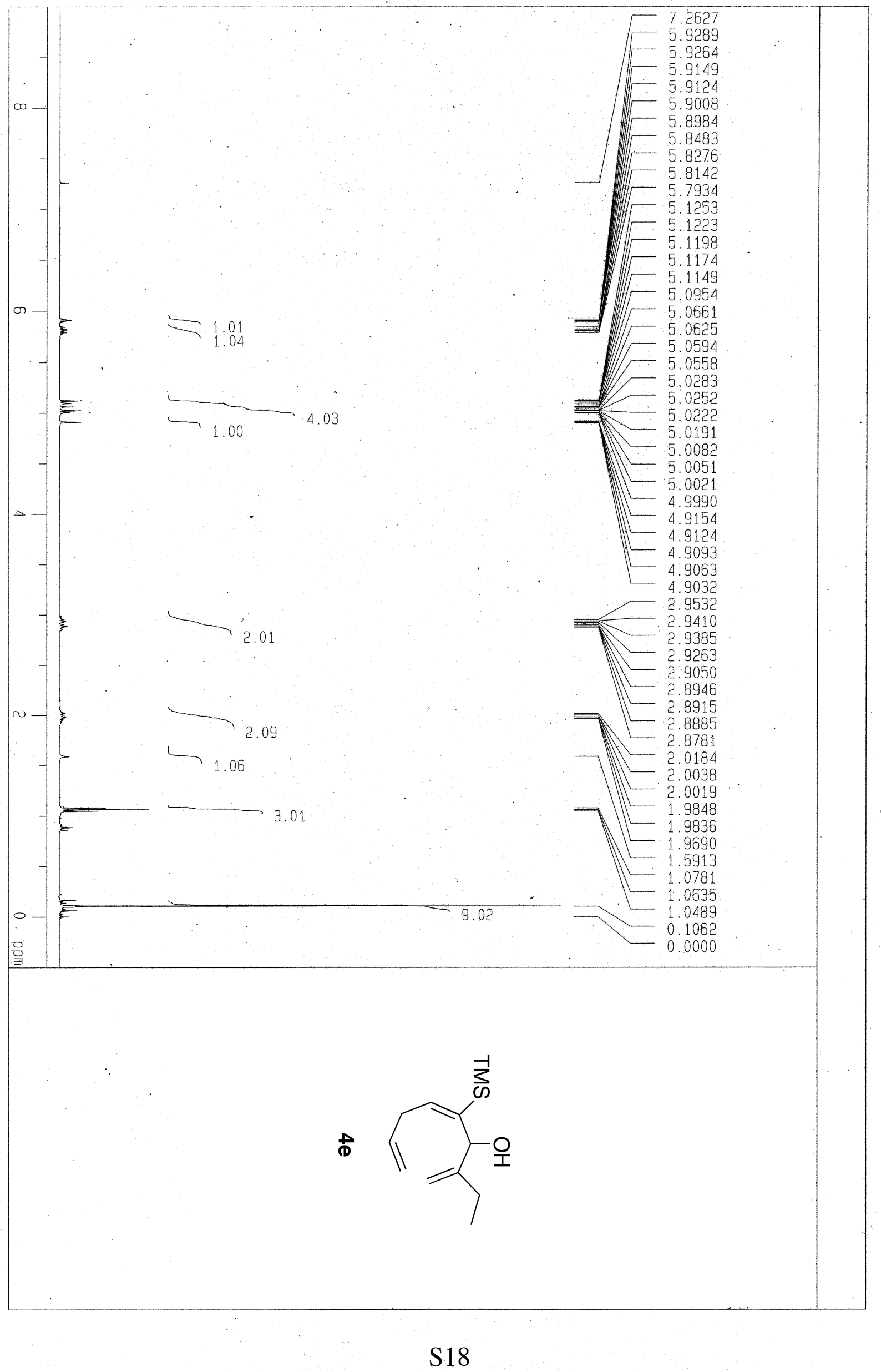




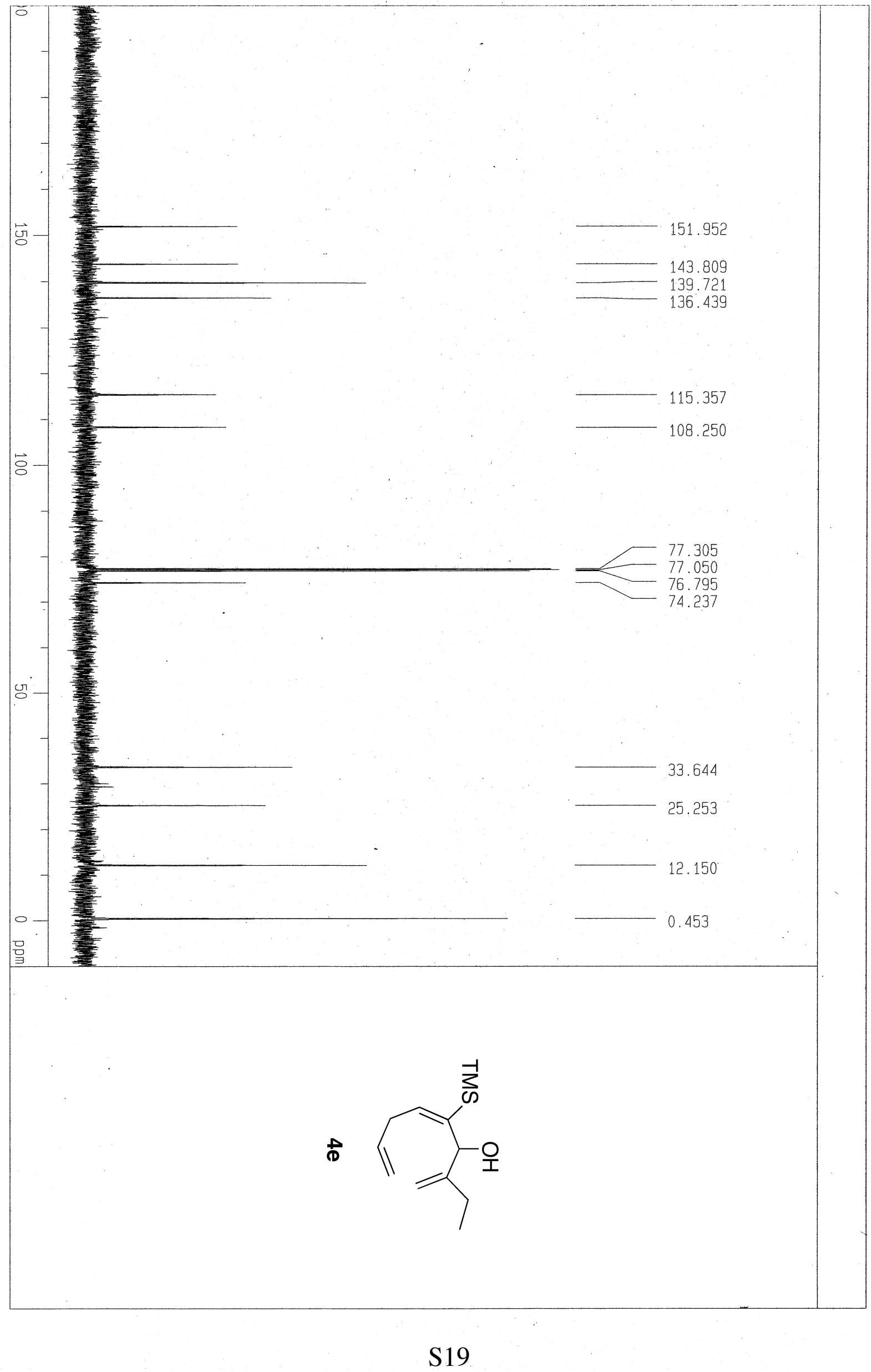




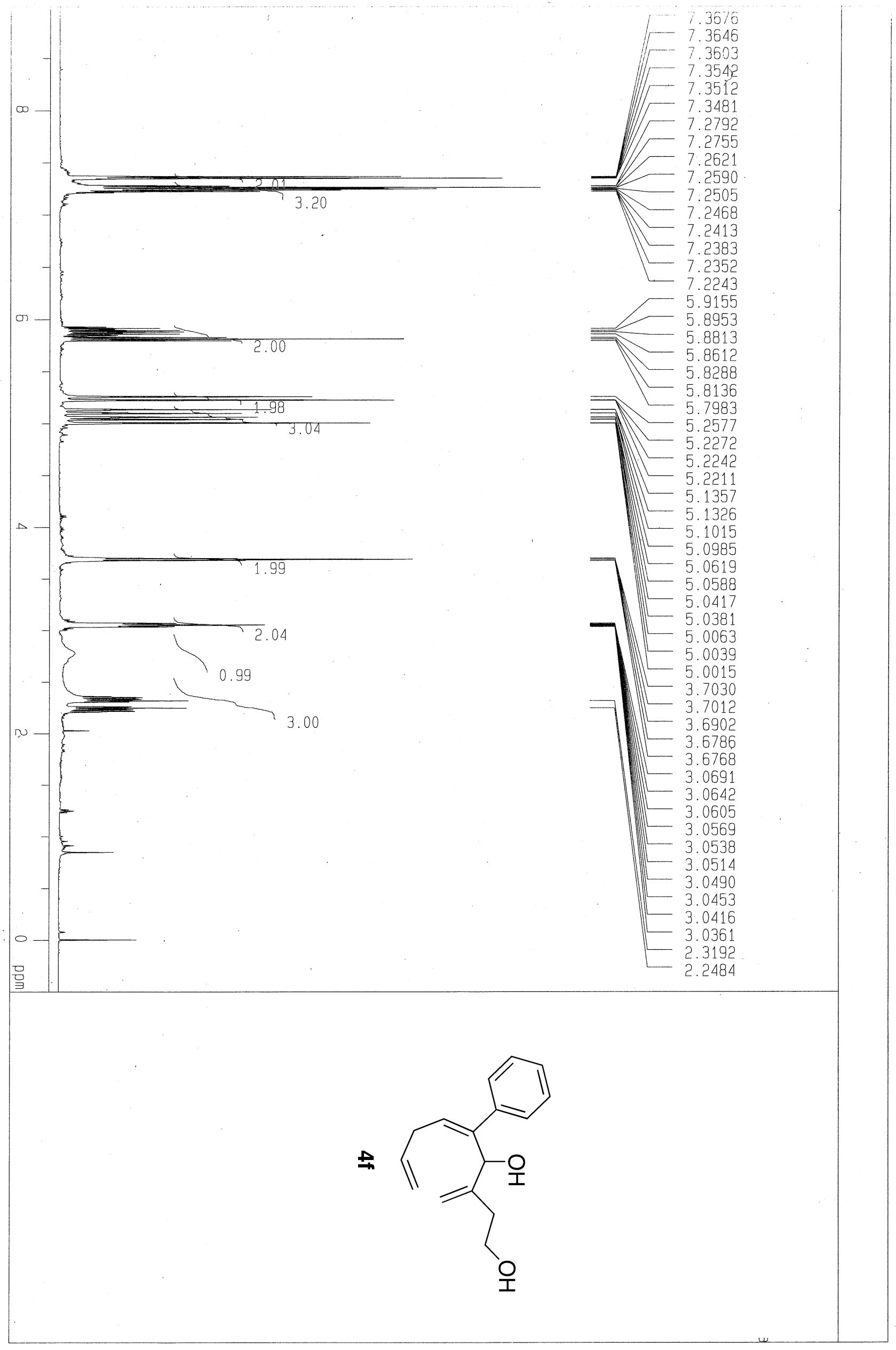




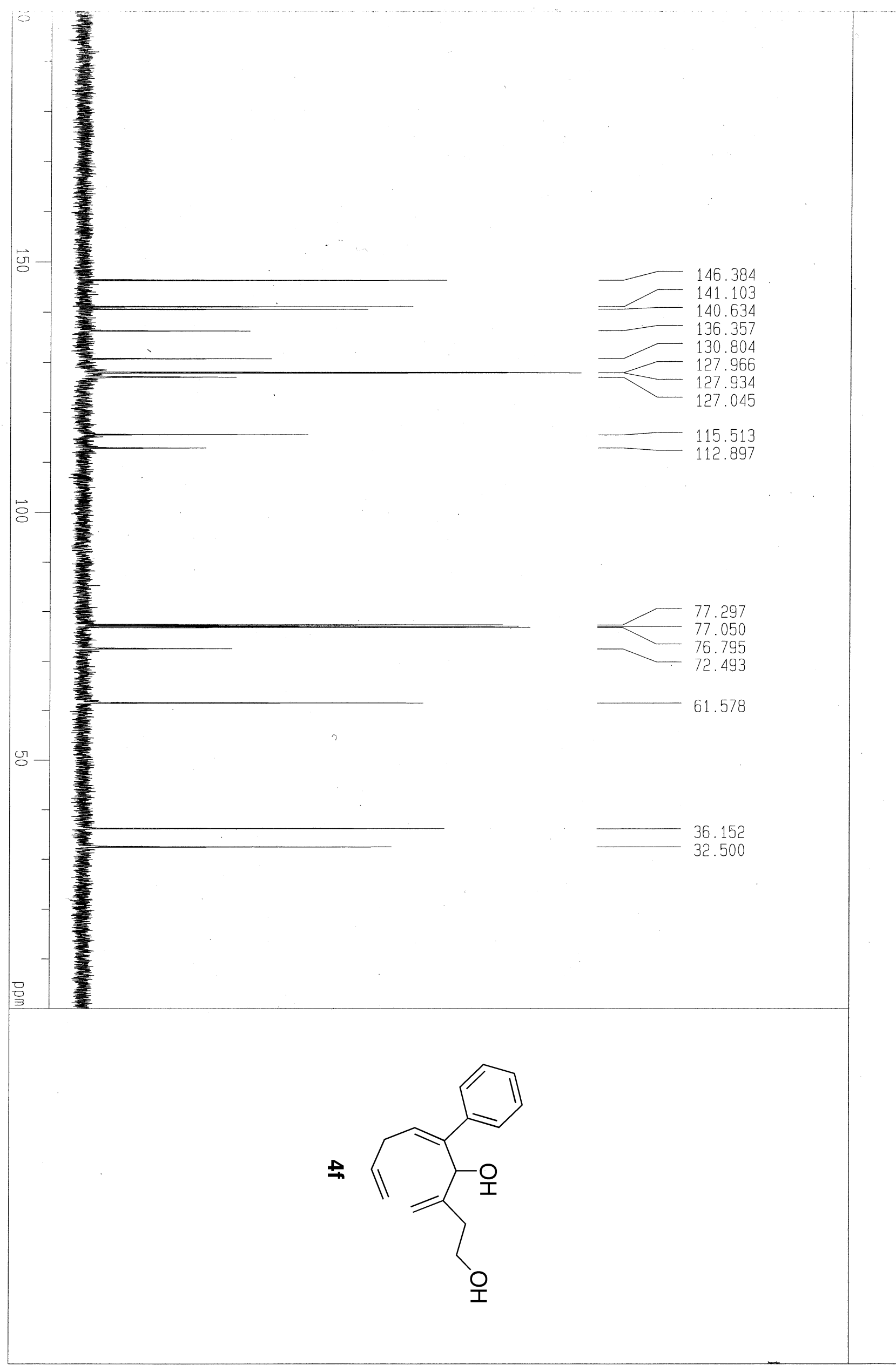




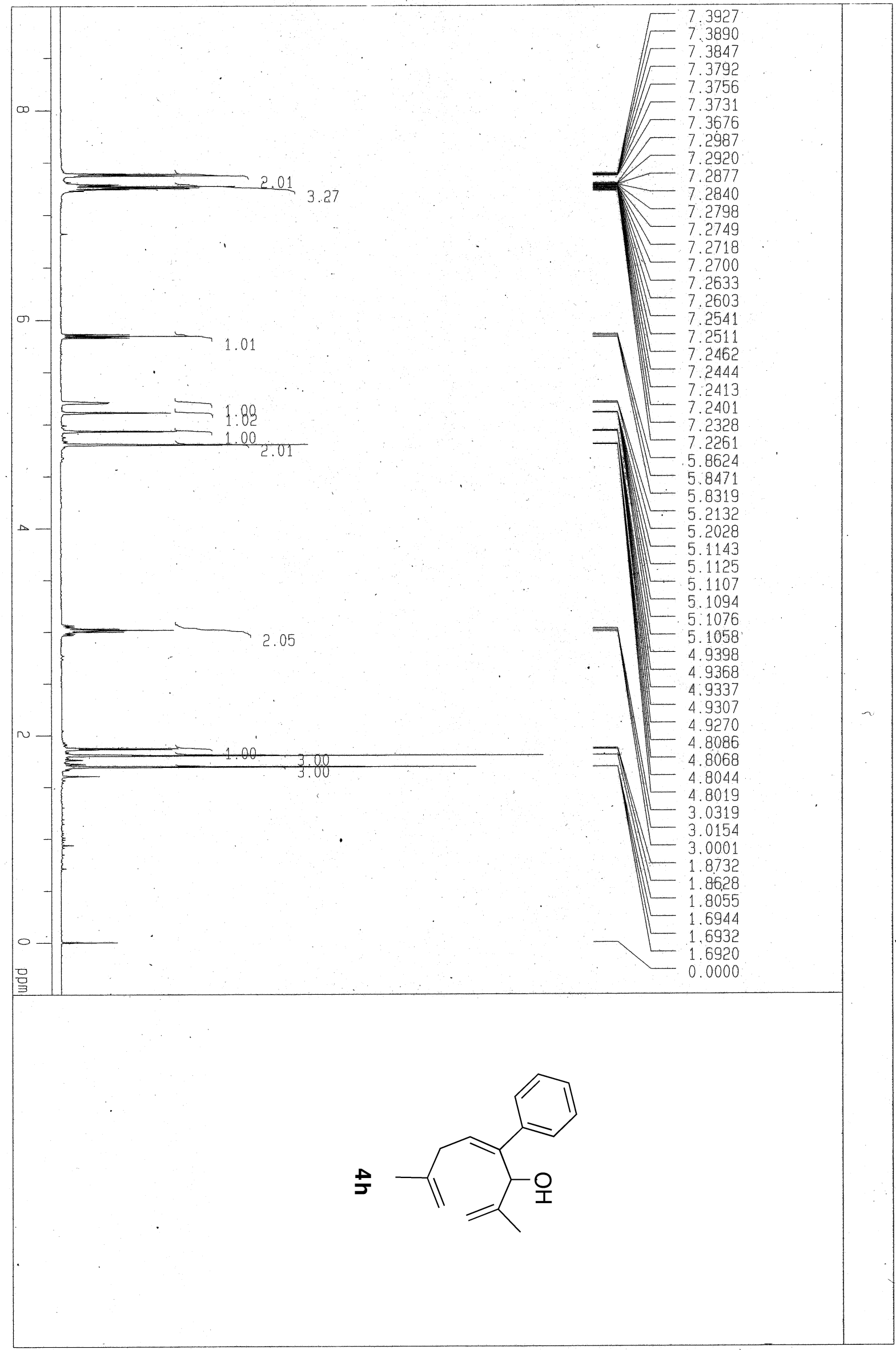




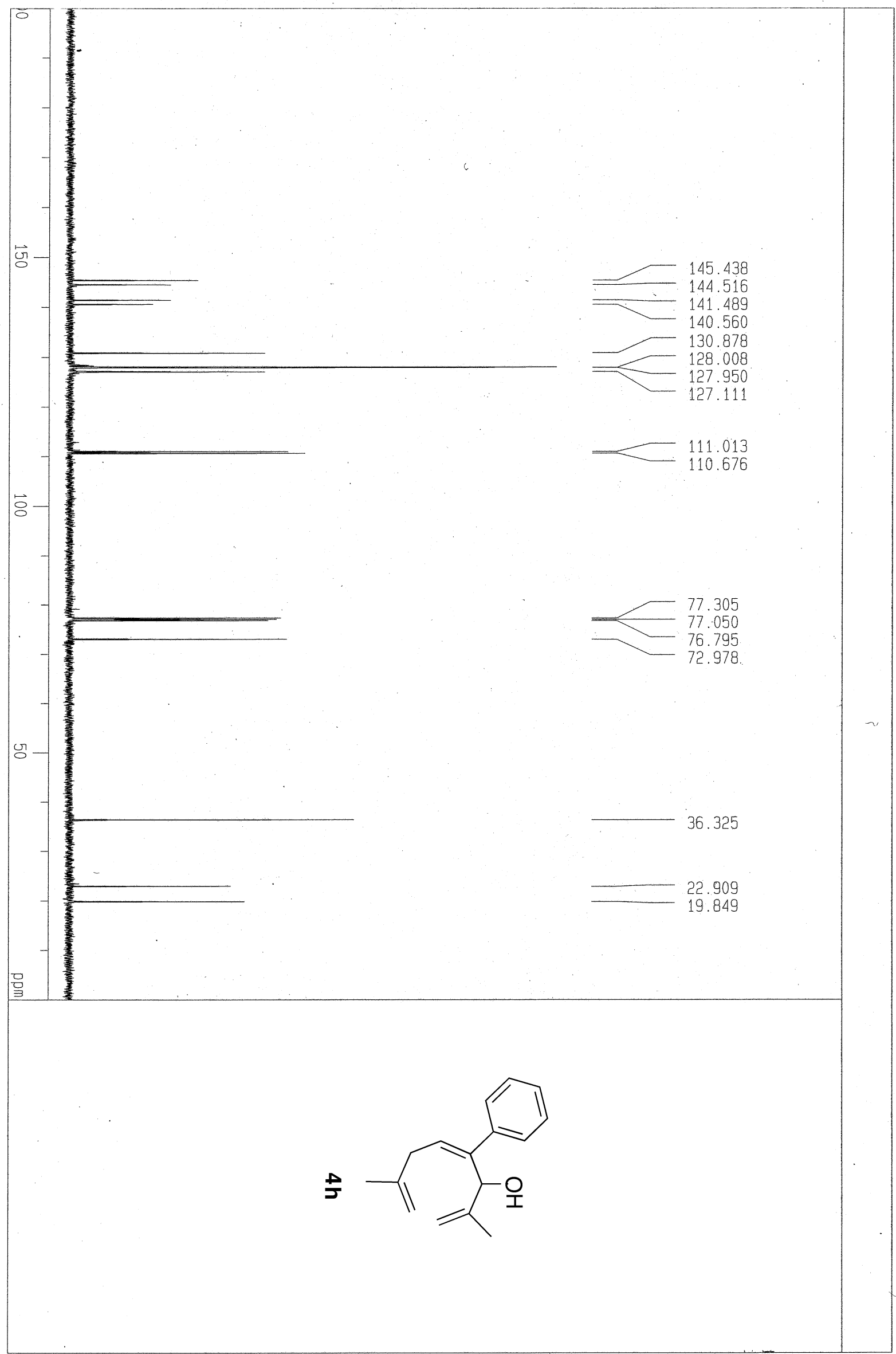




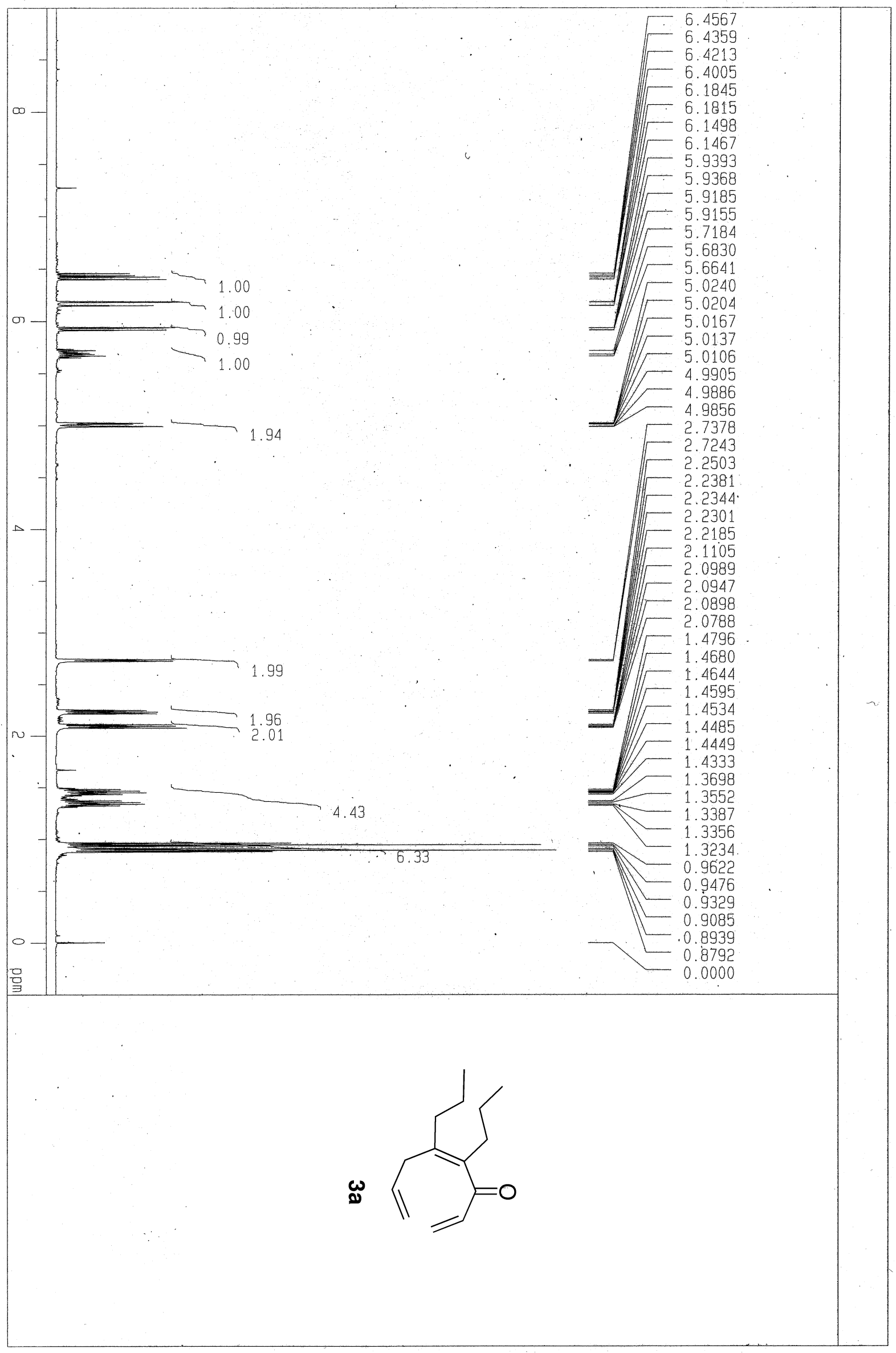

S24 


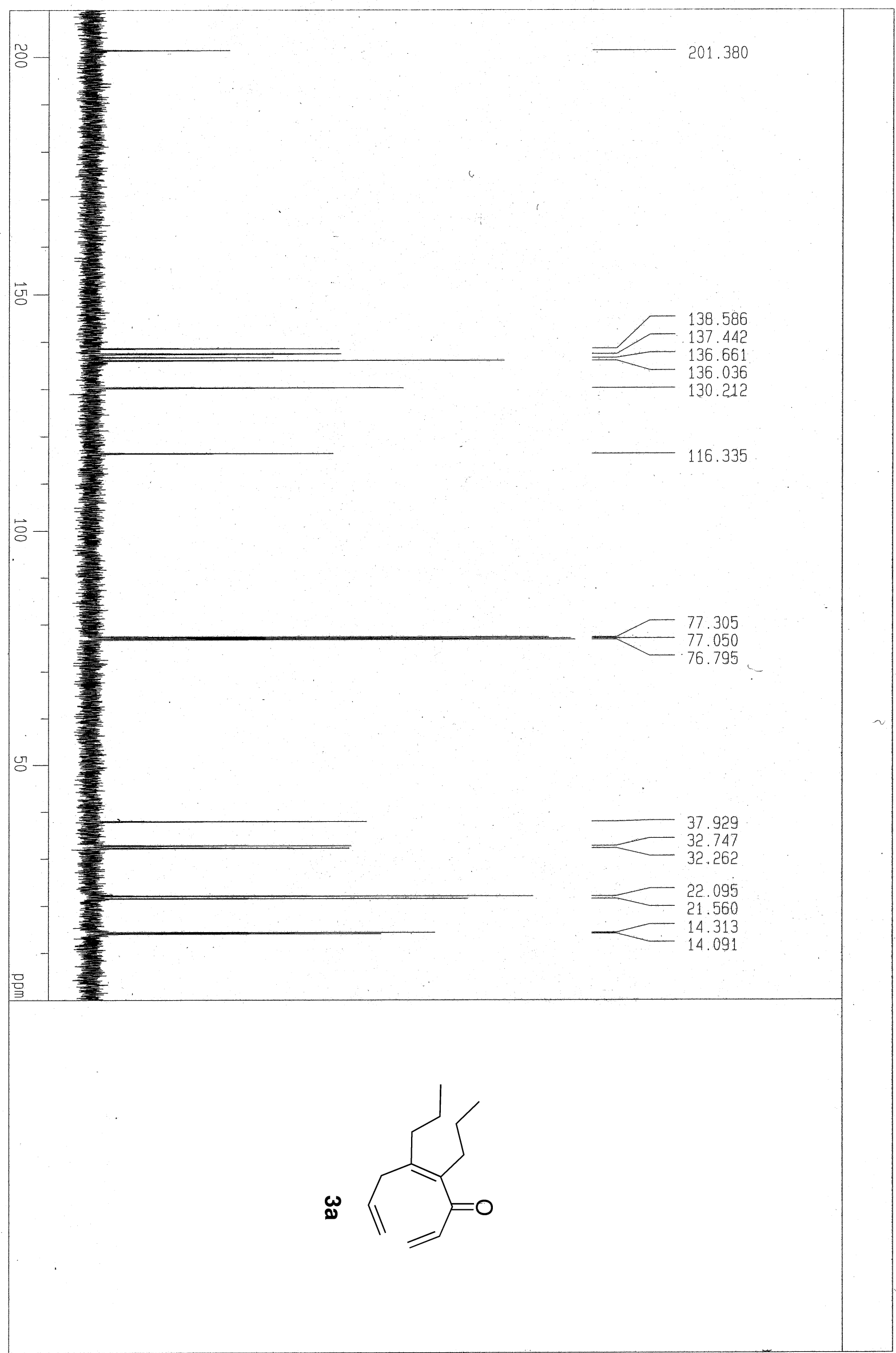




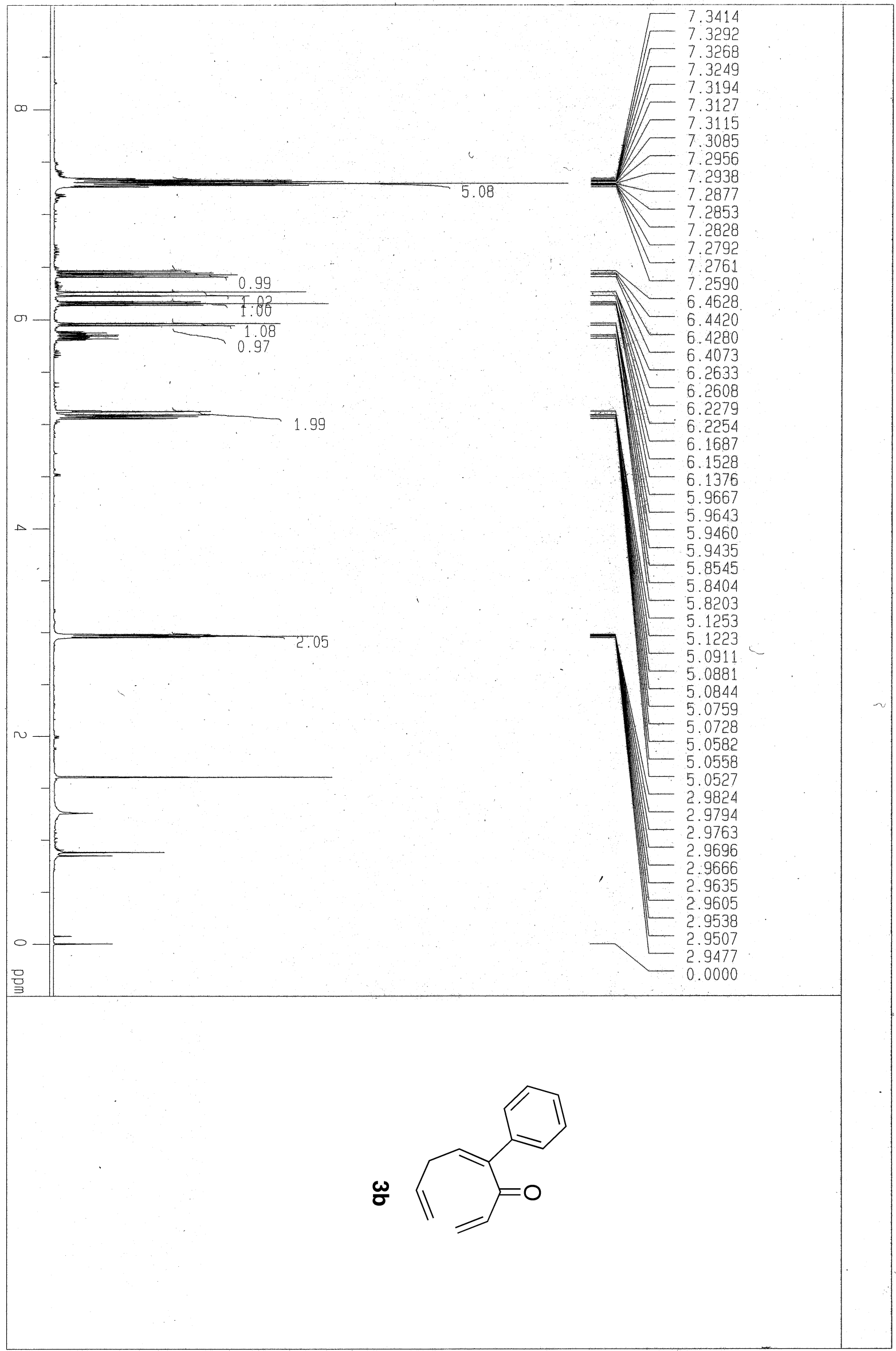




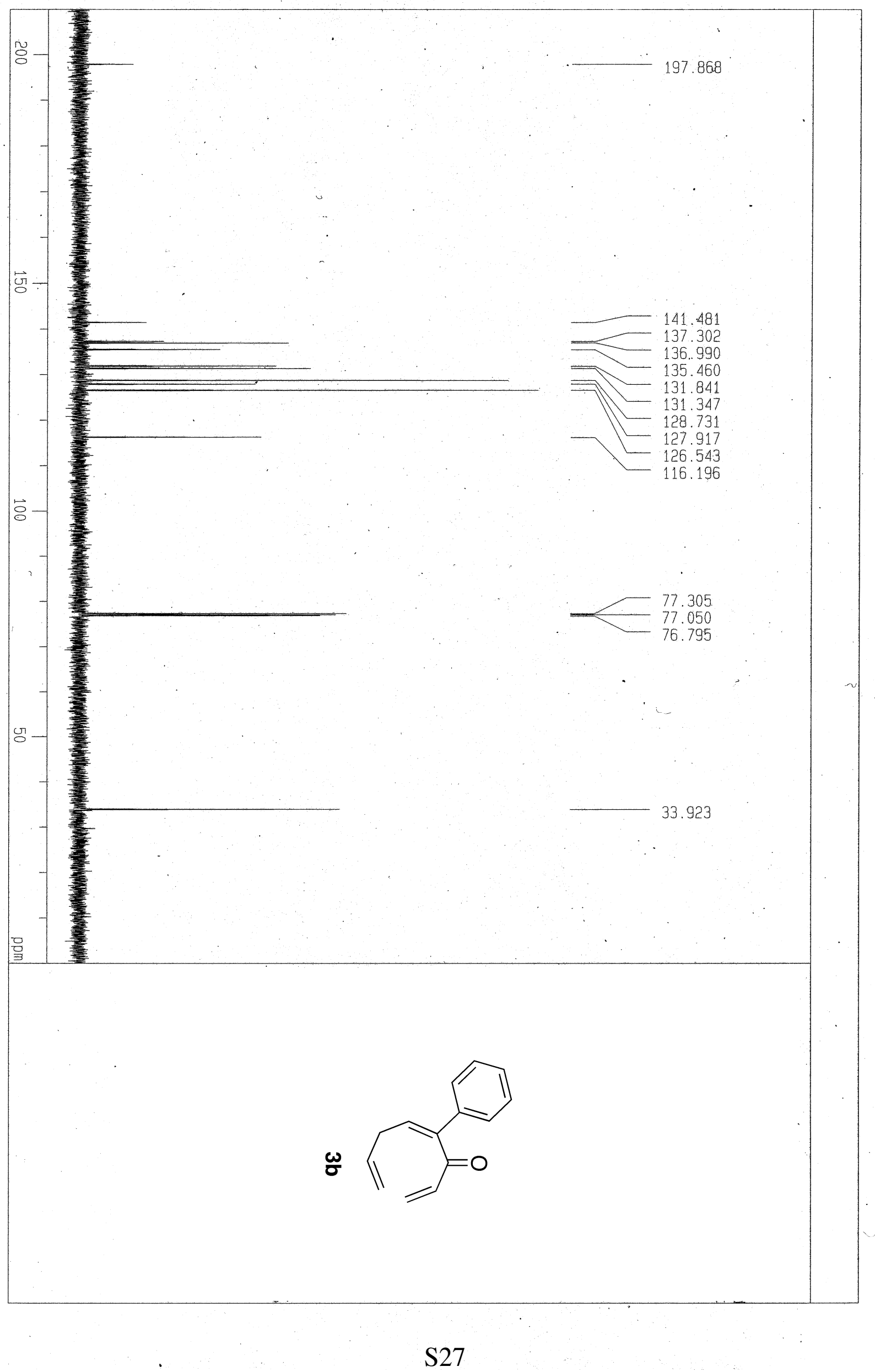




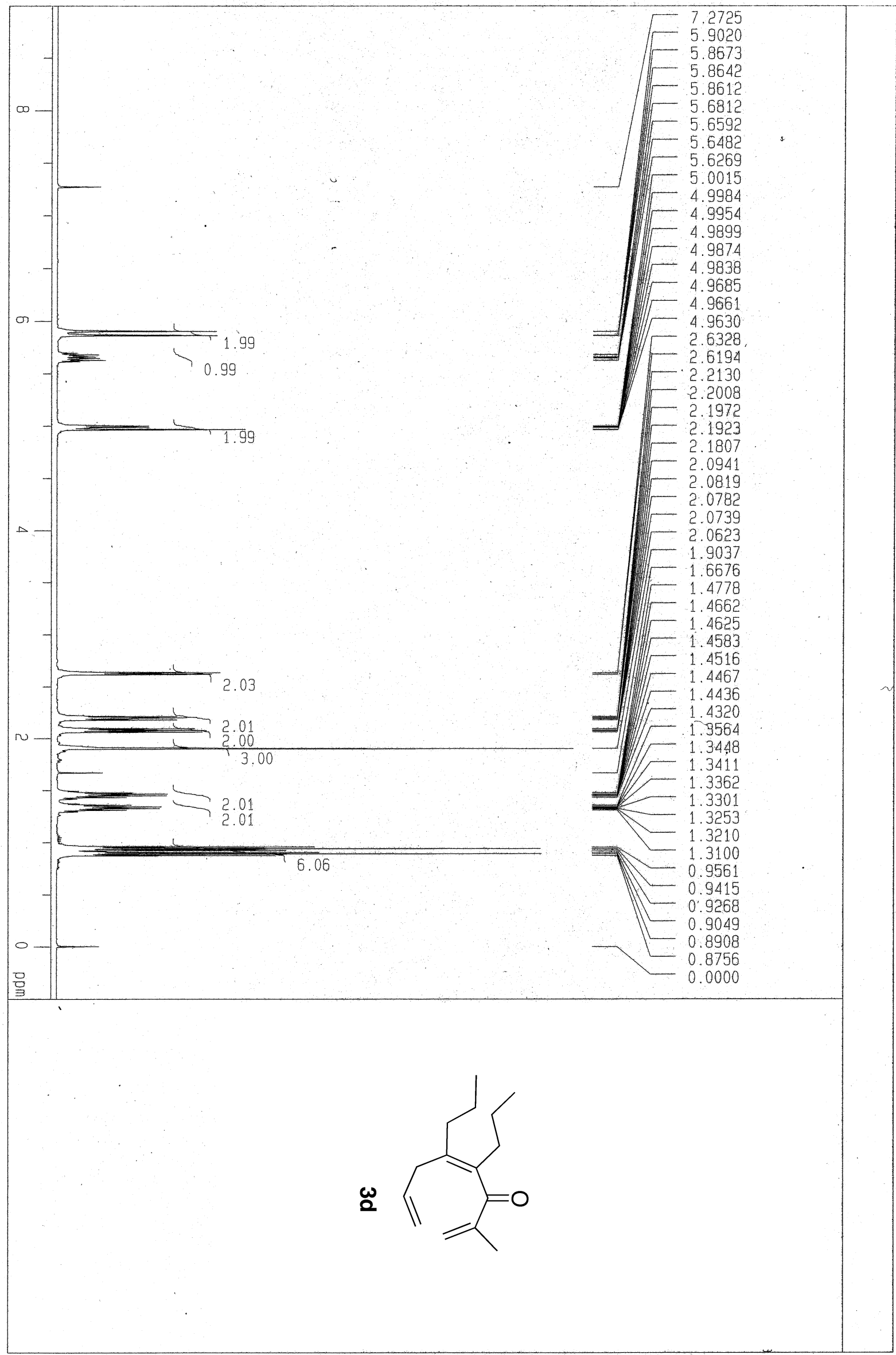




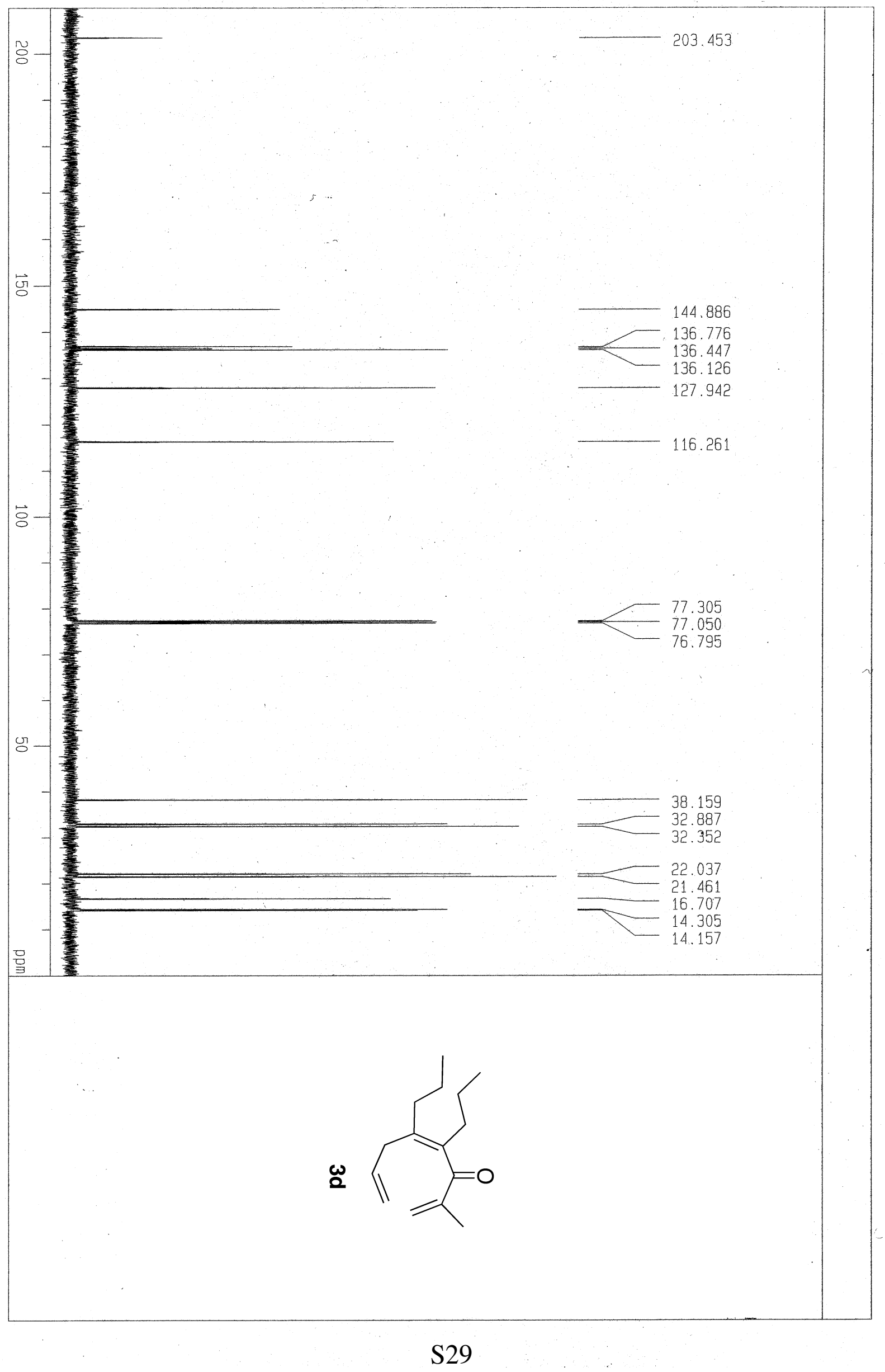




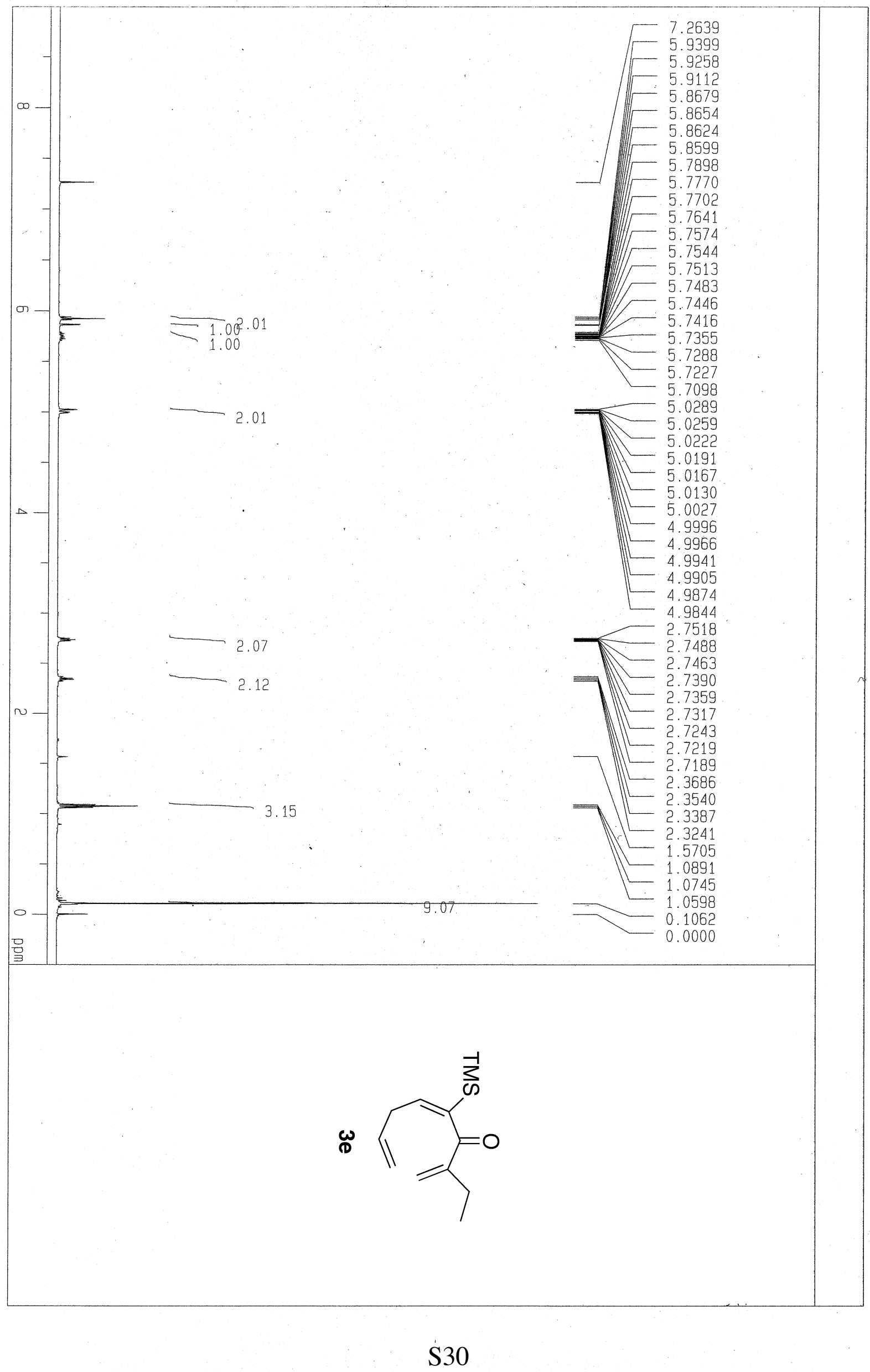




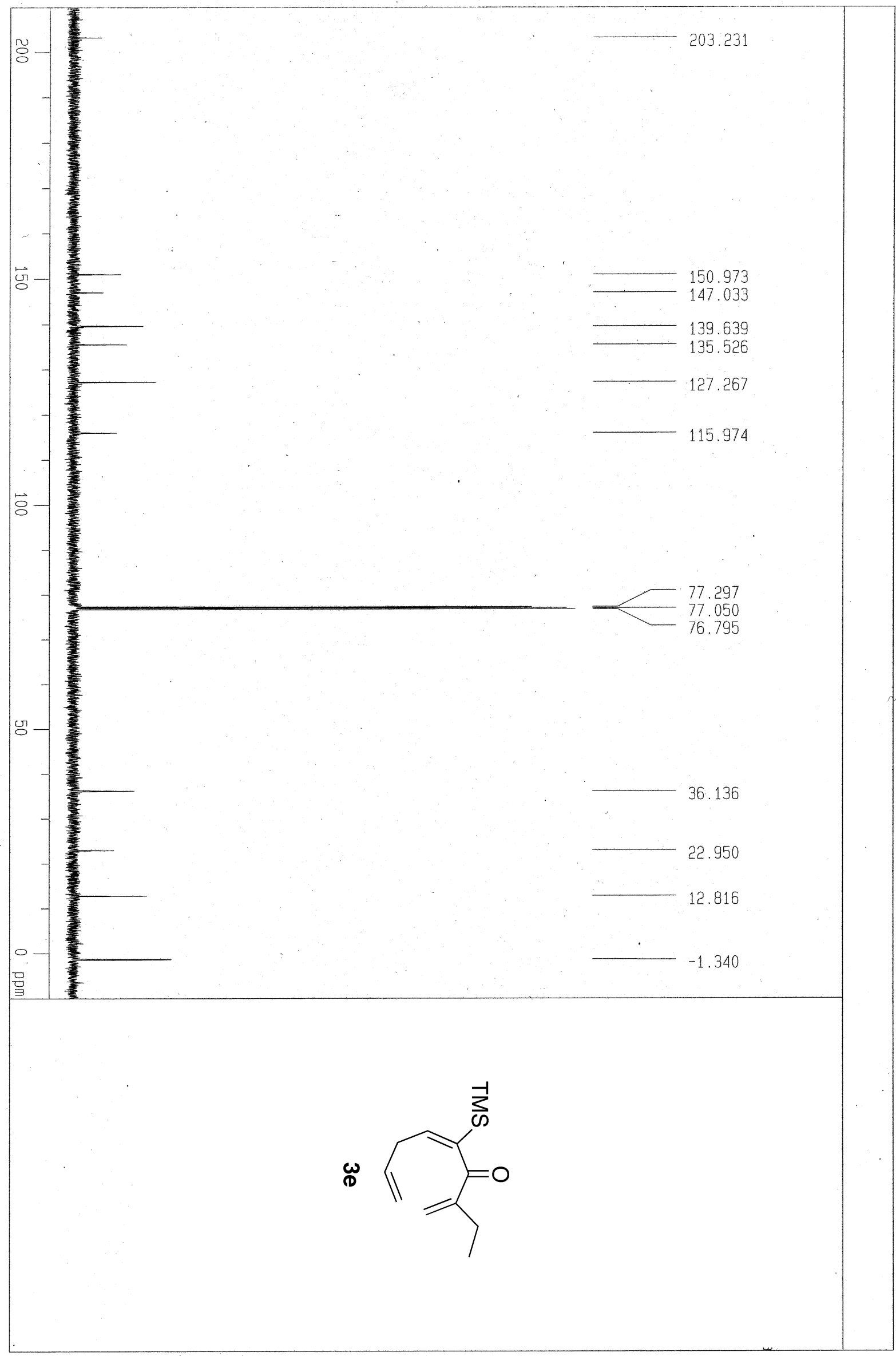




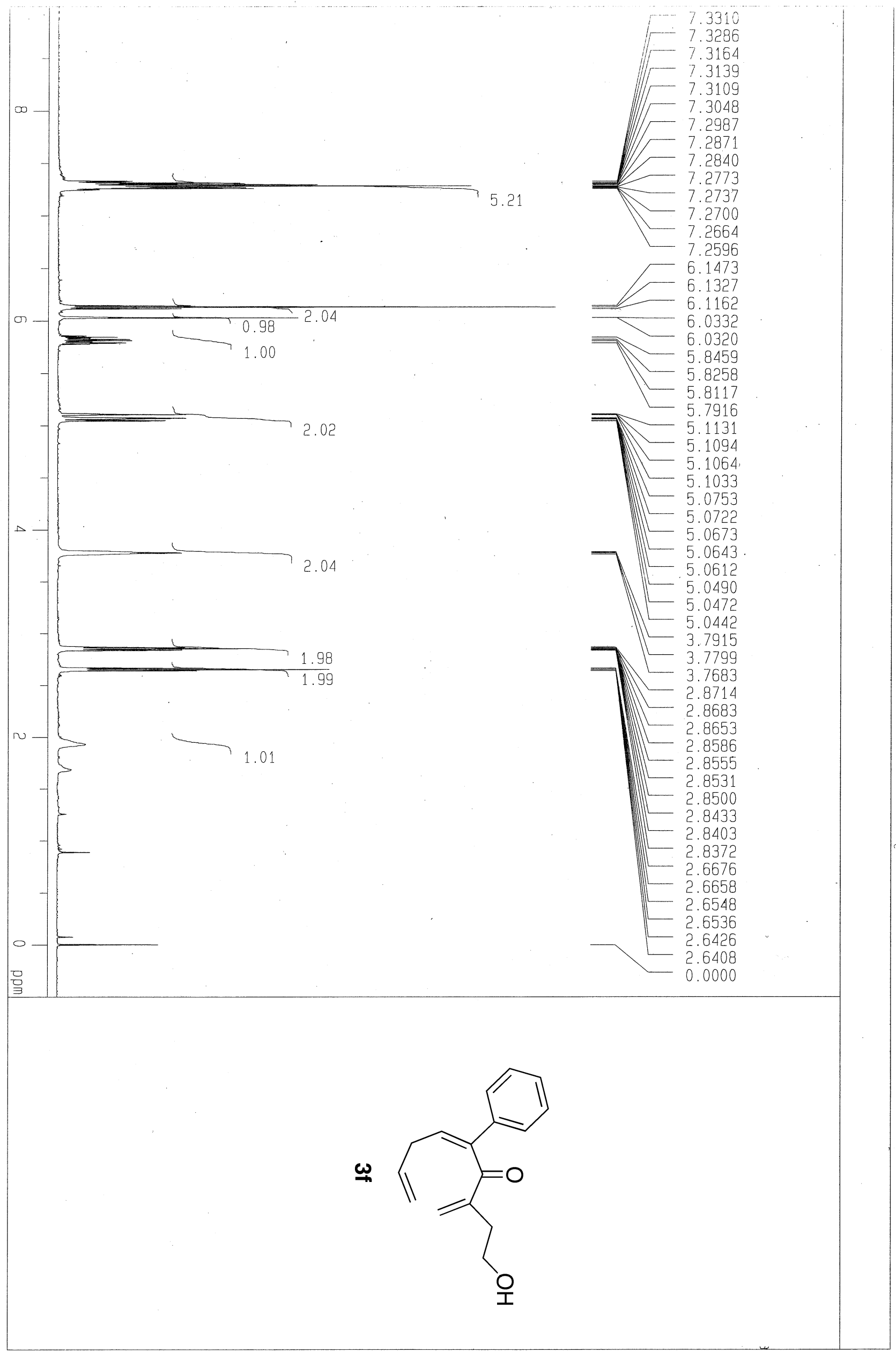




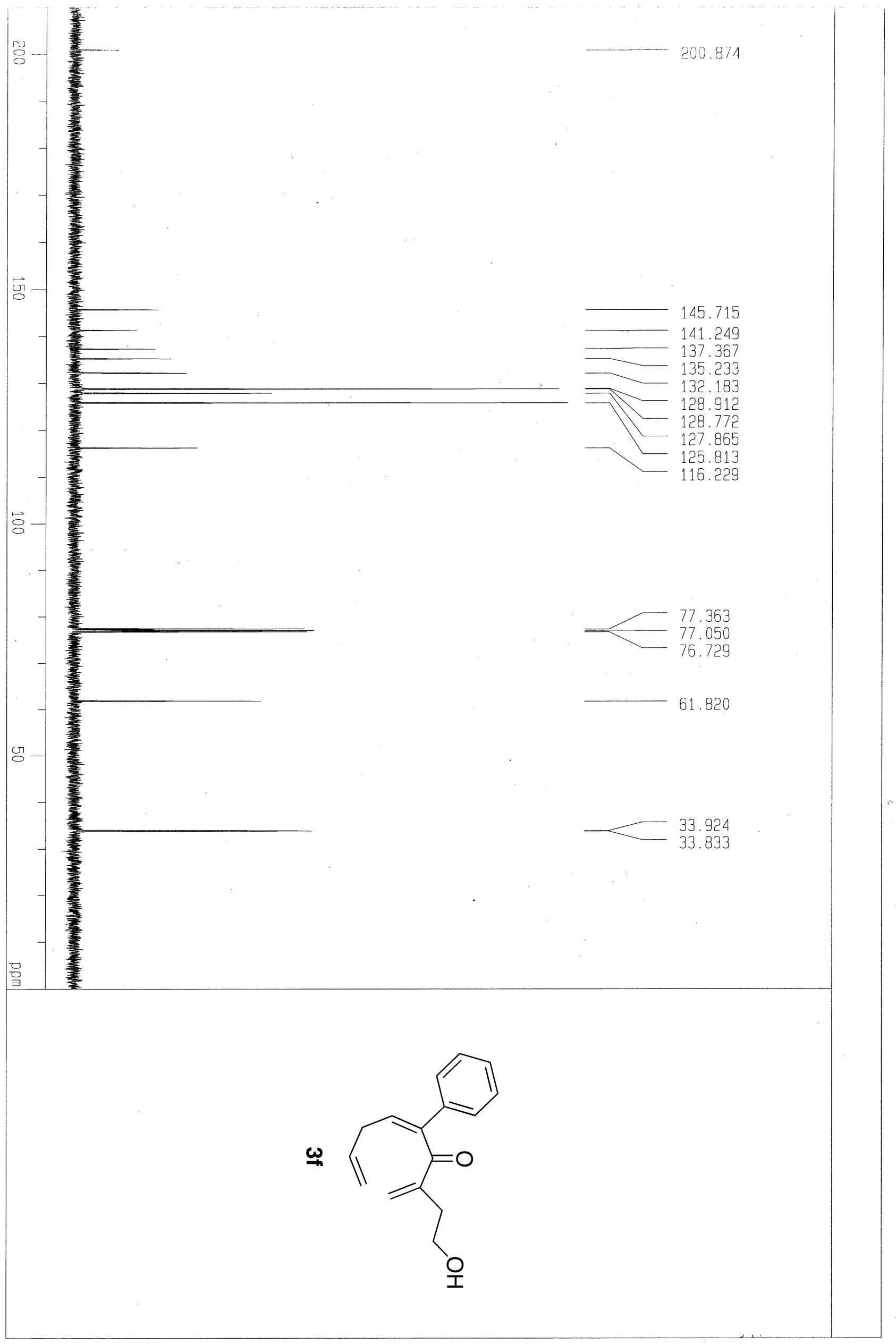

S33 


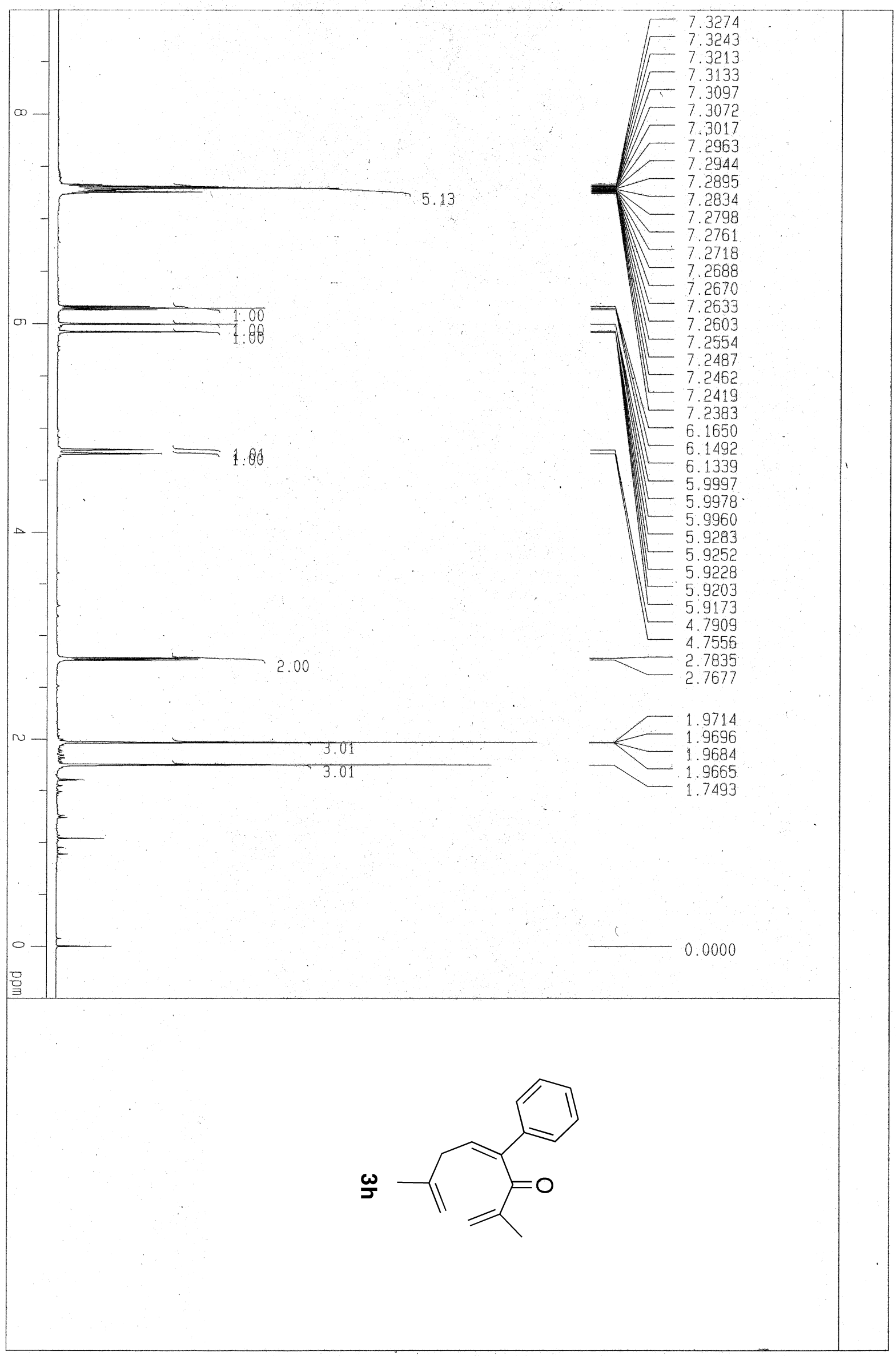




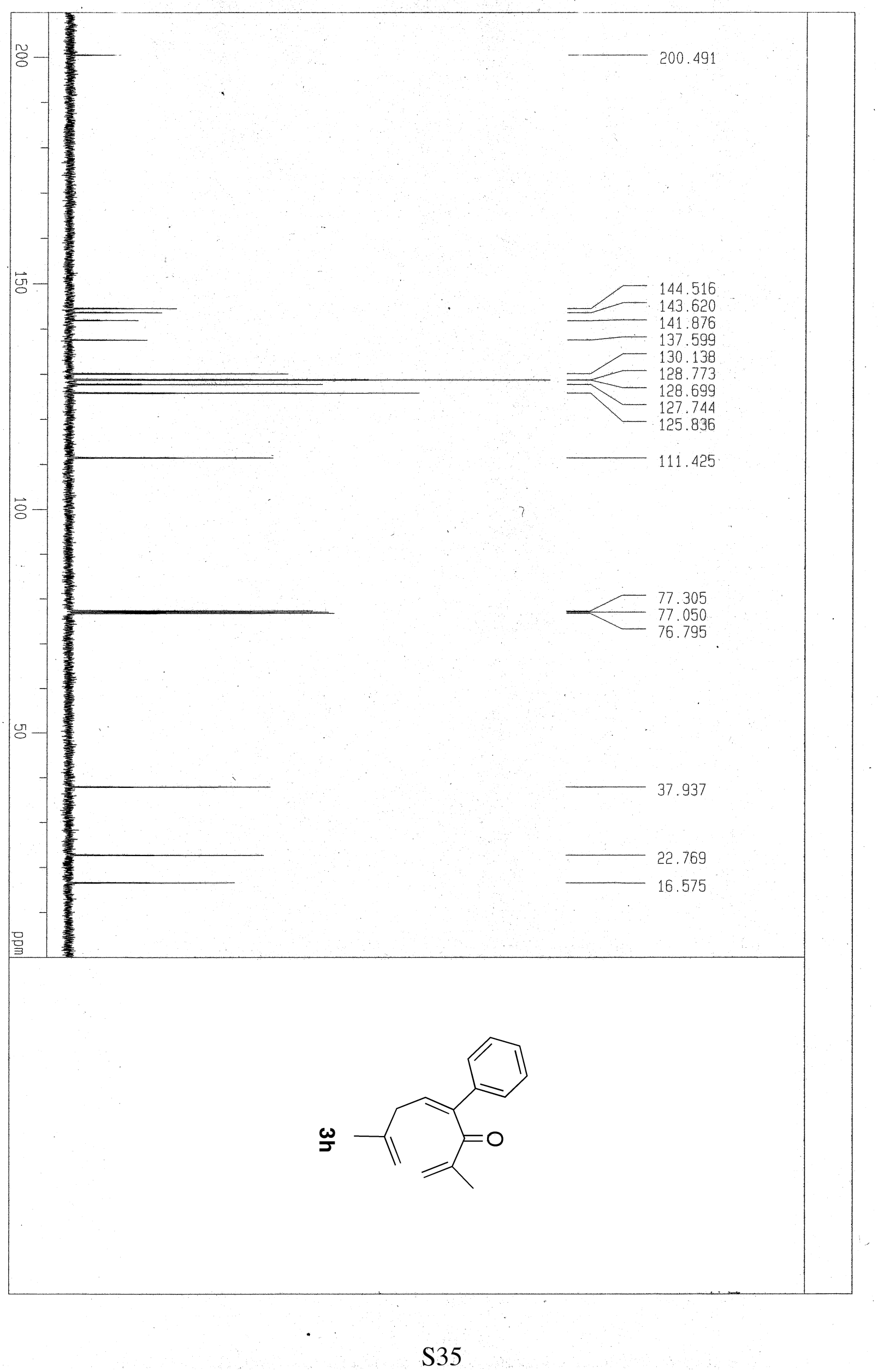




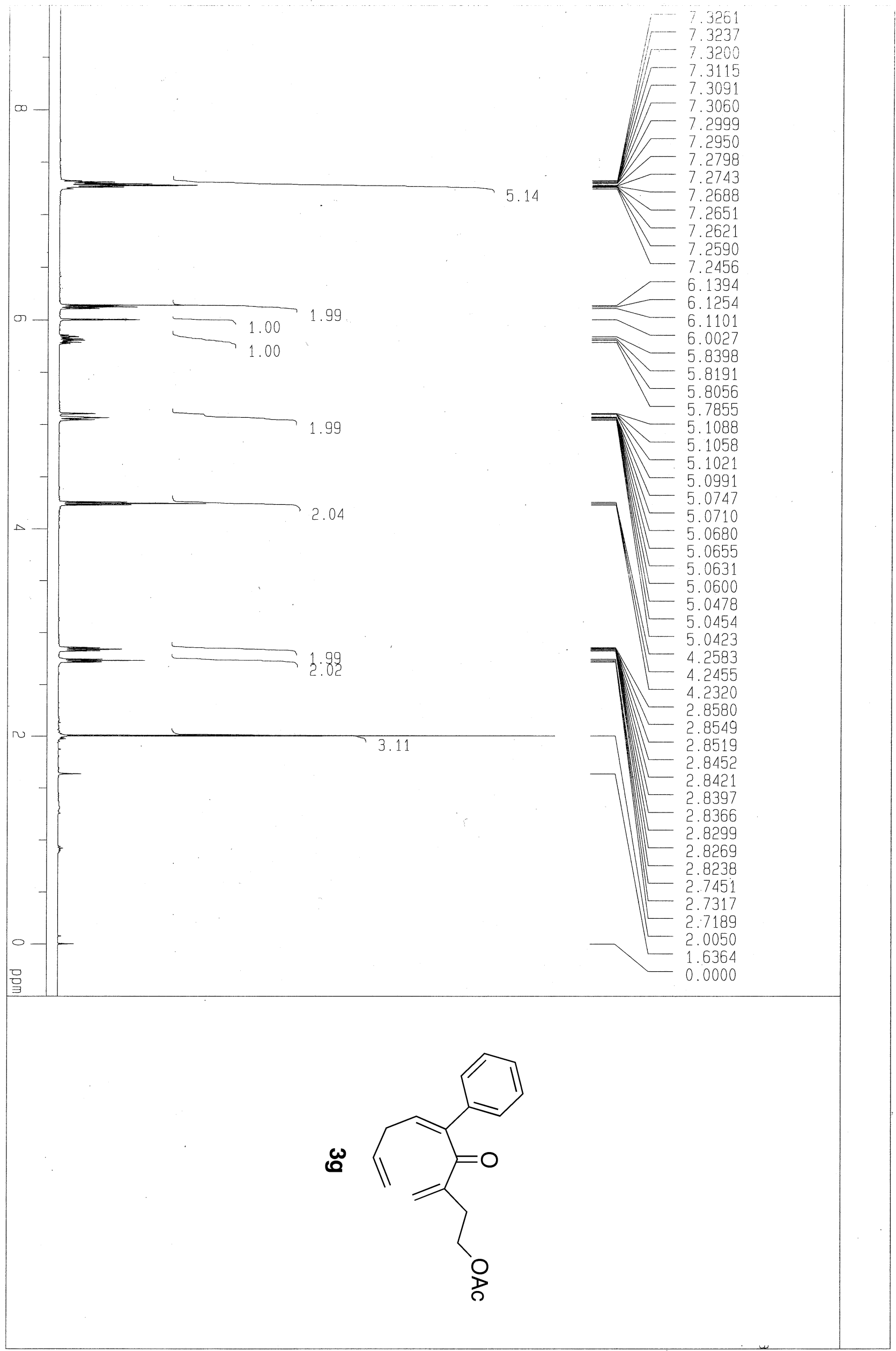




$$
\text { F }
$$




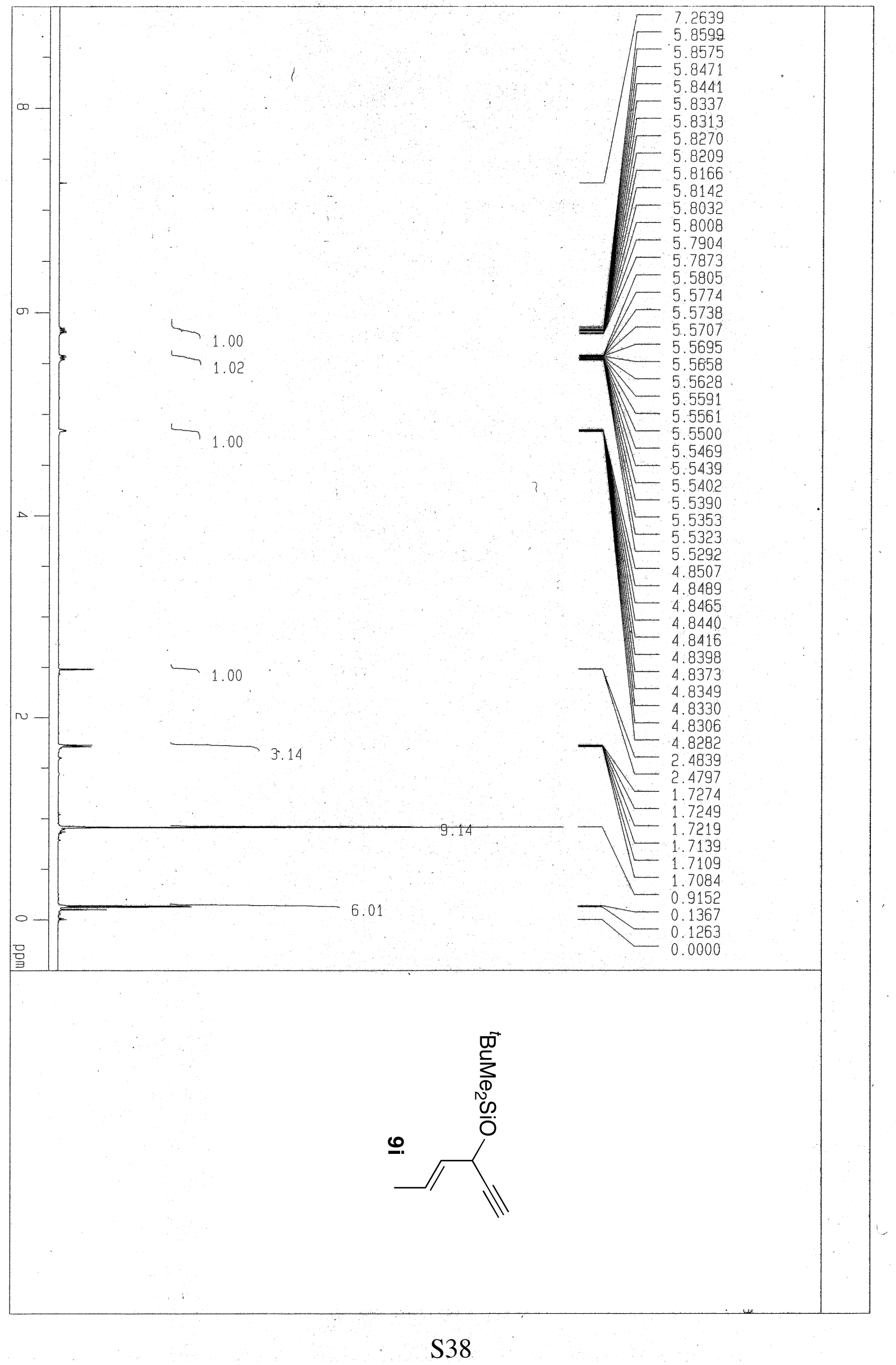




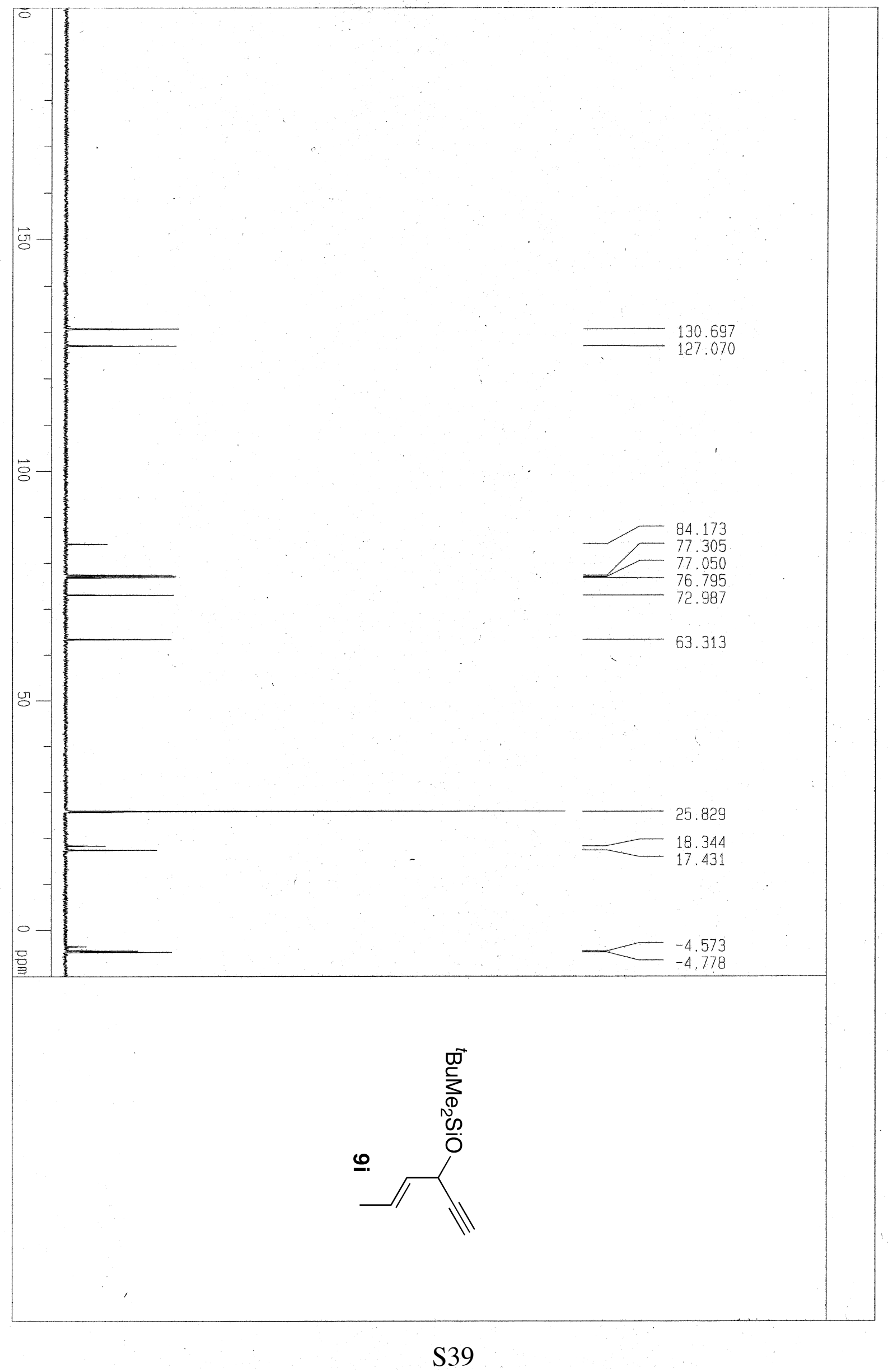









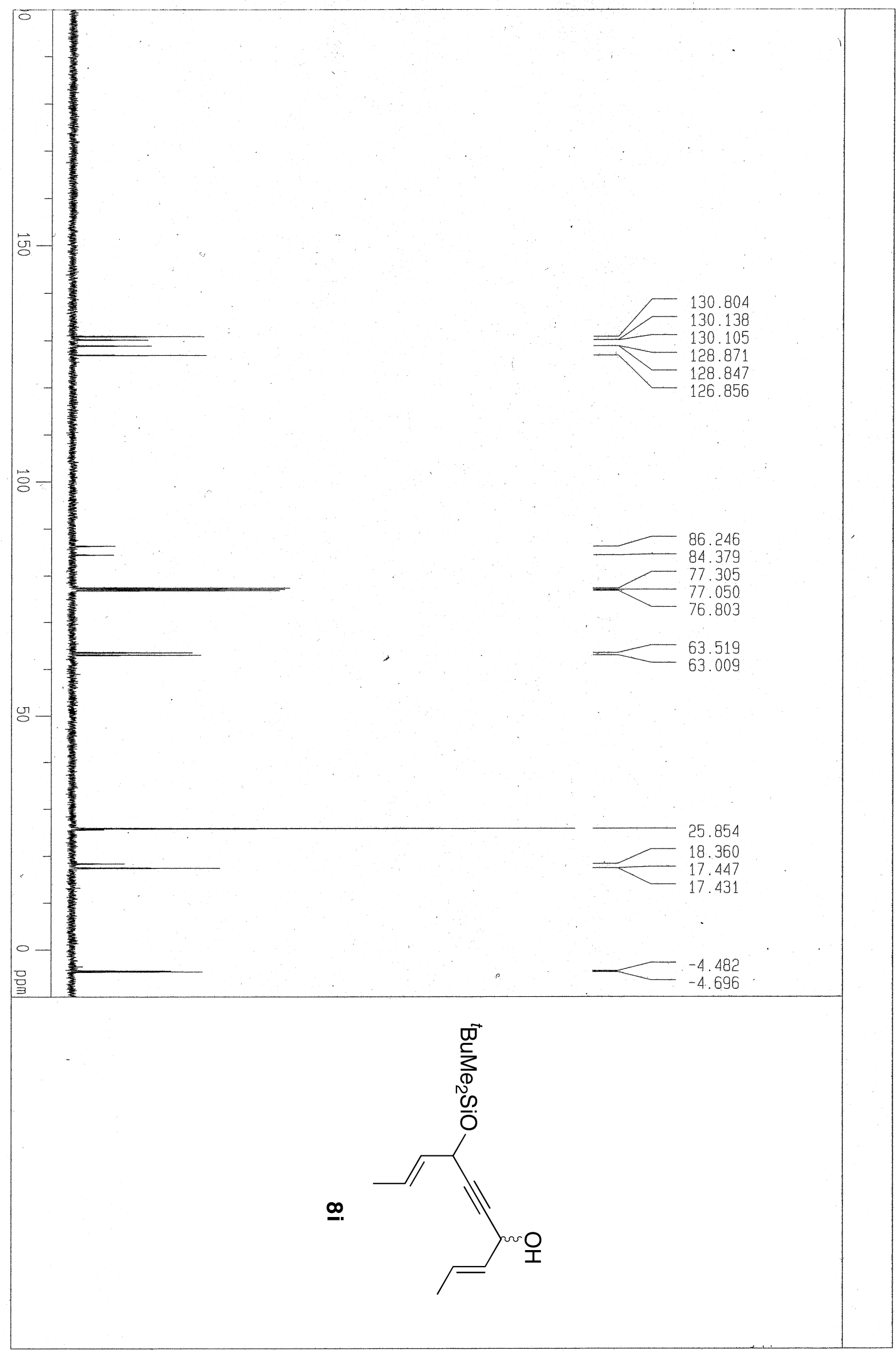




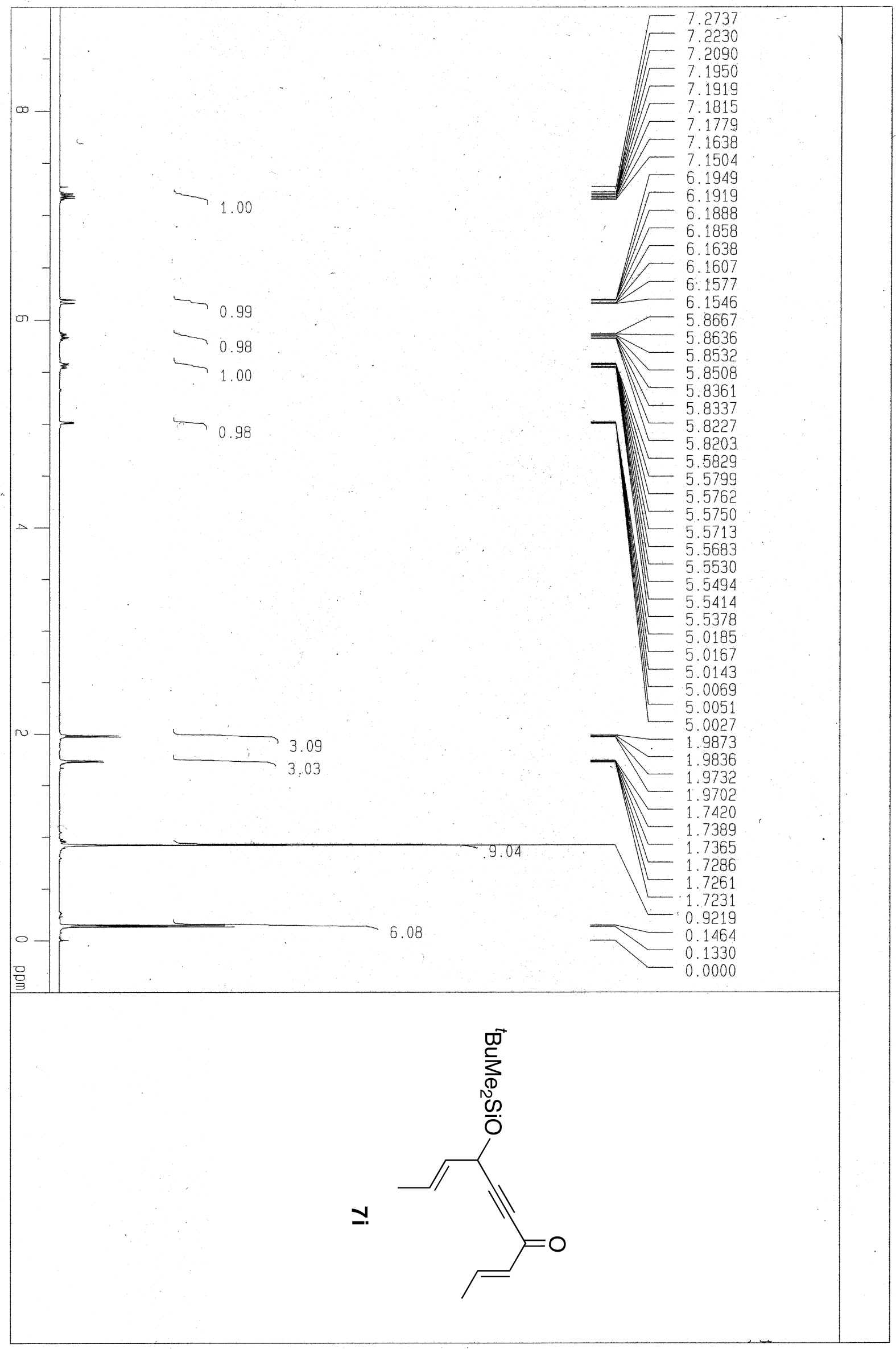




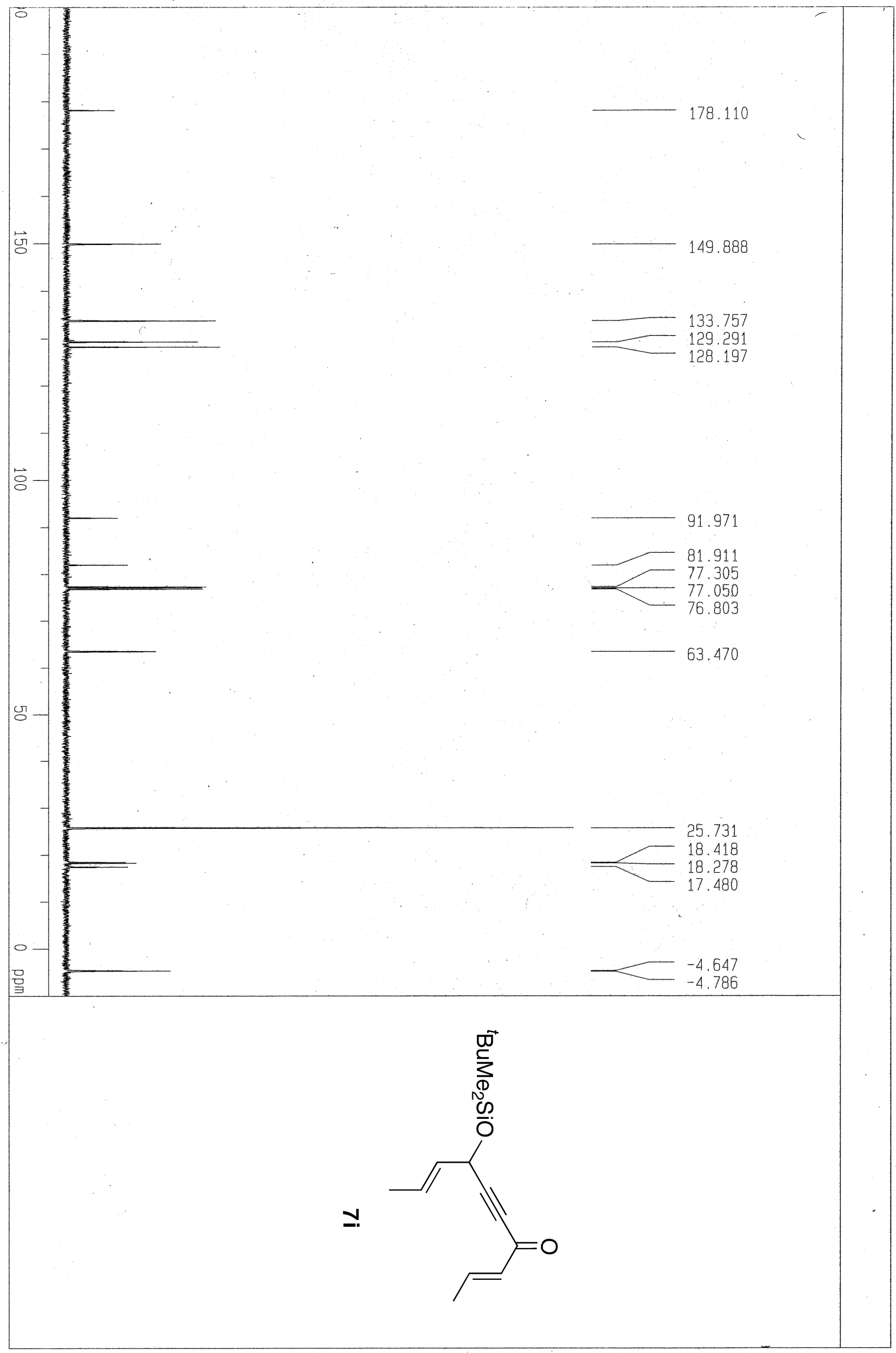

S43 


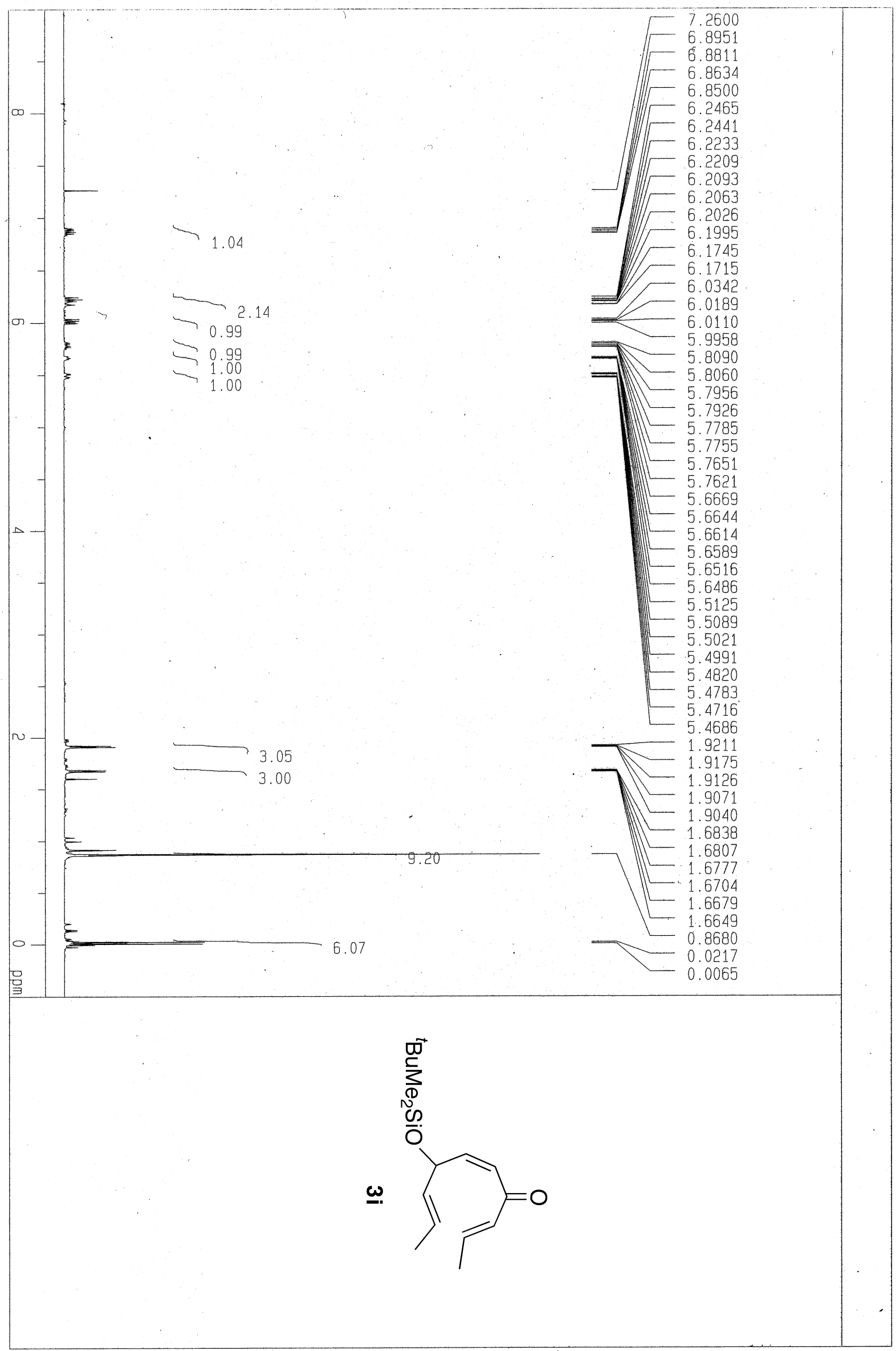




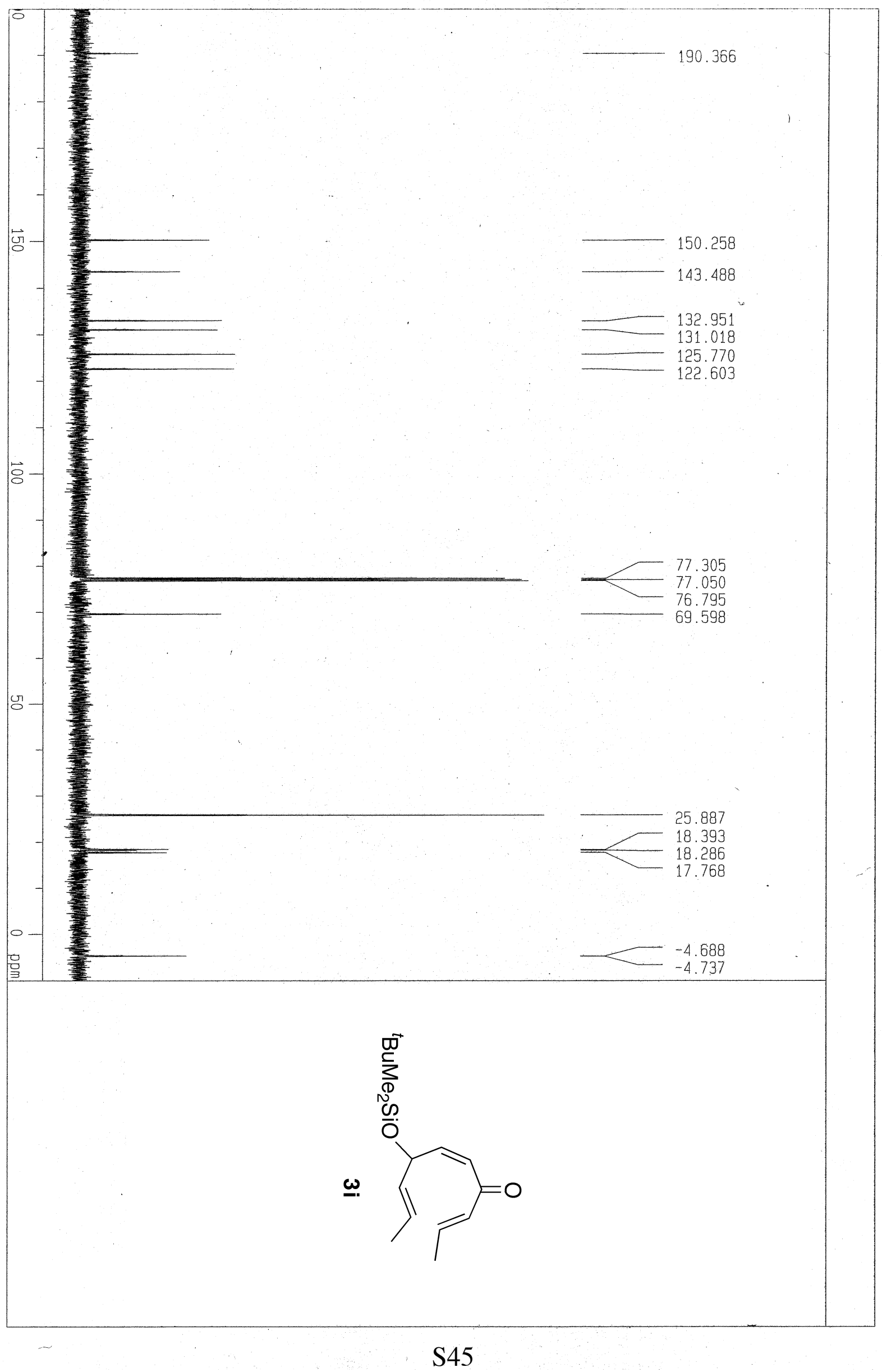




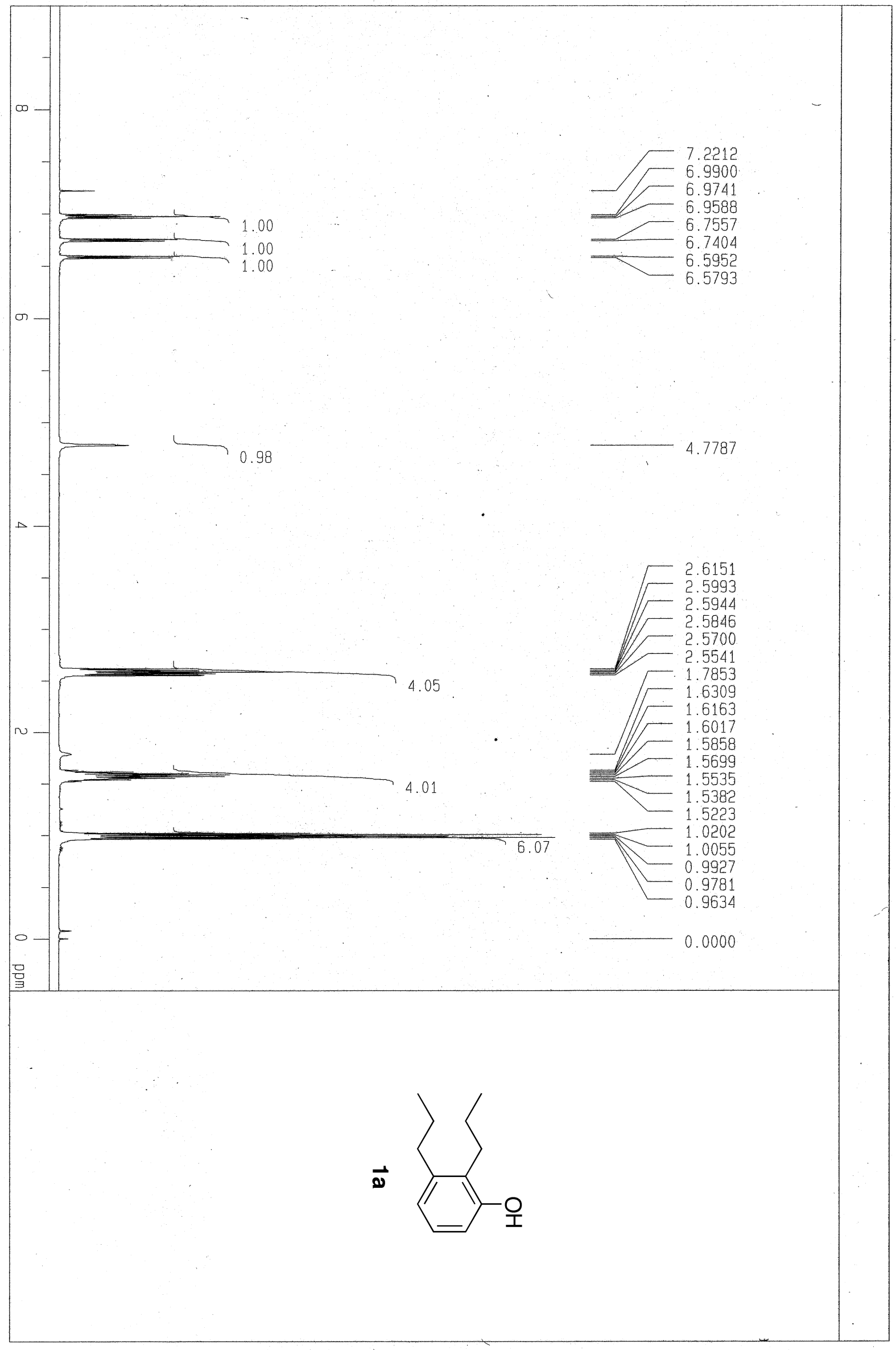




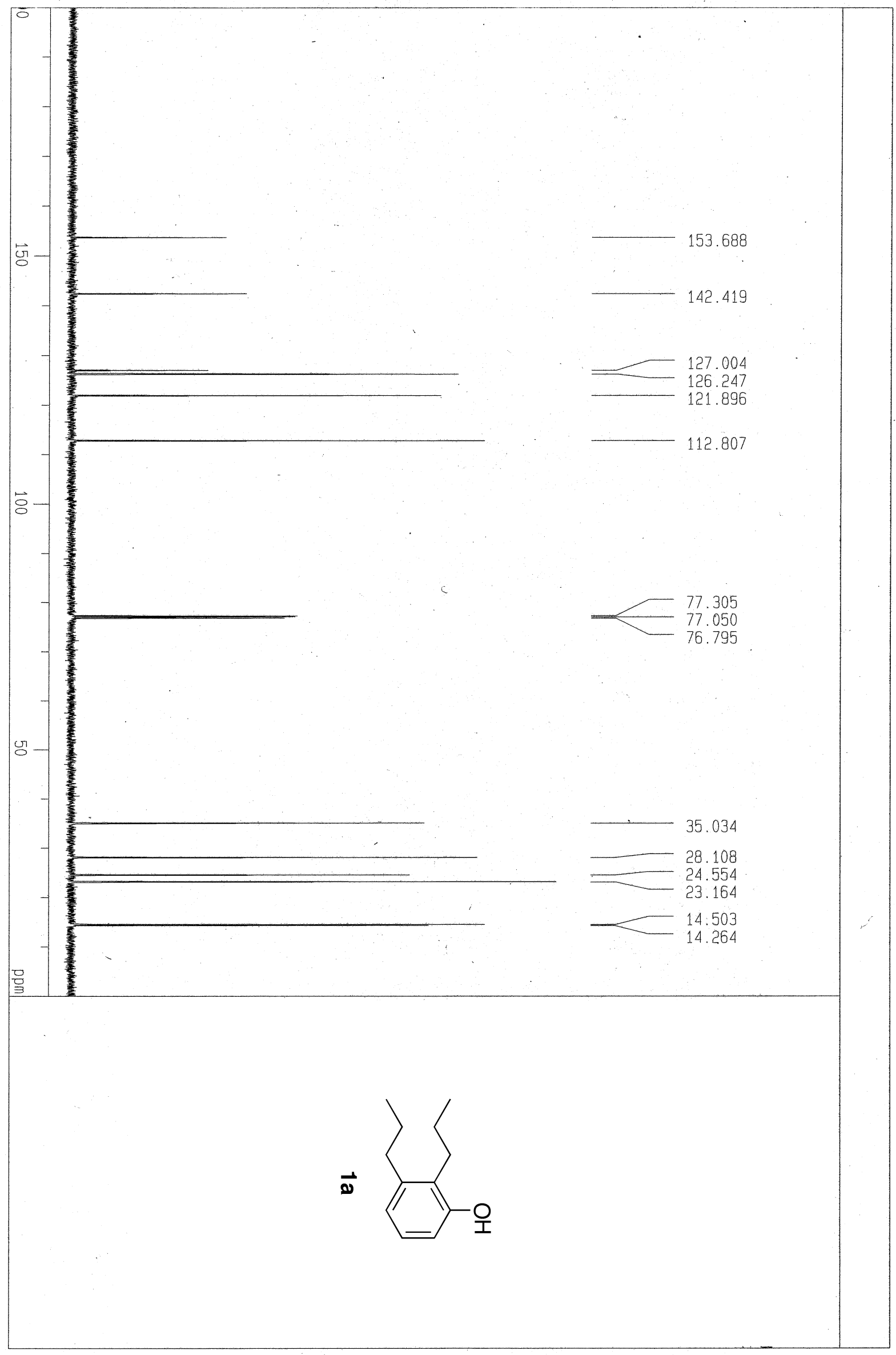




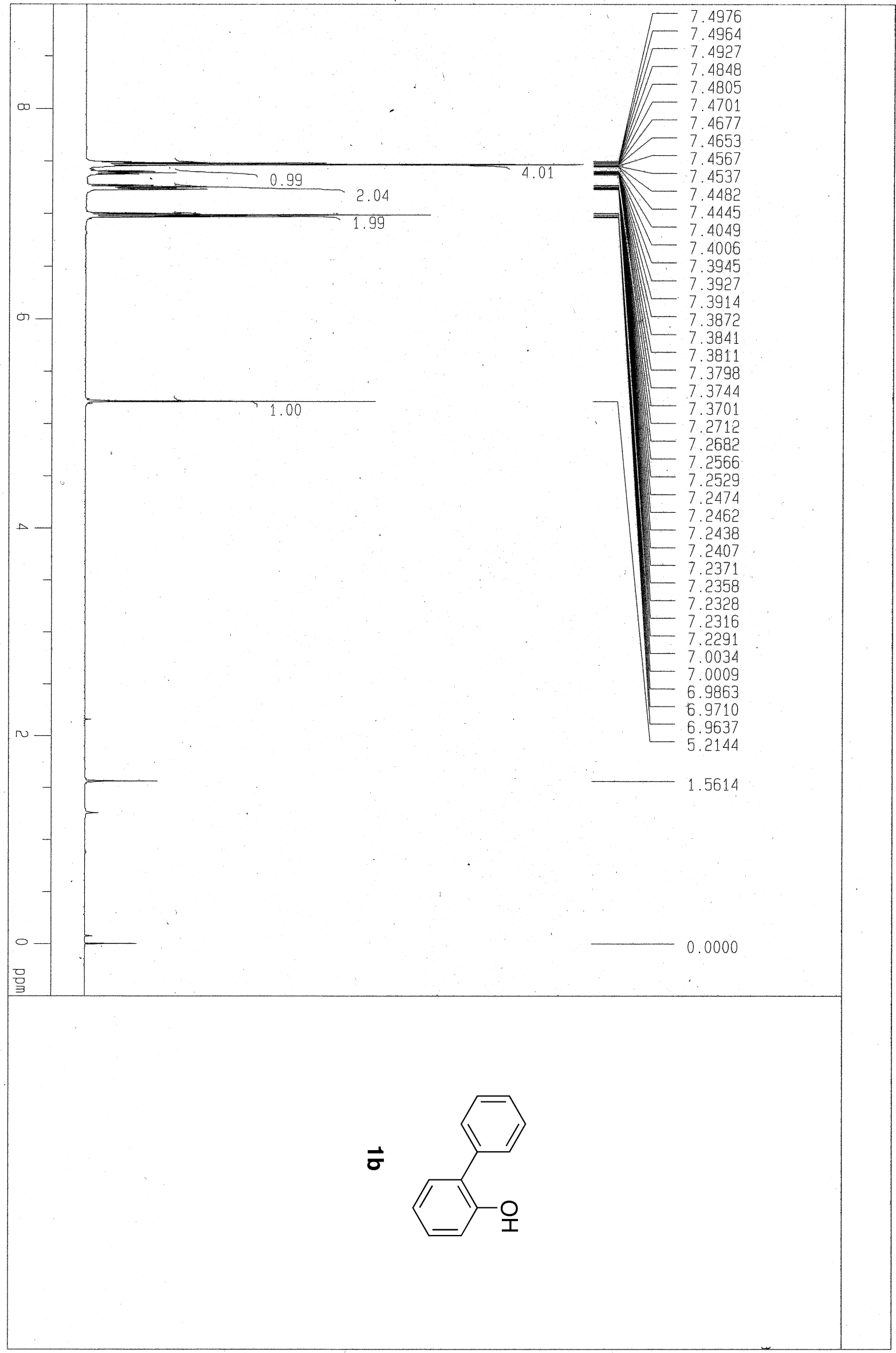




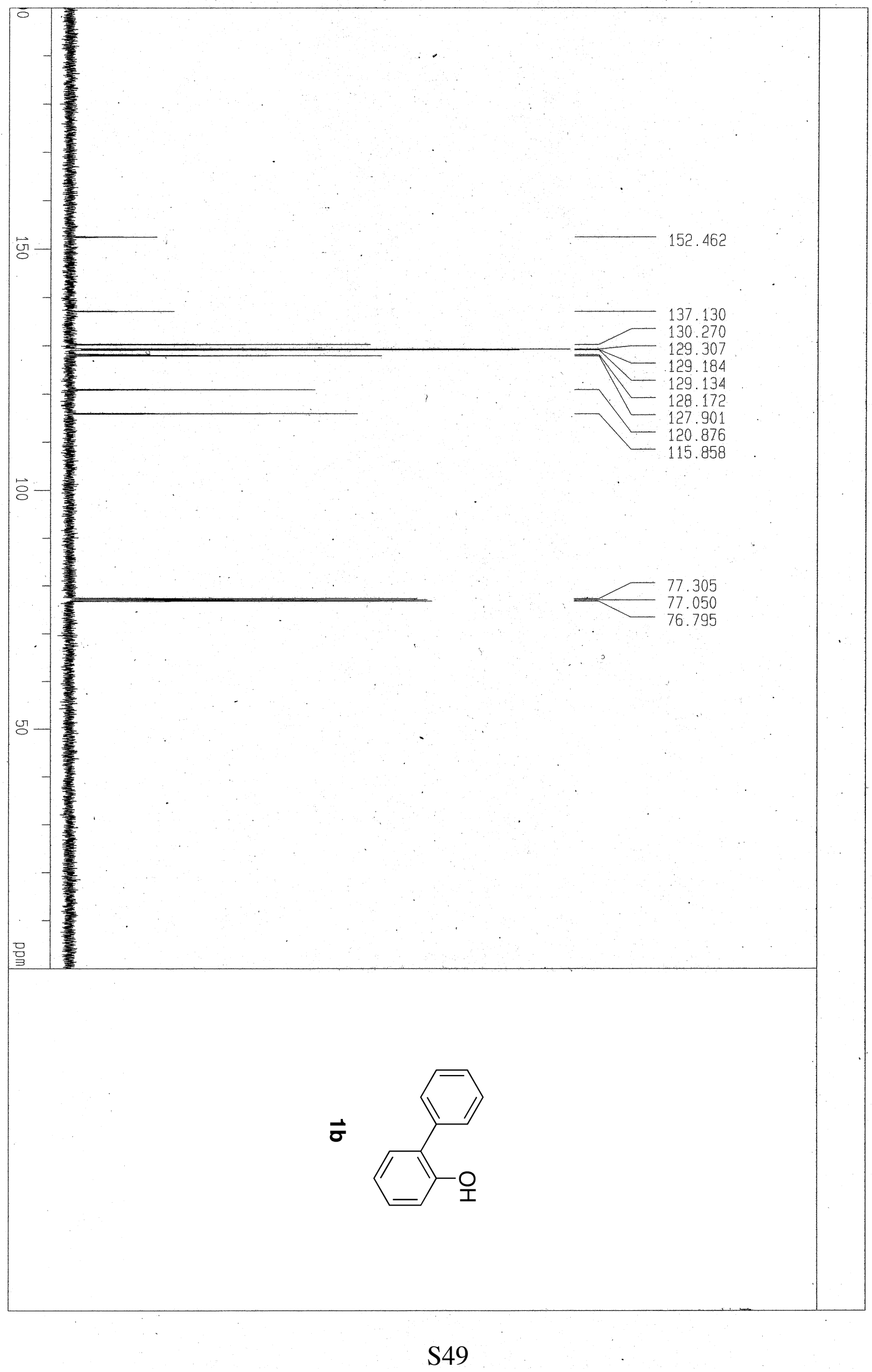




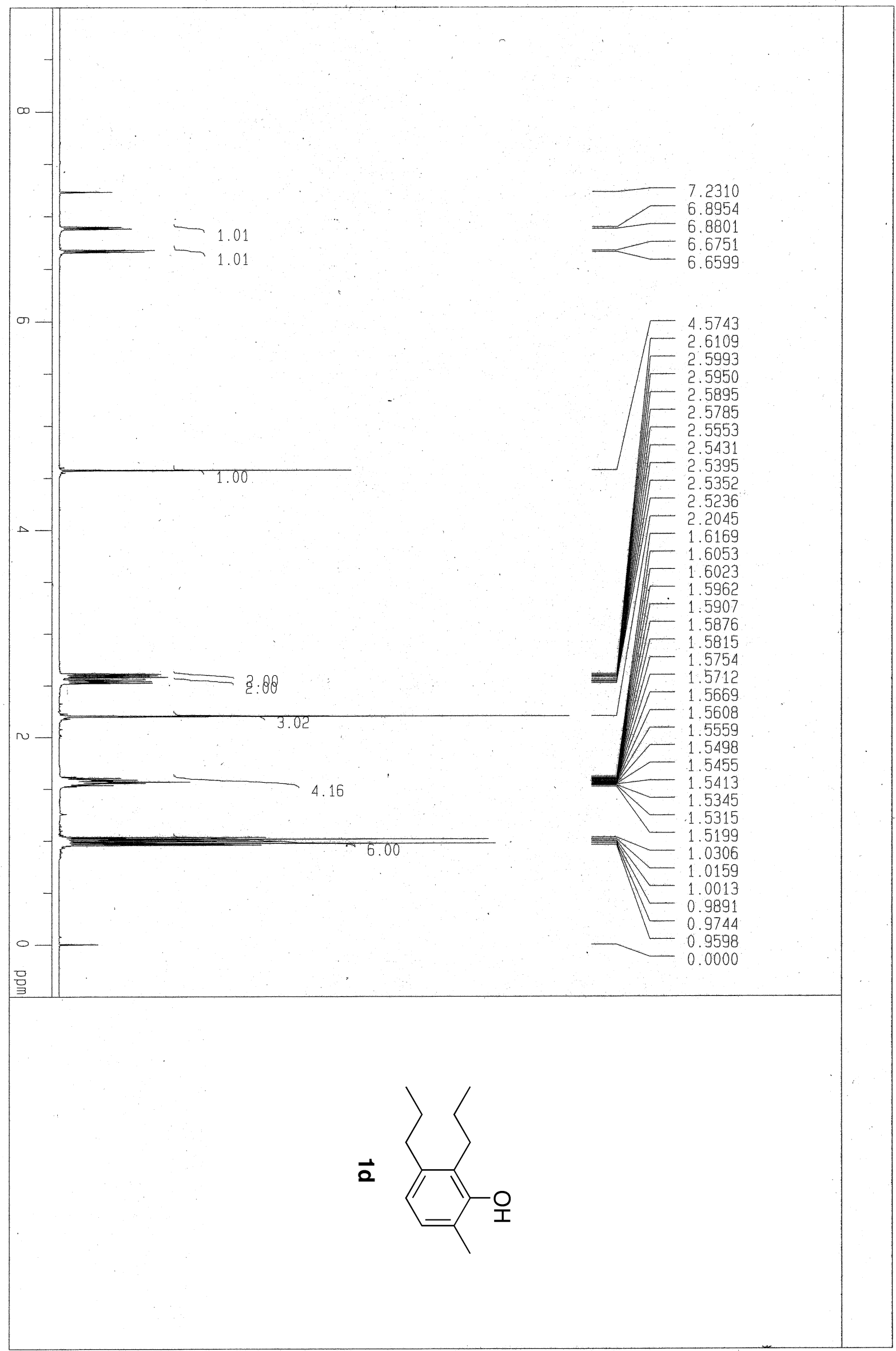




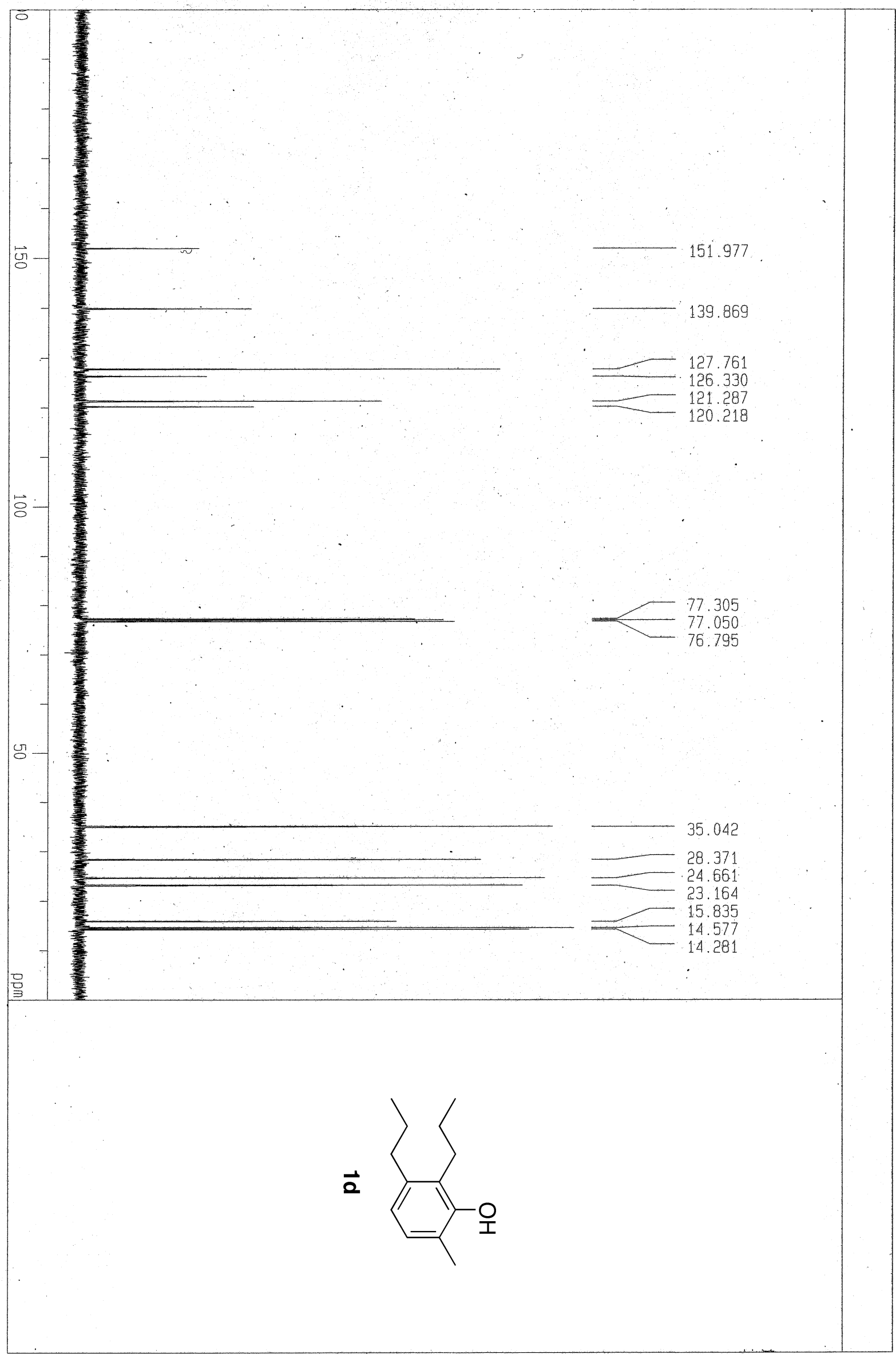




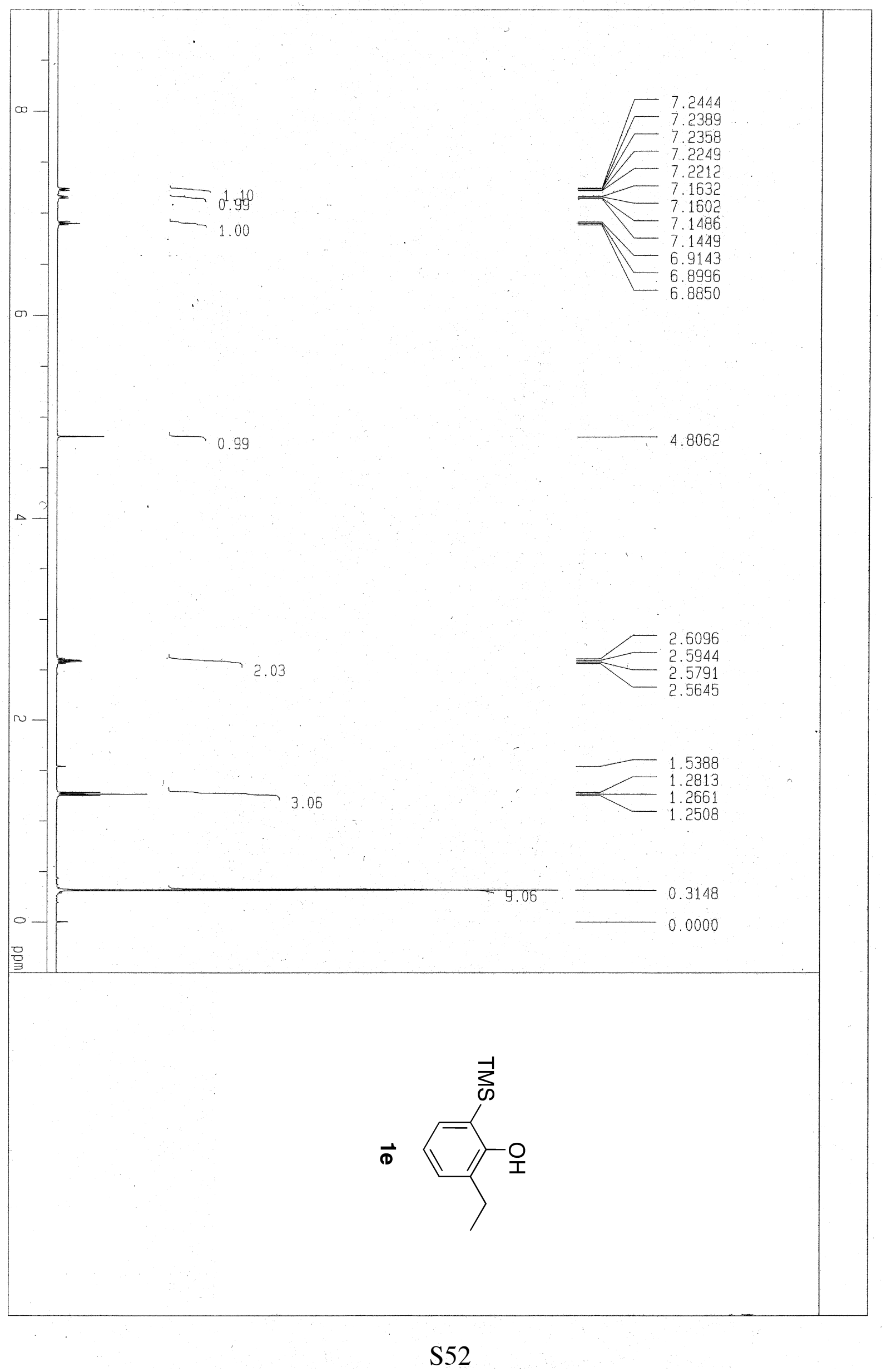









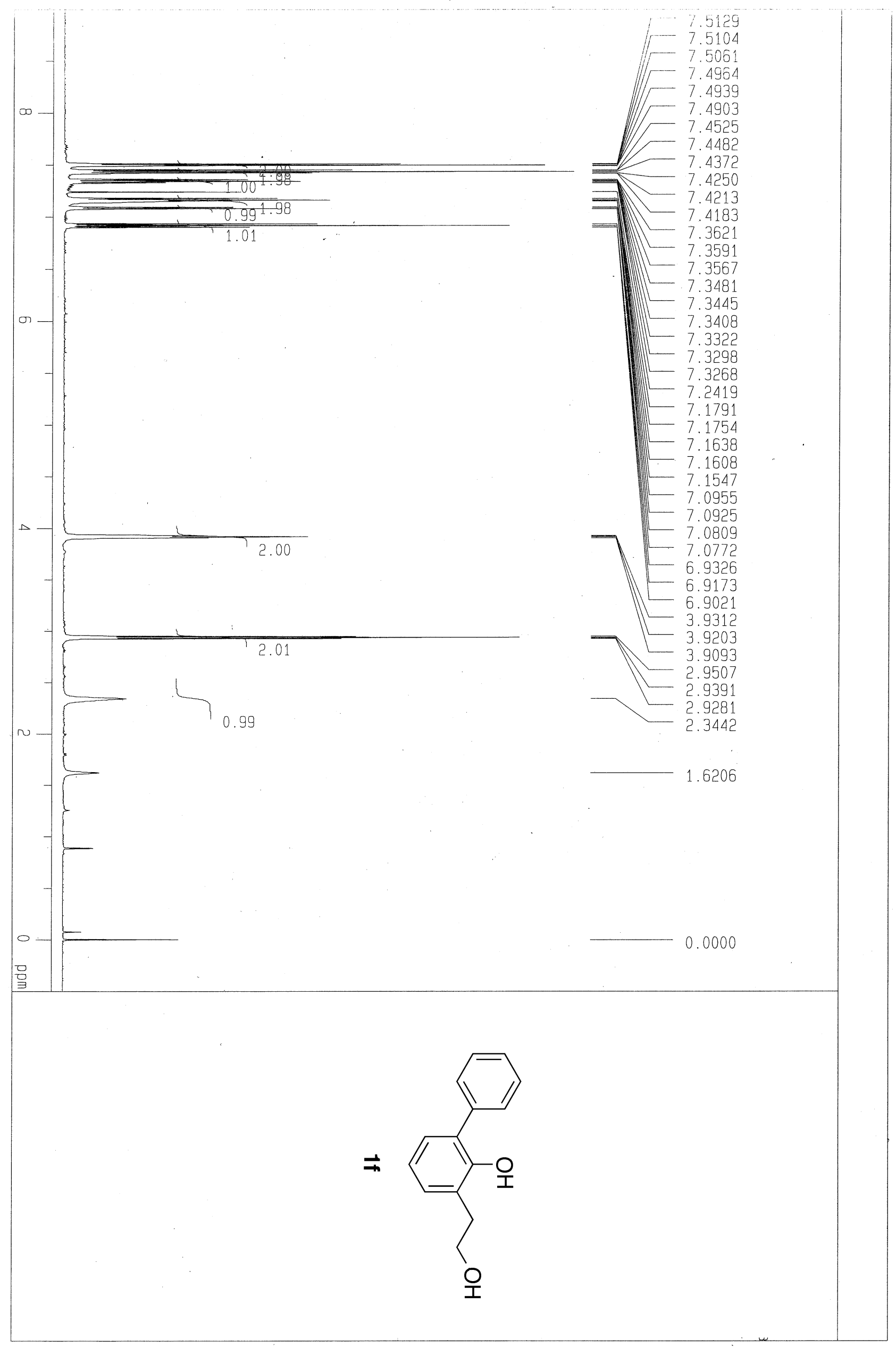




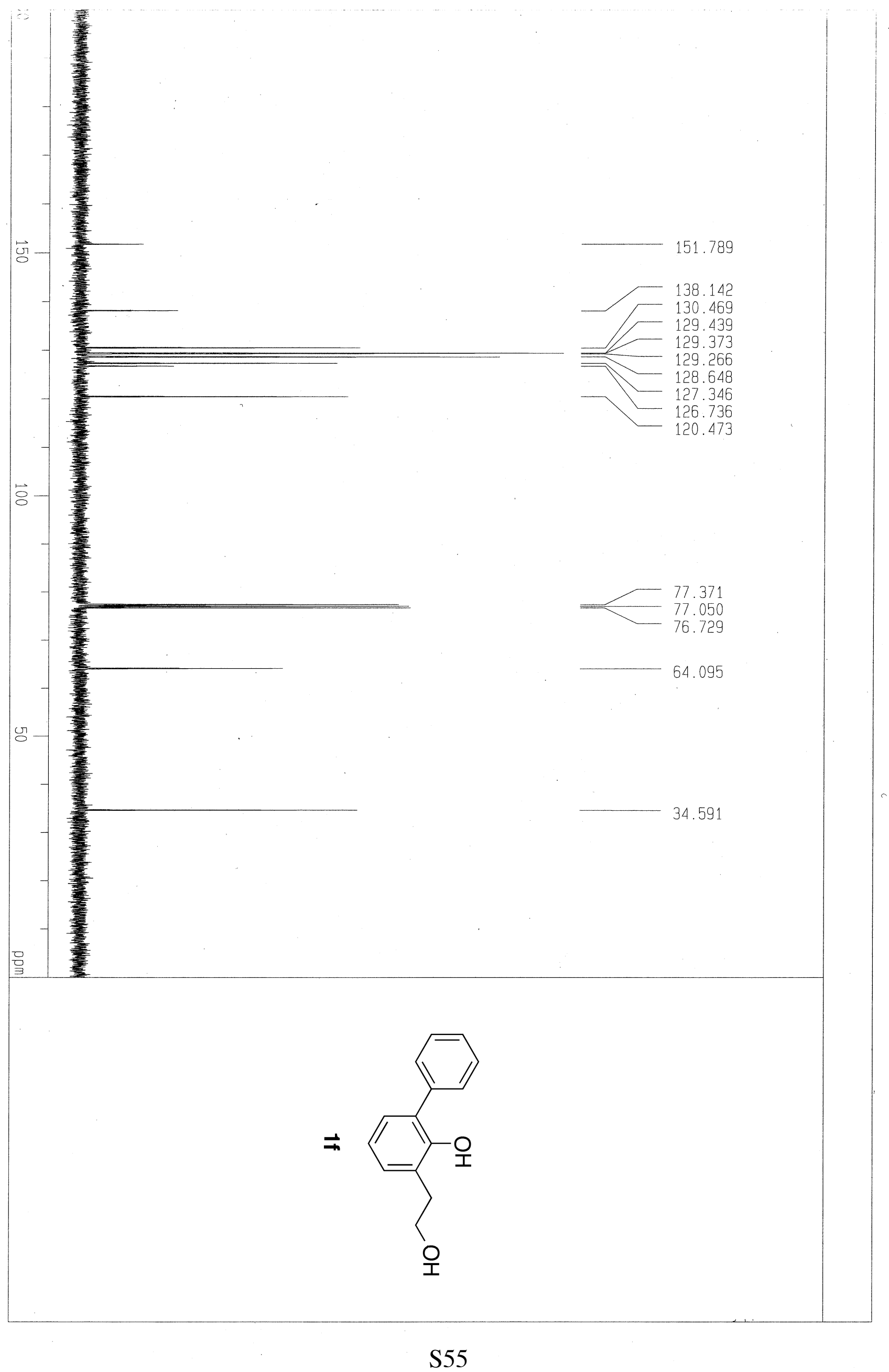




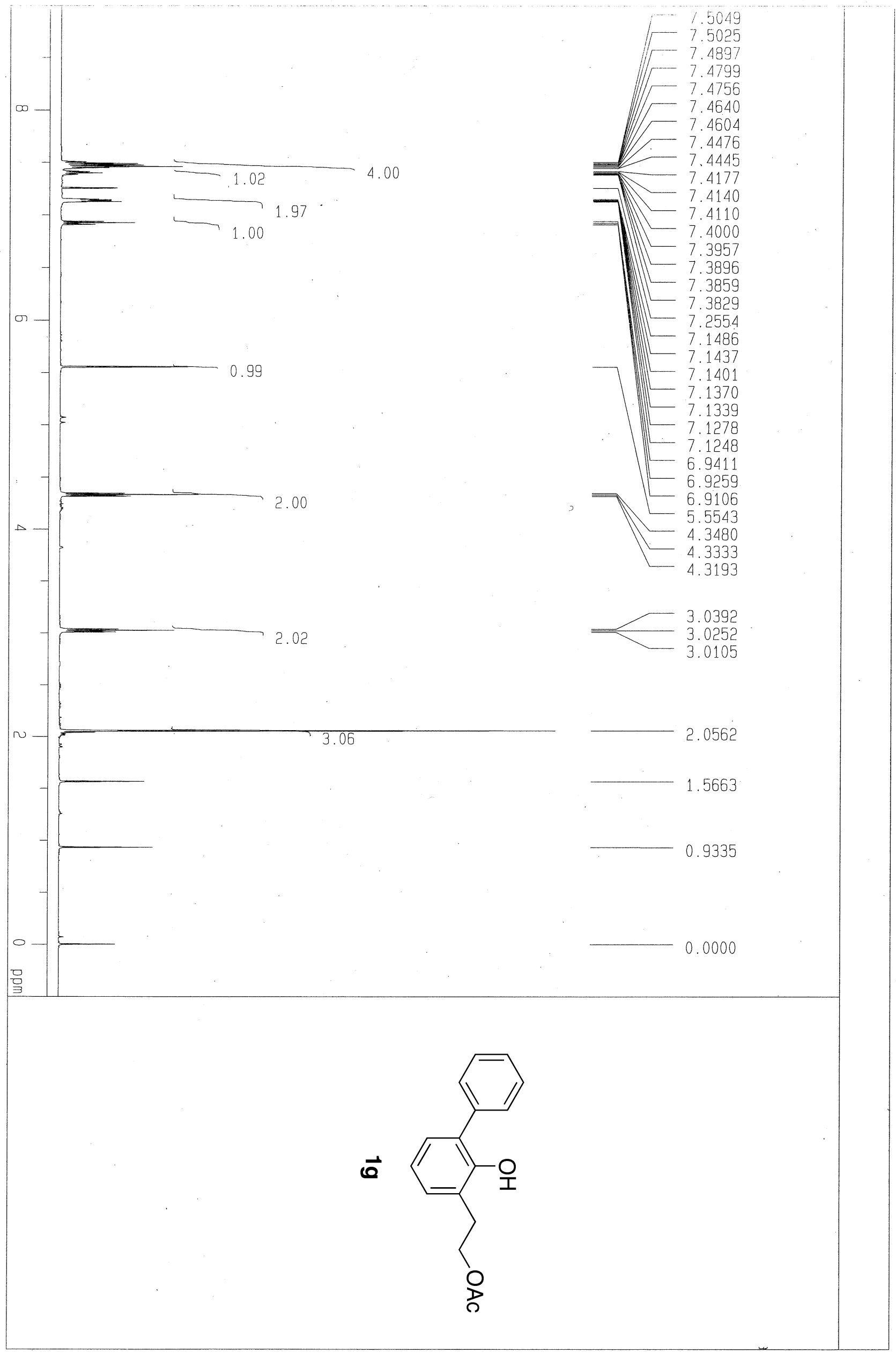




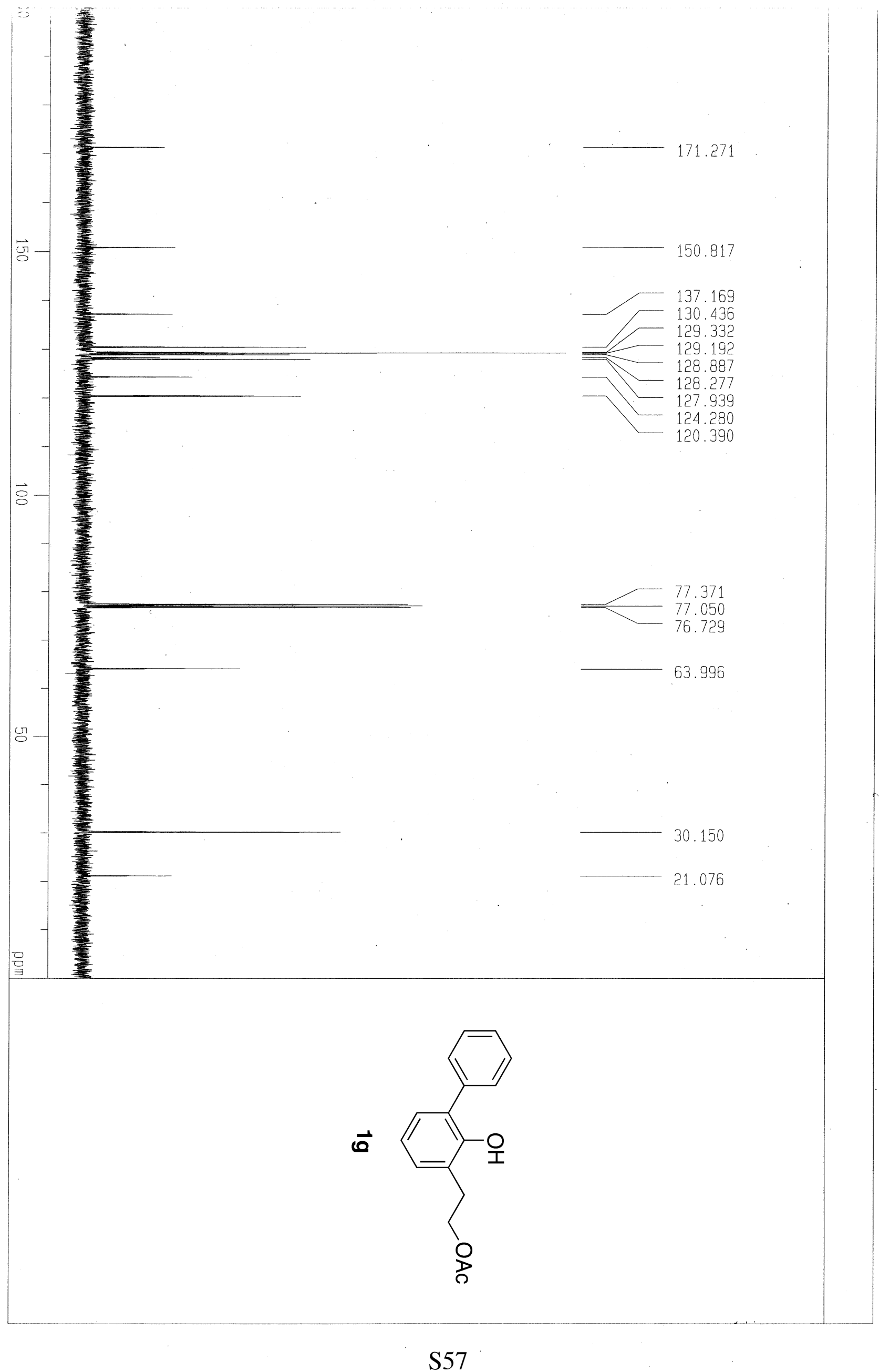




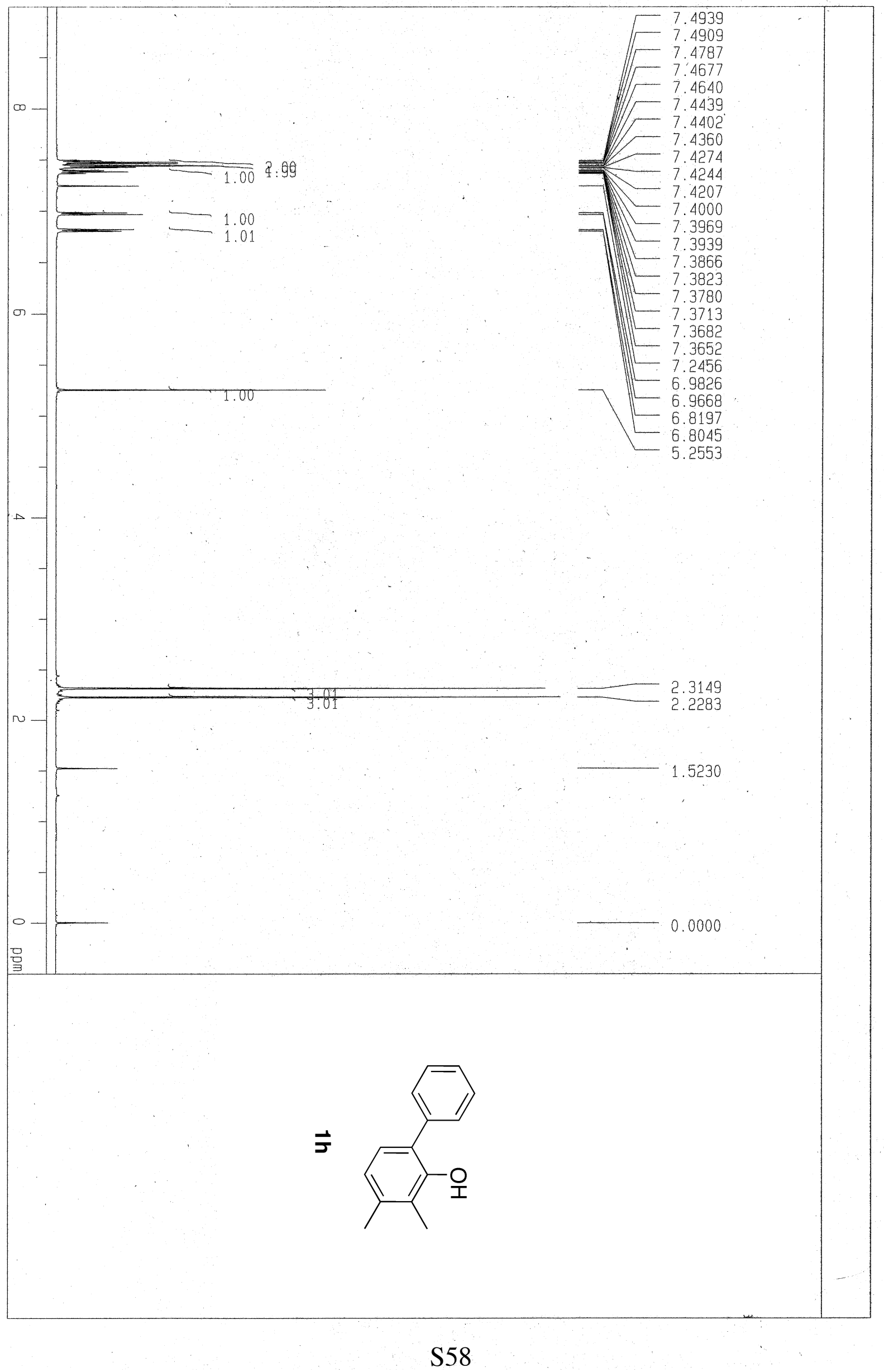




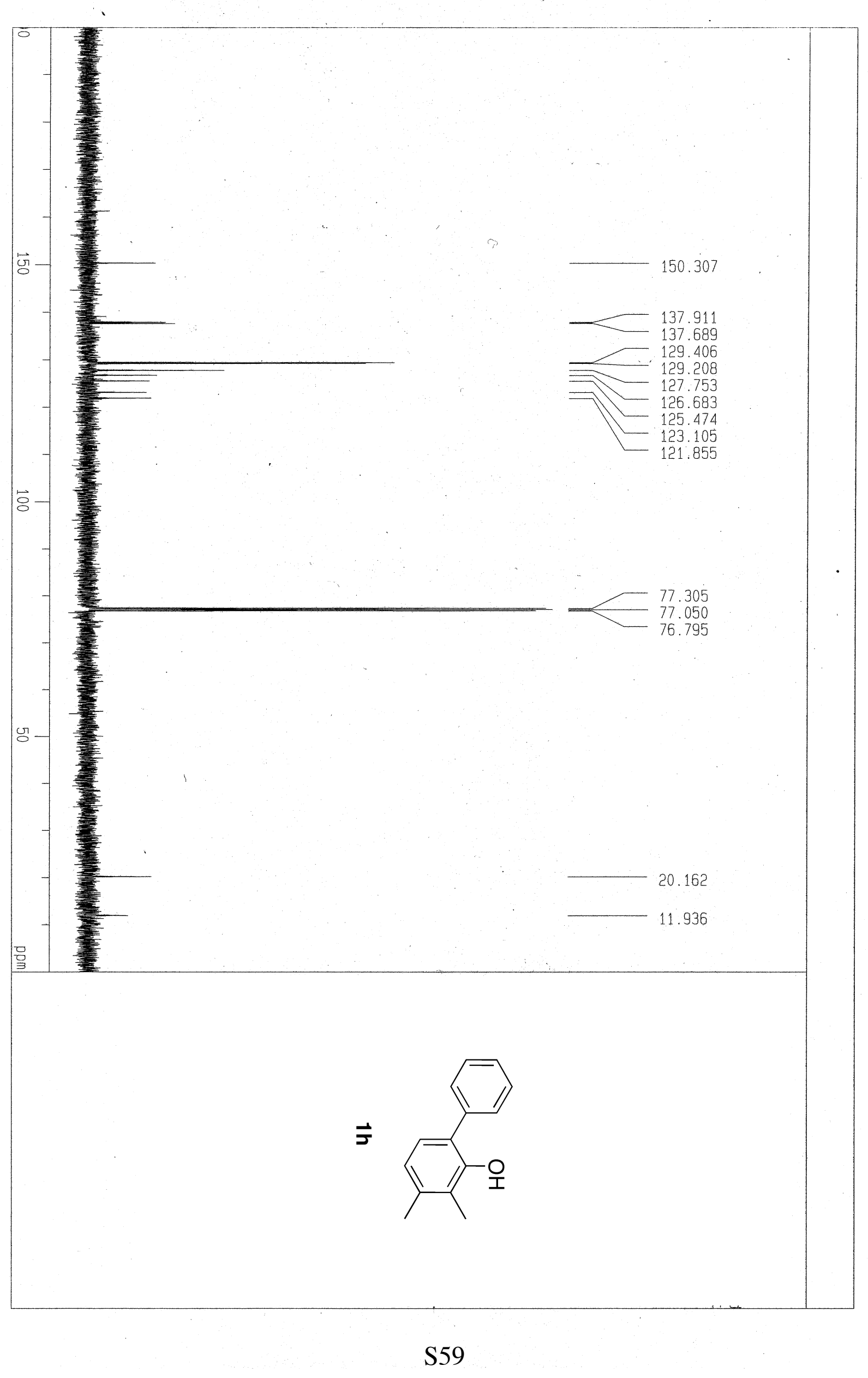




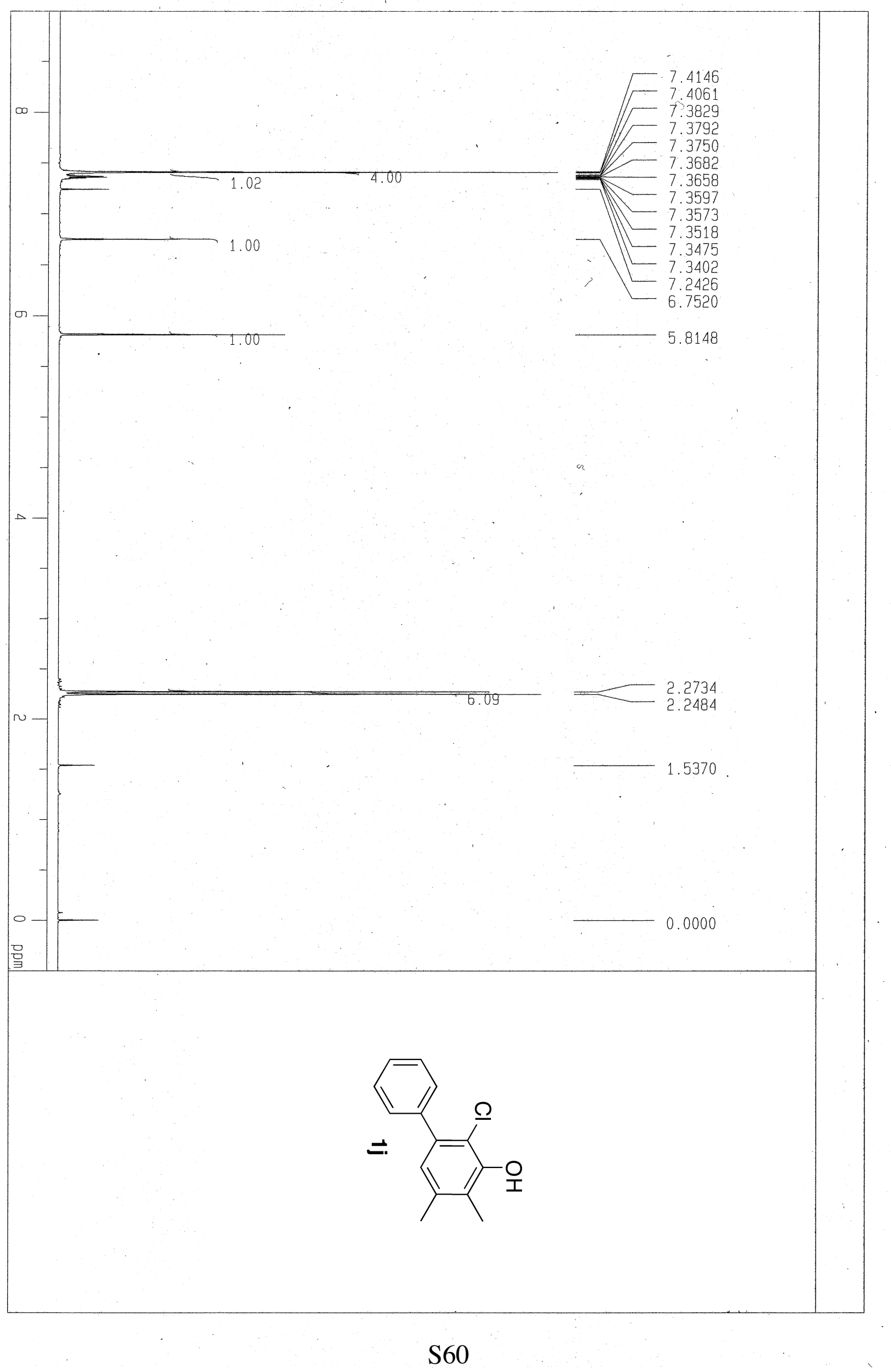




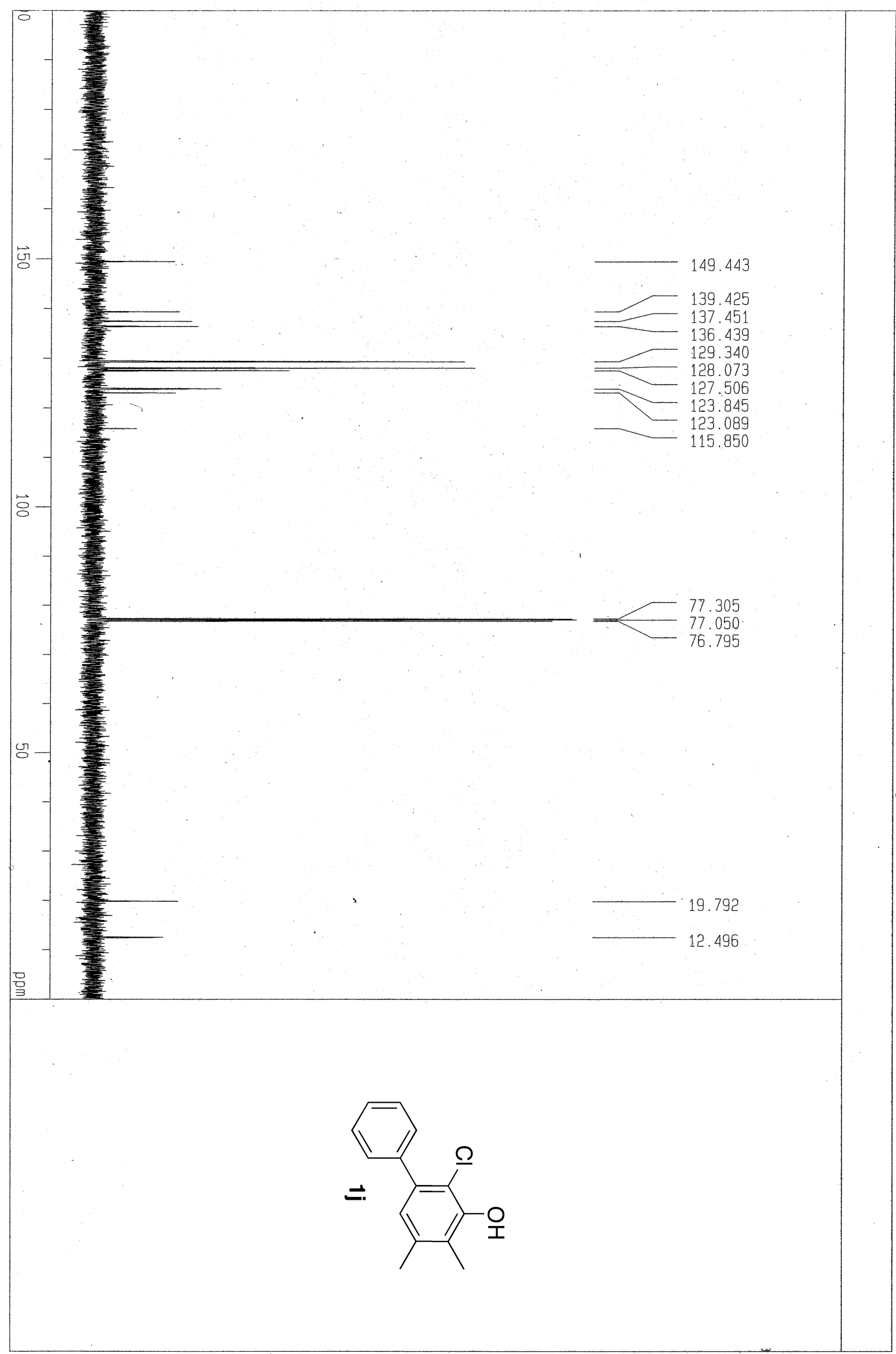

